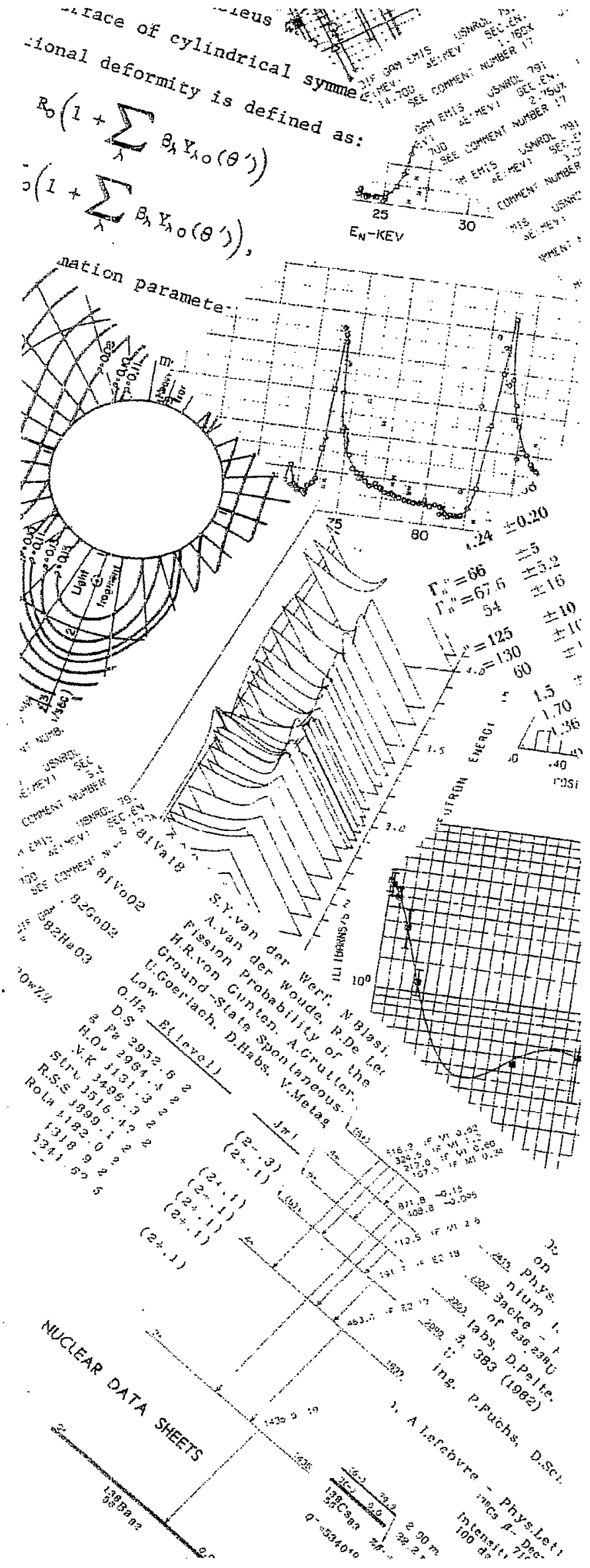

BNL-NCS-51655-01/02-Rev

Formal Report

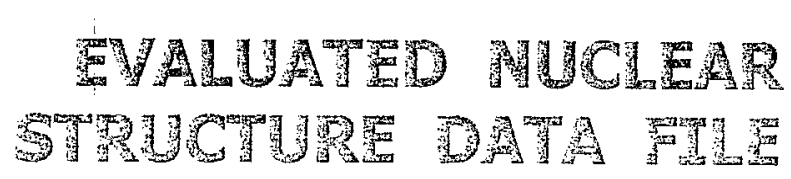

A Manual for Preparation
of Data Sets

Jagdish K: Tull

February 2001

National Nuclear Data Center Brookhaven National Laboratory

P.O. Box 5000

Upton, Long Island, New York 11973

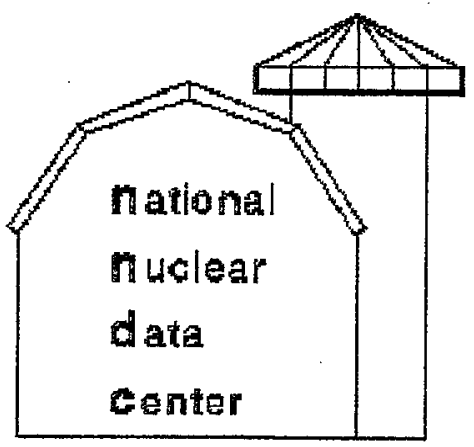

OFFICL FLE OOPY 


\section{DISCLAIMER}

This report was prepared as an account of work sponsored by an agency of the United States Government. Neither the United States Government nor any agency thereof, nor any of their employees, not any of their contractors, subcontractors, or their employees, makes any warranty, express or implied, or assumes any legal liability or responsibility for the accuracy, completeness, or usefulness of any information, apparatus, product, or process disclosed, or represents that its use would not infringe privately owned rights. Reference herein to any specific commercial product, process, or service by trade name trademark, manufacturer, or otherwise, does not necessarily constitute or imply its endorsement, recommendation, or favoring by the United States Government or any agency, contractor, or subcontractor thereof. The views and opinions of authors expressed herein do not necessarily state or reflect those of the United States Government or any agency, contractor or subcontractor thereof. 
BNL-NCS-51655-01/02-Rev Formal Report

\title{
Evaluated Nuclear Structure Data File
}

\author{
A Manual for Preparation \\ of Data Sets
}

Jagdish K. Tuli

February, 2001

National Nuclear Data Center Brookhaven National Laboratory P.O. Box 5000 Upton, New York 11973-5000 


\begin{abstract}
The structure and the format for the Evaluated Nuclear Structure Data FILE (ENSDF) is described. ENSDF is used to store nuclear structure properties of nuclides and the results of various experiments to derive those properties.
\end{abstract}




\section{Contents}

I Introduction $\quad ; \quad 1$

II GENERAL ORGANIZATION AND STRUCTURE OF THE DATA FILE

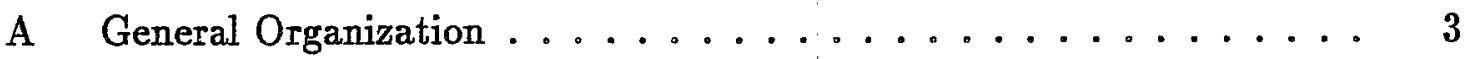

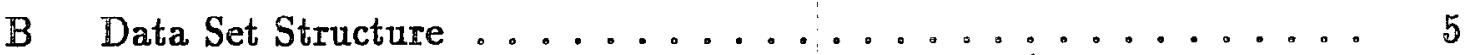

C File Storage and Transmittal ................ 5

IIISTANDARD ONE-CARD RECORD FORMATS 9

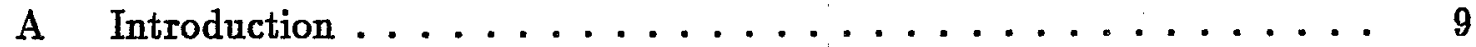

B The Standard One-Card Record Formats . . . . . . . . . . 9

1 The Identification Record ............... 10

2 The History Record .................. 10

3 The Q-value Record ...................... 11

4 The Cross-Reference Record ................ 12

5 The Comment Record ................. 13

6 The Parent Record ................... 17

7 The Normalization Record . . . . . . . . . . 18

8 The Production Normalization Record ........... 20

9 The Level Record ................... 22

10 The Beta $\left(\beta^{-}\right)$Record . . . . . . . . . . . . 23

11 The EC (or EC $+\beta^{+}$) Record .............. 24

12 The Alpha Record .................. 25

13 The (Delayed-) Particle Record ............. 26

14 The Gamma Record ... . . . . . . . . . . 28

15 The Reference Record ................. 29

16 The End Record . . . . . . . . . . . . 29

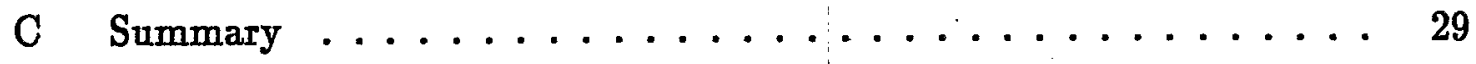

IV RECORDS CONTAINING MORE THAN ONE CARD 33

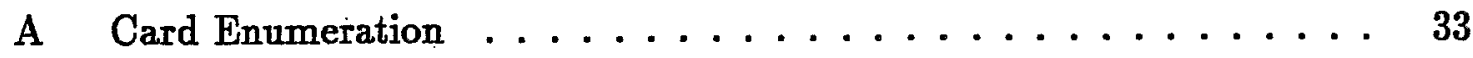


B Format for Continuation Cards . . . . . . . . . . 33

C Allowed Data Types on Continuation Records . . . . . . . . . 34

1 The Level Record . . . . . . . . . . . . . . . 35

2 The Gamma Record . . . . . . . . . . . 36

$3 \quad$ The Beta $\left(\beta^{-}\right)$Record $\ldots \ldots \ldots \ldots \ldots \ldots \ldots$

$4 \quad$ The EC Record . . . . . . . . . . . . 37

V DETAILED FIELD DESCRIPTIONS $\quad 39$

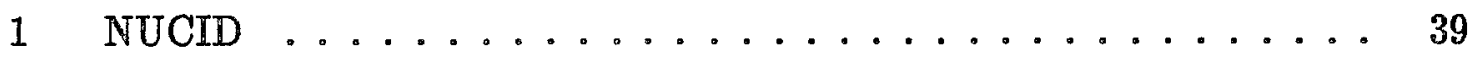

$2 \quad$ DSID . . . . . . . . . . . . . . . . . 39

3 DSREF, KEYNUM, QREF . . . . . . . . . . . 41

4 PUB $\ldots \ldots \ldots \ldots \ldots \ldots \ldots \ldots \ldots \ldots \ldots \ldots \ldots \ldots$

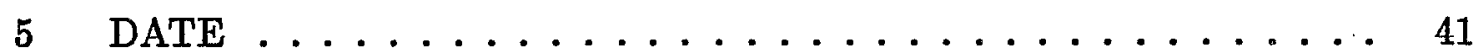

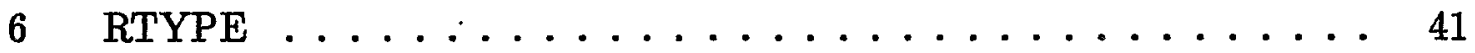

7. CTEXT ....................... 42

$8 \quad \operatorname{SYM}(\mathrm{FLAG}) \ldots \ldots \ldots \ldots \ldots \ldots \ldots \ldots \ldots \ldots \ldots$

$9 \quad \mathrm{BR}, \mathrm{CC}, \mathrm{HF}, \mathrm{LOGFT}, \mathrm{NB}, \mathrm{NP}, \mathrm{NR}, \mathrm{NT}, \mathrm{QP} \ldots \ldots \ldots \ldots \ldots$

10 MR,Q-QQA,SN,SP . . . . . . . . . . . . . . 43

11 DBR,DCC,DE,DHF,DIA,DIB,DIE,DIP,DNB $\ldots \ldots \ldots \ldots$

12 DFT,DMR,DT,DNB,DQA . . . . . . . . . . . . 44

13 IA, IB, IE, IP, RI, TI . . . . . . . . . . . . . . . 44

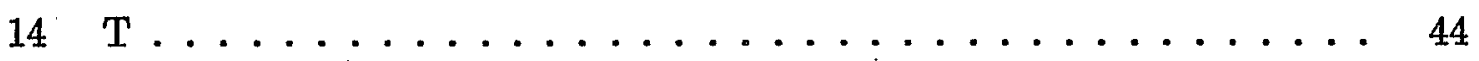

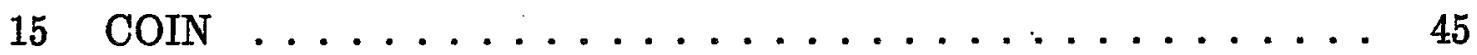

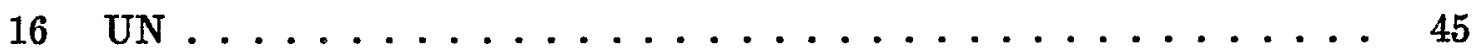

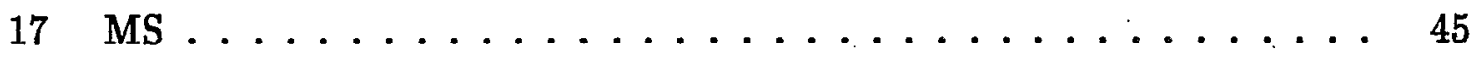

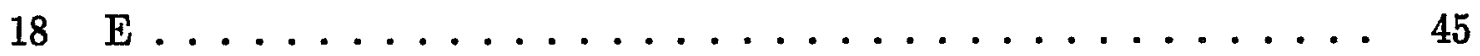

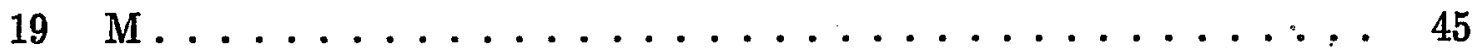

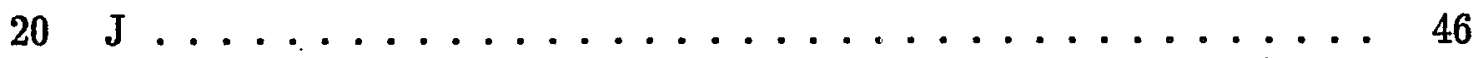

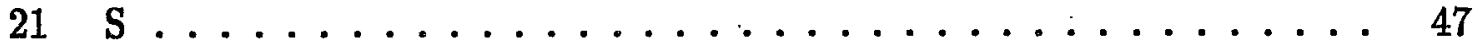

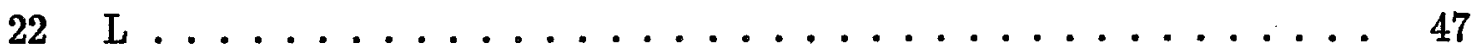

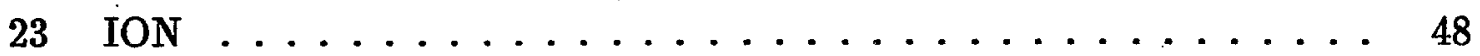

24 Cross Reference . . . . . . . . . . . . . . . . . . 48

25 History record $\ldots \ldots \ldots \ldots \ldots \ldots \ldots$ 
$\begin{array}{lll}\text { A Character Set } & 51\end{array}$

B Format For Comments Data Set 53

C Example of an adopted data set $\quad 57$

D Example of a decay data set $\quad 61$

E ENSDF coding for Ionized Atom decay $\quad 65$

F ENSDF Dictionary - Translation into true-type character set 69

G ENSDF Dictionary - ordered by output $\quad 83$

$\begin{array}{lr}\text { H ENSDF Policies } & 97\end{array}$ 


\section{Chapter I}

\section{Introduction}

This manual ${ }^{1}$ describes the organization and structure of the Evaluated Nuclear Structure Data File (ENSDF). This computer-based file is maintained by the National Nuclear Data Center (NNDC) at Brookhaven National Laboratory for the international Nuclear Structure and Decay Data Network. ${ }^{2}$

For every mass number (presently, $A \leq 293$ ), the Evaluated Nuclear Structure Data File (ENSDF) contains evaluated structure information. For masses $A \geq 44$, this information is published in the Nuclear Data Sheets; for $A<44$, ENSDF is based on compilations published in the journal Nuclear Physics. The information in ENSDF is updated by mass chain or by nuclide with a varying cycle time dependent on the availability of new information.

The author gratefully acknowledges many suggestions and comments received during the revision of this manual. Special thanks are due to the following colleagues at NNDC: M. Blennau, T. Burrows, P. Dixon, C. Dunford, R. Kinsey, P. Oblozinsky, A. Sonzogni, and D. Winchell. This research was supported by the Office of Basic Energy Sciences, U. S. Department of Energy.

\footnotetext{
${ }^{1}$ The format for ENSDF was first designed by W. B. Ewbank and M. R. Schmorak at the Nuclear Data Project, Oak Ridge National Laboratory, and was described in the Rept ORNL-5054/R1 (February 1978). The present report describes the current format and supersedes both the ORNL report and the reports BNL-NCS 51655 (March 1983) and BNL-NCS-51655-Rev.87 (April 1987) both by J. K. Tuli.

${ }^{2}$ Coordinated by the International Atomic Energy Agency, Vienna - see any issue of the Nuclear Data Sheets for list of evaluation data centers.
} 


\section{Chapter II}

\section{GENERAL ORGANIZATION AND STRUCTURE OF THE DATA FILE}

\section{A General Organization}

The Evaluated Nuclear Structure Data File (ENSDF) is made up of a collection of 'data sets' which present one of the following kinds of information:

1. The summary information for a mass chain giving information, e.g., evaluators' names and affiliations, cutoff date, evaluators' remarks, and publication details, etc.

2. The references used in all the data sets for the given mass number. This data set is based upon reference codes (key numbers) used in various data sets for a given mass number and is added to the file by the NNDC.

3. The adopted level and gamma-ray properties for each nuclide.

4. The evaluated results of a single type of experiment, e.g., a radioactive decay or a nuclear reaction for a given nuclide.

5. The combined evaluated results of a number of experiments of the same kind, e.g., (Heavy ion, xny), Coulomb excitation, etc. for a given nuclide.

The data sets in ENSDF are organized by their mass number. Within a mass number the data sets are of two kinds:

- Data sets which contain information pertaining to the complete mass chain. These data sets contain information of the type (1) and (2) given above.

- Data sets belonging to a given nuclide (Z-value). 
Latter data sets, i.e. for a given nuclide (Z-value), consist of the following:

- A Comments data set which gives abstract information for the nuclide. This data set contains summary information as described in (1) above. This data set exists only if the nuclide was evaluated or updated beyond the whole mass chain was evaluated.

- Adopted data set (only one per Z-value) giving adopted properties of the levels and gamma rays seen in that nuclide.

- Data sets giving information of the type (4) or (5) above.

If there is more than one data set of type (4) or (5) for a given nuclide, then an adopted data set is required for that nuclide. If there is only one data set for a given nuclide and no gamma-rays have been seen, then that data set is assumed also to present the adopted properties for that nuclide. If, however, there is gamma information known for the nuclide then a separate Adopted Levels, Gammas data set must be given even if all the information comes from only one experiment (data set).

The general organization of ENSDF is shown schematically in Fig. II.1. 


\section{B Data Set Structure}

A data set is composed of 80 -character records. A data set has at least two records, the beginning. (DSCID) and the endrecord. Data set structure is shown in Fig. II.2 and is described below:

A data set must begin with an IDENTIFICATION record and must end with an END record (a blank record). Between these two records, there can be as many additional records as are needed to describe fully the experimental or the evaluated information.

Immediately following the IDENTIFICATION record is a group of records which contain information about the entire data set (\#1 and \#2 in Fig. II.2). The History (H), general COMMENT (C), NORMALIZATION (N), Q-VALUE (Q), PARENT (P), and CROSS-REFERENCE (X) records are of this type. Not all of these records are included in every data set. For example, Q-VALUE (Q) and CROSS-REFERENCE (X) records normally appear only in adopted data sets while the PARENT (P) record is given only in radioactive decay data sets.

The body of a data set (\#3 and \#4 in Fig. II.2) is composed of numeric data records which describe the measured or deduced properties of levels, $\gamma$ rays, $\alpha$ particles, etc. These records are associated with the level which decays (for GAMMA, records) or the level which is populated (for BETA, EC, ALPHA, PARTICLE, or DELAYED- PARTICLE records). Thus, each LEVEL record is followed by a group of records describing $\beta, \epsilon$, or (delayed-) particle decay into the level and $\gamma$-ray out of the level (\#4 in Fig. II.2). The-LEVEL records, and the corresponding radiation records, are placed in the data set in the order of increasing energy.

If a GAMMA, ALPHA, EC, BETA, or (DELAYED-)PARTICLE record properly belongs in a data set but cannot be associated with any particular level, then the record should be placed in the data set before any LEVEL records (\#3 in fig. II.2).

The placement of COMMENT records is described in III.B.5.

\section{File Storage and Transmittal}

The data sets sent to NNDC for inclusion in ENSDF can be in any order, as the file is currently maintained using a data base management system which rearranges various data sets in their predetermined order. Copies of the file are transmitted in the form of a sequential file via various mass media. Unless requested otherwise the data sets in the sequential file are arranged by mass numbers in increasing numerical order. For a. given mass number the data sets are organized as given.in Fig. II.1, ordering them from left to right. Decay data sets are placed under the daughter nuclide and are ordered by $A, Z$ and then the excitation energy of the parent nuclide. The reaction data sets are given under the residual nuclide and ordered by the $\mathrm{A}, \mathrm{Z}$ of the target 
EVALUATED NUCLEAR STRUCTURE DATA FILE

Organization Chart

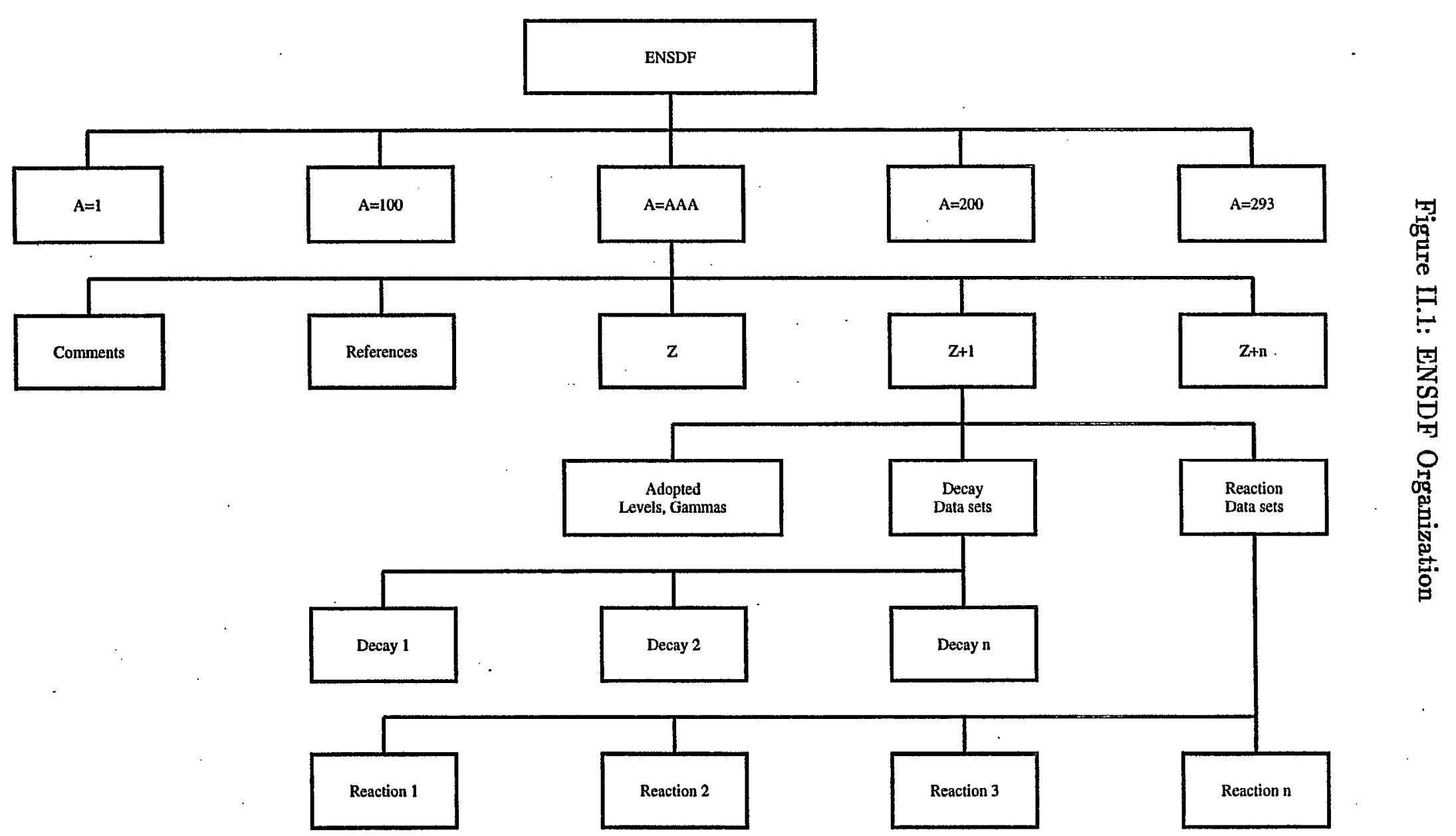


nuclide follwed by the $\mathrm{A}, \mathrm{Z}$ of the incident particle and then by the energy of the incident particle. These are followed by other data sets, e.g., Coulomb Excitation, (HI,XNG), etc. 


\section{Data Set Structure}

\section{Identification Record}

1

H, X Records, General/Flagged Comments

2

$\mathrm{Q}$ record, $\mathrm{Q}$ comments

$\mathrm{P}$ record, $\mathrm{P}$ comments

$\mathrm{N}$ record, $\mathrm{N}$ comments

3

Unplaced Radiations, G,B,A,E

Level Record, Corresponding Radiations

4

End Record

Fig. II.2 


\section{Chapter III}

\section{STANDARD ONE-CARD RECORD FORMATS}

\section{A Introduction}

In most cases, all information for a record can be placed on a single 80-column (byte) card (record) ${ }^{1}$. A 'standard' format has been defined for each one-card record, such that the most commonly used quantities can be placed on a single card. The standard formats are described in this section for each record. If a needed quantity is not included in the standard format or if a value will not fit within the field defined for the value by the standard format, or if a record cannot be contained on a single card, then additional cards can be prepared as described in Chapter IV (for examples, see Appendix $\mathrm{C}$ and $\mathrm{D}$ ). Note that many of the analysis programs may not process standard fields when placed on the continuation records.

\section{B The Standard One-Card Record Formats}

Record formats are given below in the same order in which they would normally be encountered in a data set. Conditions under which each record may appear or be required are given in parentheses. The format descriptions give the fields (in inclusive card-column numbers), the field names (the formal 'name' of the quantity that goes into the field), and a brief field description. Card columns not explicitly included in the fields are expected to be blank. A detailed description of each field can be found in the reference section noted. (Any numerical field left blank usually implies that the numerical information is lacking. Numbers will usually be assumed to be positive unless stated otherwise.) Numbers can be entered anywhere in the appropriate field (i.e., there is no need to left-adjust or right-adjust, unless stated otherwise.)

\footnotetext{
${ }^{1}$ Throughput this manual an 80 -byte record is referred to as a card of 80 columns. Column number refers to the byte number on the record, starting from the left.
} 


\section{1 . The Identification Record}

Required for all data sets.

Must precede all other records.

\begin{tabular}{|c|c|c|c|}
\hline Field (Col.) & Name & Description & \\
\hline $1-5$ & NUCID & Nuclide Identification & \\
\hline 6-9 & & Must be blank & \\
\hline $10-39$ & DSID & Data set identification & \\
\hline $40-65$ & DSREF & $\begin{array}{l}\text { References to main supporting publications } \\
\text { and analyses }\end{array}$ & \\
\hline $66-74$ & $\mathbb{P U B}$ & Publication Information & \\
\hline $75-80$ & DATE & $\begin{array}{l}\text { The date (year/month) when the data } \\
\text { set was placed in ENSDF (entered } \\
\text { automatically by computer) }\end{array}$ & \\
\hline
\end{tabular}

Note: In the rare case when DSID field is insufficient for dataset identification it may be continued on a second identification record with col 1-39 defined as above except that col. 6 will contain an alphanumeric character and columns $40-80$ will be blank. If there is a continuation record, the DSID field on the first IDENTIFICATION record must end with a ',' (comma).

\section{The History Record}

The history records follow the Identification record and should appear in reverse-chronological order, most recent being the first

\begin{tabular}{|c|c|c|}
\hline Field (Col.) & Name & Description \\
\hline $1-5$ & NUCID & Nuclide identification \\
\hline 6 & & Blank \\
\hline & & $\begin{array}{l}\text { Any alphanumeric character other than ' } 1 \text { ' } \\
\text { for continuation records }\end{array}$ \\
\hline 7 & & Must be blank \\
\hline 8 & $\mathbf{H}$ & Letter ' $H$ ' is required \\
\hline 9 & & Must be blank \\
\hline $10-80$ & History & $\begin{array}{l}\text { Dataset history consisting of various } \\
\text { field descriptors and their values in cols } \\
10-80 \text { continued on any number of continuation } \\
\text { records. Field descriptor is followed by an '=' } \\
\text { (without spaces before or after ' }=\text { ') and the value } \\
\text { and a terminator '\$' ('\$' is not needed for the } \\
\text { last field descriptor). }\end{array}$ \\
\hline
\end{tabular}

Reference

V.1 


\section{The Q-value Record}

Required for adopted data sets.

If there is only one data set for the nuclide then the Q-value record should be given in that data set.

Must precede L, G, B, E, A, DP records.

If signs are not given, they will be assumed to be + .

\begin{tabular}{|c|c|c|c|}
\hline Field (Col.) & Name & Description & Reference \\
\hline $1-5$ & NUCID & Nuclide identification & V.1 \\
\hline 6 & & Blank & \\
\hline 7 & & Must be blank & \\
\hline 8 & $Q$ & Letter ' $Q$ ' is required' & \\
\hline 9 & & Must be blank & \\
\hline $10-19$ & $\mathbf{Q}^{-}$ & $\begin{array}{l}\text { Total energy ( } \mathrm{keV} \text { ) available for } \beta^{-} \text {decay } \\
\text { of the ground state. ( } \mathbf{Q}^{-}>0 \text { if } \beta^{-} \\
\text {decay is energetically possible. } \\
\mathbf{Q}^{-}<0 \text { represents the } Q_{\epsilon} \text { energy of } \\
\text { the } \mathrm{Z}+1 \text { ( } \mathrm{Z}=\text { proton number) isobar.) }\end{array}$ & V.10 \\
\hline $20-21$ & $\mathbf{D Q}^{-}$ & Standard uncertainty in $\mathbf{Q}^{-}$ & V.11 \\
\hline $22-29$ & SN & Neutron separation energy in $\mathrm{keV}$ & V.10 \\
\hline 30-31 & DSN & Standard uncertainty in SN & V.11 \\
\hline $32-39$ & SP & Proton separation energy in $\mathrm{keV}$ & V.10 \\
\hline $40-41$ & DSP & Standard uncertainty in SP & V.11 \\
\hline $42-49$ & QA & $\begin{array}{l}\text { Total energy }(\mathrm{keV}) \text { available for } \alpha \text { decay } \\
\text { of the ground state }\end{array}$ & V.10 \\
\hline $50-55$ & DQA & Standard uncertainty in QA & V.12 \\
\hline $56-80$ & QREF & Reference citation(s) for the Q-values & V.3 \\
\hline
\end{tabular}




\section{The Cross-Reference Record}

Given only in adopted data sets.

Must precede L, G, B, E, A, DP records.

\begin{tabular}{|c|c|c|c|}
\hline Field (Col.) & Name & Description & Reference \\
\hline $1-5$ & NUCID & Nuclide identification & V.1 \\
\hline 6 & & Blank & \\
\hline 7 & & Must be blank & \\
\hline 8 & $\mathbf{X}$ & Letter ' $\mathrm{X}$ ' is required & \\
\hline 9 & DSSYM & $\begin{array}{l}\text { Any ASCII character that uniquely } \\
\text { identifies the data set whose DSID is } \\
\text { given in col. } 10-39 \text {. }\end{array}$ & \\
\hline $10-39$ & DSID & Must exactly match one of the DSID's used & V.2 \\
\hline $40-80$ & & Blank & \\
\hline
\end{tabular}

1. In the Nuclear Data Sheets the DSID on the first ' $\mathrm{X}$ ' record in the data set will be identified with character ' $A$ ' and second DSID with ' $B$ ' and so on irrespective of DSSYM on the X card. Only the first 14 DSID's on ' $\mathrm{X}$ ' records are given different symbols. All the rest are given the symbol ' $O$ ' (for others). By merely reshuffling the $\mathrm{X}$-records, evaluators can ascertain the DSID's that will be identified individually. This has no effect on the file and affects only the published output.

2. If the DSID for the data set is continued on to a second card, the DSID on XREF record must match the DSID on the the first card, including the terminating ',' which will be translated into ellipses in the cross-reference table in the output.

3. There must be a data set corresponding every given $\mathrm{X}$-record. 


\section{The Comment Record}

\section{General Comments}

Must precede all $\mathrm{L}, \mathbf{G}, \mathbf{B}, \mathbf{E}, \mathbf{A}, \mathrm{DP}$ records.

Field (Col.) Name Description

Reference

1-5 NUCID Nuclide identification

V.1

6

Blank

Any alphanumeric character other

than ' 1 ' for continuation records

$7 \quad \mathrm{C} \quad$ Letter ' $\mathrm{C}$ ', ' $\mathrm{D}$ ', or ' $\mathrm{T}$ ' is required

See notes 3- 5 below

8 RTPE Blank or record type of records to

which the comment pertains

9 PSYM Blank, or symbol for a (delayed-)particle, e.g., $\mathrm{N}, \mathrm{P}$, etc.

10-80 CTEXT Text of the comment.

[See ENSDF Translation Dictionary

(Appendix F)]

NOTES:

1. The comment refers only to records of specified RTYPE given in that data set. The comment will normally appear only in the table for that RTYPE in the output. For example, if the comment is on levels (' $L$ ' in col. 8) it will appear only in the level properties table.

2. If col. 8 and 9 are blank then the comment refers to the whole data set. These general comments precede formatted level or the radiation records. See Appendix B for use of comment records in COMMENTS data set.

3. Letter ' $T$ ' in place of ' $C$ ' in col. 7 of a comment record indicates to the output programs that this record should be reproduced 'as is' and the blanks in the record should not be squeezed out.

4. Letter ' $\mathrm{D}$ ' in place of ' $\mathrm{C}$ ' in col. 7 of a comment record indicates to the output programs that this is a documentation record and can be ignored. This record will also be ignored by the various analysis programs.

5. Lower case letters ' $c$ ' and ' $t$ ' in col. 7 of a comment record indicate to the output programs that CTEXT in these records should not be translated. These will appear as written in the Nuclear Data Sheets. In this mode one must write special characters directly, for example, ' $\mid g$ ' for $\gamma$, ' $\{+238\} \mathrm{Pu}^{\prime}$ for ${ }^{238} \mathrm{Pu}$. See Appendix A for list of special characters. 


\section{Record Comments}

Must follow the record to which the comment pertains.

\begin{tabular}{|c|c|c|}
\hline Field (Col.) & Name & Description \\
\hline $1-5$ & NUCID & Nuclide identification \\
\hline 6 & & Blank \\
\hline & & $\begin{array}{l}\text { Any alphanumeric character other } \\
\text { than ' } 1 \text { ' for continuation records }\end{array}$ \\
\hline 7 & $\mathbf{C}$ & $\begin{array}{l}\text { Letter 'C' or ' } \mathrm{D} \text { ' is required } \\
\text { See notes } 4 \text { and } 5 \text { on General Comments }\end{array}$ \\
\hline 8 & RTYPE & $\begin{array}{l}\text { Record type being commented upon } \\
\text { It can be blank for Particle records }\end{array}$ \\
\hline 9 & PSYM & $\begin{array}{l}\text { Blank, or symbol for a particle, } \\
\text { e.g., } \mathrm{N}, \mathrm{P} \text {, etc. }\end{array}$ \\
\hline $10-80$ & $\begin{array}{l}\text { SYM\$ or } \\
\text { SYM,SYM, } \ldots, \$\end{array}$ & $\begin{array}{l}\text { SYM = type of data being commented upon } \\
\text { Specified SYMs must be followed by a ' } \$ \text { ' } \\
\text { except as in note } 1 \text { below. }\end{array}$ \\
\hline $10-80$ & CTEXT & $\begin{array}{l}\text { Text of comment follows the ' } \$ \text { ' } \\
\text { On continuation comment records, } \\
\text { CTEXT may start in col. 10, and } \\
\text { SYM or SYMs are not repeated. } \\
\text { [See ENSDF Translation Dictionary, } \\
\text { Appendix F] }\end{array}$ \\
\hline
\end{tabular}

NOTES:

1. The old format, where SYM were specified in col. 10-19, will be accepted without the '\$' delimiter as long as col. 19 is a blank. In this case comment text begins in col. 20 .

2. Record comments placed following a record of the same RTYPE refer only to that one record. (For example, a comment record with 'CL' in cols. 7-8 and ' $\mathrm{T} \$$ ' in col. 10-11 placed following the level record for the second-excited state refers to the half-life of only the second-excited state.) 


\section{Footnote Comments \\ Must precede L, G, B, E, A, DP records}

\begin{tabular}{|c|c|c|}
\hline $\begin{array}{l}\text { Field (Col.) } \\
\quad 1-9\end{array}$ & Name & $\begin{array}{l}\text { Description } \\
\text { same as in ii (Record Comments) }\end{array}$ \\
\hline $10-80$ & $\begin{array}{l}\text { SYM\$ or } \\
\text { SYM,SYM, ..,\$ or } \\
\text { SYM(FLAG)\$ or } \\
\text { SYM(FLAG), } \\
\text { SYM(FLAG),..,\$ }\end{array}$ & $\begin{array}{l}\text { SYM = see note } 1 \text { below } \\
\text { FLAG = any ASCII alphanumeric char- } \\
\text { acter or string of alphanumeric characters } \\
\text { Field must end with a ' } \$ \text { ' } \\
\text {-See note } 1 \text { on Record comments } \\
\text { for exception }\end{array}$ \\
\hline $10-80$ & CTEXT & $\begin{array}{l}\text { Text of comment follows ' } \$ \text { ' } \\
\text { On continuation comment records } \\
\text { SYM or SYM(FLAG) are not repeated. } \\
\text { [See ENSDF Translation Dictionary } \\
\text { (Appendix F)] }\end{array}$ \\
\hline
\end{tabular}

Reference

NOTES:

1. SYM can only be one of the following:

- The fields defined in formated $\mathbf{L}, \mathbf{G}, \mathbf{B}, \mathbf{E}, \mathbf{A}, \mathbf{D P}$ records.

- BAND. This SYM must be accompanied with a FLAG. Note also that text following ' $\$$ ' delimiter, or in col. 20-80 in old format, will appear as the band label in some of the drawings. Any other information on that band should, therefore, be given on continuation records.

2. Footnote without FLAG

- This refers to all records of the specified RTYPE in the data set.

- The footnote will normally appear only in the table for that RTYPE in the output. For example, if the footnote is on levels (' $L$ ' in col. 8) it will appear only in the level properties table.

- Footnote with FLAG

- Only those records are footnoted for which footnote flags are given, see note 4 below.

- Only those data values of data types specified by SYM which is associated with a given FLAG are footnoted. 
3. Footnote FLAG must be either a single character placed in col. 77 of the formatted record or a string of characters assigned to a special data type called FLAG on the following continuation record.

Examples of flags on a continuation record:

\section{EU2 G FLAG=ABCD $\$$ \\ 156GD2 L FLAG=KMP\$}

4. No footnotes are allowed for records of RTYPE: $\mathbf{N}, \mathbf{P}$, or $\mathbf{Q}$.

5. To change the standard label heading of a formated field, e.g., S to $C^{2} S$ for I records, CTEXT should have the form LABEL=name, where 'name' is the new label desired. The new label should be kept as short as possible. Note that FLAG can not be specified with relabeling; also any other comment on the relabelled field must appear on a different record.

Examples of field relabel:

156GD CL S\$LABEL=C2S

156GD CL S\$LABEL=DSIGMA/DOMEGA (45 DEG) 


\section{The Parent Record}

Required for all decay data sets.

Must precede L, G, B, E, A, DP records.

\begin{tabular}{|c|c|c|c|}
\hline Field (Col.) & Name & Description & Reference \\
\hline $1-5$ & NUCID & Parent Nuclide identification & V.1 \\
\hline 6 & & Must be blank & \\
\hline 7 & & Must be blank & \\
\hline 8. & $\mathbf{P}$ & Letter ' $\mathrm{P}$ ' is required & \\
\hline 9 & & Blank or an integer in case of multiple & \\
\hline $10-19$ & $\mathbb{E}$ & $\begin{array}{l}\text { Energy of the decaying level in } \mathrm{keV} \\
\text { ( } 0.0 \text { for g.s.) }\end{array}$ & V.18 \\
\hline 20-21 & $\mathbf{D E}$ & Standard uncertainty in $\mathbf{E}$ & V.11 \\
\hline $22-39$ & $\mathbf{J}$ & Spin and parity. & V.20 \\
\hline $40-49$ & $\mathbf{T}$ & Half-life; units must be given & V.14 \\
\hline $50-55$ & DT & Standard uncertainty in $T$ & V.12 \\
\hline $56-64$ & & Must be blank & \\
\hline $65-74$ & QP & $\begin{array}{l}\text { Ground-state Q-value in } \mathrm{keV} \text { (total energy } \\
\text { available for } g . s . \rightarrow \text { g.s. transition); it will } \\
\text { always be a positive number. } \\
\text { Not needed for IT and SF decay. }\end{array}$ & V.9 \\
\hline $75-76$ & DQP & Standard uncertainty in $\mathbf{Q P}$ & V.11 \\
\hline $77-80$ & ION & $\begin{array}{l}\text { Ionization State (for Ionized Atom decay), } \\
\text { blank otherwise }\end{array}$ & \\
\hline
\end{tabular}

NOTES:

1. More than one parent card is allowed in a data set. If the decay scheme is due to more than one parent then separate $\mathbf{P}$ records should be given for each parent level.

2. Currently, publication program allows maximum of two parent cards.

3. Parent information, namely, E, J, T, QP must be identical to their values given in its Adopted Levels data set. 


\title{
7 The Normalization Record
}

\author{
Must precede $\mathbf{L}, \mathbf{G}, \mathbf{B}, \mathbf{E}, \mathbf{A}, \mathbf{D P}$ records.
}

Required if an absolute normalization is possible;

used mainly with decay and $(n, \gamma)$ reaction data sets.

Field (Col $)$
$1-5$
6
7.
8
9

$10-19$

20-21

$22-29$

30-31

32-39

$40-41$

$42-49$
Name

NUCID

$\mathbf{N}$

Description

Nuclide (Daughter/Product) identification

Must be blank

Must be blank

Letter ' $N$ ' is required

Blank or an integer in case of multiple

$P$ records in the data set.

It should correspond to the designator on the $P$ record.

NR Multiplier for converting relative photon intensity (RI in the GAMMA record) to photons per 100 decays of the parent through the decay branch or to photons per 100 neutron captures in an $(\mathrm{n}, \gamma)$ reaction.

Required if the absolute photon intensity can be calculated.

DNR Standard uncertainty in NR

Multiplier for converting relative transition intensity (including conversion electrons) [TI in the GAMMA record] to transitions per 100 decays of the parent through this decay branch or per 100 neutron captures in an $(n, \gamma)$ reaction.

Required if TI are given in the GAMMA record and the normalization is known.

standard uncertainty in NT

Branching ratio multiplier for converting intensity per 100 decays through this decay branch to intensity per 100 decays of the parent nuclide.

Required if known.

DNT

Standard uncertainty in BR

Multiplier for converting relative $\beta^{-}$and $\epsilon$ intensities (IB in the B- record; IB, IE, TI in the EC record) to intensities per 100 decays through this decay branch. Required if known.
V.11

Reference

V.1

V.9

V.11

V.9

V.11

V.9

V.9 
Field (Col.) Name Description

$50-55$

$56-62$

$63-64$

$65-80$ precursor
DNB Standard uncertainty in NB

Multiplier for converting per hundred delayedtransition intensities to per hundred decays of

DNP standard uncertainty in NP Must be blank
Reference

V.11

V.9

V.11

Note: Normally $\beta^{-}$and $\epsilon$ intensities are given as per 100 parent decays. One should remember that the multiplier for conversion to per 100 decays is $\mathrm{NB} \times \mathrm{BR}$ and, therefore, $N B=1 / B R$. Also, the uncertainties in $\mathrm{I}\left(\beta^{-}\right)$will be calculated from addition of three quantities $\Delta\left(I\left(\beta^{-}\right)\right), \mathrm{DBR}$ and $\mathrm{DNB}$ in quadrature. Unless the uncertainties are precisely known it is recommended that NB be given without uncertainty. See PN record.

If more than one $\mathbf{P}$ records exist in the data set then there should be corresponding $\mathbf{N}$ records giving the respective branching ratios. 


\section{The Production Normalization Record}

Must follow $N$ record, if $N$ record present.

It should be given when $\mathbf{G}$ records with intensities are present.

\begin{tabular}{|c|c|c|}
\hline Field & Name & Description \\
\hline $1-5$ & NUCID & Nuclide (Daughter/Product) identification \\
\hline 6 & & Blank. \\
\hline 7 & $\mathbf{P}$ & Letter ' $\mathrm{P}$ ' (for production) is required \\
\hline 8 & $\mathbf{N}$ & Letter ' $N$ ' is required \\
\hline 9 & & Must be blank \\
\hline 10-19 & $\mathbf{N} \mathbb{R} \times \mathbf{B R}$ & $\begin{array}{l}\text { Multiplier for converting relative photon } \\
\text { intensity (RI in the GAMMA record) to } \\
\text { photons per } 100 \text { decays of the parent. } \\
\text { (Normally } N R \times B R) \text {. } \\
\text { If left blank (NR DNR) } \times(B R \text { DBR) from } N \text { record will } \\
\text { be used for normalization. }\end{array}$ \\
\hline $20-21$ & $\mathrm{UNC}^{1}$ & Standard uncertainty in $\mathbf{N R} \times \mathbf{B R}$ \\
\hline 22-29 & $\mathbf{N T} \times \mathbf{B R}$ & $\begin{array}{l}\text { Multiplier for converting relative transition } \\
\text { intensity (including conversion electrons) } \\
\text { [TI in the GAMMA record] to transitions } \\
\text { per } 100 \text { decays of the parent. (Normally } N T \times B R \text { ) } \\
\text { If left blank (NT DNT) } \times(B R \text { DBR) from } N \text { record will } \\
\text { be used for normalization. }\end{array}$ \\
\hline $30-31$ & $\mathbf{U N C}^{1}$ & standard uncertainty in $\mathbf{N T} \times \mathbf{B R}$ \\
\hline $42-49$ & $\mathbf{N B} \times \mathbf{B R}$ & $\begin{array}{l}\text { Multiplier for converting relative } \beta^{-} \text {and } \epsilon \\
\text { intensities (IB in the B- record; IB, IE, } \\
\text { TI in the EC record) to intensities per } \\
100 \text { decays. } \\
\text { If left blank (NB DNB) } \times(B R \text { DBR) from } N \text { record will be } \\
\text { used for normalization. }\end{array}$ \\
\hline $50-55$ & $\mathbf{U N C}^{1}$ & Standard uncertainty in $(\mathrm{NB} D N T) \times($ BR DBR $)$ \\
\hline $56-62$ & NP & Same as in ' $N$ ' record \\
\hline 63-64 & $\mathbf{U N C}^{\mathbf{1}}$ & standard uncertainty in NP \\
\hline 77 & COM & $\begin{array}{l}\text { Blank or ' } C \text { ' (for comment) } \\
\text { If blank, comment associated with the intensity } \\
\text { option will appear in the drawing in the Nuclear Data Sheets. } \\
\text { If letter 'C' is given, the desired comment to appear in the } \\
\text { drawing should be given on the continuation ('nPN') record(s), } \\
\text { col. } 10-80 \text {. }\end{array}$ \\
\hline
\end{tabular}

${ }^{1}$ If left blank no uncertainty will appear in the publication. 


\section{Field Name Description}

78 OPT Intensity Option. Option as to what intensity to display in the drawings in the Nuclear Data Sheets. The available options are given below (default option 3).

\begin{tabular}{|c|c|}
\hline Option & Intensity displayed \\
\hline 1 & TI or $\mathrm{RI}(1+\alpha)$ \\
\hline 2 & $\mathrm{TI} \times \mathrm{NT}$ or $\mathrm{RI} \times \mathrm{NR} \times($ \\
\hline 3 & $\begin{array}{l}\mathrm{TI} \times \mathrm{NT} \times \mathrm{BR} \text { or } \\
\mathrm{RI} \times \mathrm{BR} \times \mathrm{NR} \times(1+\alpha)\end{array}$ \\
\hline 4 & $\mathrm{RI} \times \mathrm{NT} \times \mathrm{BR}$ \\
\hline 5 & RI \\
\hline 6 & $\mathrm{RI}$ \\
\hline 7 & RI \\
\hline
\end{tabular}

Comment in drawing

Relative $\mathrm{I}(\gamma+c e)$

$\mathrm{I}(\gamma+c e)$ per 100 (mode) decays

$\mathrm{I}(\gamma+c e)$ per 100 parent decays

$\mathrm{I}(\gamma)$ per 100 parent decays

Relative $\mathbb{I}(\gamma)$

Relative photon branching from each level

$\%$ photon branching from each level 


\section{The Level Record}

Optional, although a data set usually has at least one.

$\begin{array}{cl}\begin{array}{c}\text { Field (Col.) } \\ 1-5\end{array} & \text { Nam } \\ 6 & \\ & \\ & \\ 7 & \\ 8 & \text { L } \\ 9 & \\ 10-19 & \text { E } \\ 20-21 & \text { DE } \\ 22-39 & \text { J } \\ 40-49 & \text { T } \\ & \\ & \\ 50-55 & \text { DT } \\ 56-64 & \text { L }\end{array}$

65-74 S

75-76 DS

77

78-79 MS
Description

Nuclide identification

Blank

Any alphanumeric character other than ' 1 ' for continuation records

Must be blank

Letter ' $L$ ' is required

Must be blank

Luevel energy in $\mathrm{keV}$ - Must not be blank

Standard uncertainty in $\mathbf{E}$

V.18

V.11

V.20

V.14

Half-life of the level; units must be given.

Mean-life expressed as the width of a level, in units of energy, may also be used

Standard uncertainty in $\mathbf{T}$

Angular momentum transfer in the reaction

V.22

determining the data set. (Whether it

is $L_{n}, L_{p}, \Delta \mathbf{L}$, etc., is determined from

the DSID field of the IDENTIFICATION record.)

Spectroscopic strength for this level as deter-

V.21

mined from the reaction in the IDENTI-

FICATION record. (Spectroscopic factor for

particle-exchange reactions; $\beta$ for inelastic

scattering.)

Note: If a quantity other than spectroscopic factor is given in this field, a footnote relabelling the field is required.

Standard uncertainty in $\mathbf{S}$

V.11

Comment FLAG used

to refer to a particular comment record

Metastable state is denoted by ' $M$ ' or

V.17

'M2', for the second isomer, etc.

For Ionized Atom Decay field gives the atomic electron shell or subshell in which $\beta^{-}$ particle is captured 
Field (Col.) Name Description

80
$\mathbf{Q}$
The character '?' denotes an uncertain or questionable level.

Letter ' $\mathrm{S}$ ' denotes neutron, proton, alpha separation energy or a level expected

but not observed

\section{The Beta $\left(\beta^{-}\right)$Record}

Must follow the LEVEL record for the level which is fed by the $\beta^{-}$.

\begin{tabular}{|c|c|c|c|}
\hline Field (Col.) & Name & Description & Reference \\
\hline $1-5$ & NUCID & Nuclide identification & V.1 \\
\hline 6 & & Blank & \\
\hline & & $\begin{array}{l}\text { Any alphanumeric character other than ' } 1 \text { ' } \\
\text { for continuation records }\end{array}$ & \\
\hline 7 & & Must be blank & \\
\hline 8 & $\mathbf{B}$ & Letter ' $\mathrm{B}$ ' is required' & \\
\hline 9 & & Must be blank & \\
\hline 10-19 & $\mathbf{E}$ & $\begin{array}{l}\text { Endpoint energy of the } \beta^{-} \text {in } \mathrm{keV} \\
\text { Given only if measured }\end{array}$ & V.18 \\
\hline $20-21$ & DE & Standard uncertainty in $\mathbf{E}$ & V.11 \\
\hline $22-29$ & IB & Intensity of the $\beta^{-}$-decay branch ${ }^{1}$ & V.13 \\
\hline $30-31$ & DIB & Standard uncertainty in IB & V.11 \\
\hline $42-49$ & LOGFT & $\begin{array}{l}\text { The } \log f t \text { for the } \beta^{-} \text {transition } \\
\text { for uniqueness given in col. } 78-79\end{array}$ & V.9 \\
\hline $50-55$ & DFT & Standard uncertainty in LOGFT & V.12 \\
\hline $56-76$ & & Must be blank & \\
\hline 77 & $\dot{\mathbf{C}}$ & $\begin{array}{l}\text { Comment FLAG (Letter 'C' denotes } \\
\text { coincidence with a following radiation: } \\
\text { A '?' denotes probable coincidence with a } \\
\text { following radiation.) }\end{array}$ & V.8 \\
\hline 78-79 & $\mathbf{U N}$ & $\begin{array}{l}\text { Forbiddenness classification for the } \beta^{-} \text {decay, } \\
\text { e.g. ' } 1 \mathrm{U} \text { ', ' } 2 U \text { ' for first-, second-unique forbidden. } \\
\text { (A blank field signifies an allowed } \\
\text { transition. Nonunique forbiddenness can be } \\
\text { indicated in col } 78 \text {, with col } 79 \text { blank) }\end{array}$ & V.16 \\
\hline 80 & $\mathbf{Q}$ & $\begin{array}{l}\text { The character '?' denotes an uncertain or } \\
\text { questionable } \beta \text { ' decay } \\
\text { Letter 'S' denotes an expected or predicted } \\
\text { transition }\end{array}$ & \\
\hline
\end{tabular}

${ }^{1}$ The intensity units are defined by the NORMALIZATION record. 


\section{The EC (or EC $+\beta^{+}$) Record}

Must follow the LEVEL record for the level being populated in the decay.

\begin{tabular}{|c|c|c|}
\hline Field (Col.) & Name & Description \\
\hline $1-5$ & NUCID & Nuclide identification \\
\hline 6 & & Blank \\
\hline & & $\begin{array}{l}\text { Any alphanumeric character other than ' } 1 \text { ' } \\
\text { for continuation records }\end{array}$ \\
\hline 7 & & Must be blank \\
\hline 8 & $\mathbf{E}$ & Letter ' $\mathrm{E}$ ' is required \\
\hline 9 & & Must be blank \\
\hline $10-19$ & $\mathbb{E}$ & $\begin{array}{l}\text { Energy for electron capture to the level } \\
\text { Given only if measured or deduced from measured } \beta^{+} \\
\text {end-point energy }\end{array}$ \\
\hline $20-21$ & $\mathbf{D E}$ & Standard uncertainty in $\mathbf{E}$ \\
\hline $22-29$ & IB & Intensity of $\beta^{+}$-decay branch ${ }^{1}$ \\
\hline 30-31 & DIB & Standard uncertainty in IB \\
\hline $32-39$ & $\mathrm{IE}$ & Intensity of electron capture branch ${ }^{1}$ \\
\hline $40-41$ & DIE & Standard uncertainty in IE \\
\hline $42-49$ & LOGFT & $\begin{array}{l}\text { The } \log f t \text { for }\left(\epsilon+\beta^{+}\right) \text {transition } \\
\text { for uniqueness given in col. } 78-79\end{array}$ \\
\hline $50-55$ & DFT & Standard uncertainty in LOGFT \\
\hline $65-74$ & $\mathbf{T I}$ & Total $\left(\epsilon+\beta^{+}\right)$decay intensity ${ }^{1}$ \\
\hline $75-76$ & DTI & Standard uncertainty in TI \\
\hline 77 & $\mathbf{C}$ & $\begin{array}{l}\text { Comment FLAG (Letter 'C' denotes } \\
\text { coincidence with a following radiation. } \\
\text { A '?' denotes probable coincidence with a } \\
\text { following radiation.) }\end{array}$ \\
\hline $78-79$ & UN & $\begin{array}{l}\text { Forbiddenness classification for } \epsilon, \beta^{+} \text {decay, } \\
\text { e.g. ' '1U', ' } 2 U \text { 'for first, second unique forbidden. } \\
\text { (A blank signifies an allowed or a nonunique forbidden } \\
\text { transition. Nonunique forbiddenness can be } \\
\text { indicated in col } 78 \text {, with col } 79 \text { blank) }\end{array}$ \\
\hline 80 & $\mathbf{Q}$ & $\begin{array}{l}\text { The character '?' denotes an uncertain or } \\
\text { questionable } \epsilon, \beta^{+} \text {branch } \\
\text { Letter 'S' denotes an expected or predicted } \\
\text { transition }\end{array}$ \\
\hline
\end{tabular}

Reference

V.1

V.18

V.11

V.13

V.11

V.13

V.11

V.9

V.12

V.13

V.11

V.8

V.16

${ }^{1}$ IE, IB and TI must be in the same units (see also NB in NORMALIZATION record). 


\section{The Alpha Record}

Must follow the LEVEL record for the level being populated in the decay.

\begin{tabular}{|c|c|c|c|}
\hline Field (Col.) & Name & Description & Reference \\
\hline $1-5$ & NUCID & Nuclide identification & V.1 \\
\hline 6 & & Blank & \\
\hline 7 & & Must be blank & \\
\hline 8 & $\mathbf{A}$ & Letter ' $A$ ' is required & \\
\hline 9 & & Must be blank & \\
\hline $10-19$ & $\mathbf{E}$ & Alpha energy in $\mathrm{keV}$ & V.18 \\
\hline $20-21$ & $\mathbb{D E}$ & Standard uncertainty in $\mathbb{E}$ & $\mathbb{V} .11$ \\
\hline $22-29$ & $\mathbb{I A}$ & $\begin{array}{l}\text { Intensity of } \alpha \text {-decay branch in percent of } \\
\text { the total } \alpha \text { decay }\end{array}$ & V.13 \\
\hline $30-31$ & DIA & Standard uncertainty in IA & V.11 \\
\hline $32-39$ & $\mathbf{H F}$ & Hindrance factor for $\alpha$ decay & V.9 \\
\hline $40-41$ & DHF & Standard uncertainty in $\mathbf{H F}$ & V.11 \\
\hline $42-76$ & & Must be blank & \\
\hline 77 & $\mathbf{C}$ & $\begin{array}{l}\text { Comment FLAG (Letter ' } \mathrm{C} \text { ' denotes } \\
\text { coincidence with a following radiation. } \\
\text { A '?' denotes probable coincidence with a } \\
\text { following radiation.) : }\end{array}$ & V.8 \\
\hline $78-79$ & & Must be blank & \\
\hline 80 & $\mathbf{Q}$ & $\begin{array}{l}\text { The character '?' denotes uncertain or } \\
\text { questionable } \alpha \text { branch } \\
\text { Letter 'S' denotes an expected or pre- } \\
\text { dicted } \alpha \text { branch }\end{array}$ & \\
\hline
\end{tabular}




\section{The (Delayed-) Particle Record}

Must follow the LEVEL record for the level which is fed by the particle. Records for particles which are unassigned in a level scheme should precede the first level of the data set.

\begin{tabular}{|c|c|c|c|}
\hline Field (Col.) & Name & Description & Reference \\
\hline $1-5$ & NUCID & Nuclide identification & V.1 \\
\hline \multirow[t]{2}{*}{6} & & Blank & \\
\hline & & $\begin{array}{l}\text { Any alphanumeric character other than ' } 1 \text { ' } \\
\text { for continuation records }\end{array}$ & \\
\hline 7 & & Must be blank & \\
\hline 8 & $\mathbb{D}$ & $\begin{array}{l}\text { Blank for prompt-, Letter ' } D \text { ' for delayed- } \\
\text { particle emission }\end{array}$ & \\
\hline 9 & Particle & $\begin{array}{l}\text { The symbol for the (delayed) particle } \\
\text { ( } N=\text { neutron, } P=\text { proton, } A=\text { alpha particle) is } \\
\text { required) }\end{array}$ & \\
\hline $10-19$ & $\mathbf{E}$ & Energy of the particle in $\mathrm{keV}$ & V.18 \\
\hline $20-21$ & $\mathbf{D E}$ & Standard uncertainty in $\mathbf{E}$ & V.11 \\
\hline $22-29$ & IP & $\begin{array}{l}\text { Intensity of (delayed) particles in percent } \\
\text { of the total (delayed-) particle emissions }\end{array}$ & V.13 \\
\hline $30-31$ & DIP & Standard uncertainty in IP & V.11 \\
\hline \multirow[t]{2}{*}{$32-39$} & EI & Energy of the level in the & V.13 \\
\hline & & $\begin{array}{l}\text { 'intermediate' (mass }=A+1 \text { for } n, p ; A+4 \text { for } \alpha \text { ) } \\
\text { nuclide in case of delayed particle }\end{array}$ & \\
\hline $40-49$ & $\mathbf{T}$ & Width of the transition in $\mathrm{keV}$ & V.14 \\
\hline $50-55$ & $\mathbf{D T}$ & Uncertainty in $\mathbf{T}$ & V.12 \\
\hline $56-64$ & $\mathbf{L}$ & $\begin{array}{l}\text { Angular-momentum transfer of the } \\
\text { emitted particle }\end{array}$ & V.22 \\
\hline $65-76$ & Blank & & \\
\hline 77 & $\mathbf{C}$ & $\begin{array}{l}\text { Comment FLAG used to refer to } \\
\text { a particular comment record. }\end{array}$ & V.8 \\
\hline 78 & COIN & $\begin{array}{l}\text { Letter 'C' denotes placement confirmed by } \\
\text { coincidence. Symbol '?' denotes probable } \\
\text { coincidence. }\end{array}$ & V.15 \\
\hline 79 & & Blank & \\
\hline 80 & $\mathbf{Q}$ & $\begin{array}{l}\text { The character '?' denotes an uncertain } \\
\text { placement of the transition in the level } \\
\text { scheme } \\
\text { Letter 'S' denotes an expected, but as yet } \\
\text { unobserved, transition. }\end{array}$ & . \\
\hline
\end{tabular}


Notes:

1. The delayed-particle record will appear in a delayed-particle data set (e.g., B-N DECAY, ECP DECAY, etc.) which should be given under the A-chaan for the final nuclide. For example, '95RB B-N DECAY' should be given as data set for ${ }^{94} \mathrm{Sr}$.

2. The intensity units are defined by the NORMALIZATION record. 


\section{The Gamma Record}

Must follow the LEVEL record for the level from which the $\gamma$ ray decays. Records for $\gamma$ rays which are unassigned in a level scheme should precede the first level of the data set.

\begin{tabular}{|c|c|c|c|}
\hline Field (Col.) & Name & Description & Reference \\
\hline $1-5$ & NUCID & Nuclide identification & V.1 \\
\hline 6 & & Blank & \\
\hline & & $\begin{array}{l}\text { Any alphanumeric character other than ' } 1 \text { ' } \\
\text { for continuation records }\end{array}$ & \\
\hline 7 & & Must be blank & \\
\hline 8 & G & Letter ' $G$ ' is required & \\
\hline 9 & & Must be blank & \\
\hline 10-19 & $\mathbf{E}$ & $\begin{array}{l}\text { Energy of the } \gamma \text {-ray in } \mathrm{keV} \\
\text { - Must not be blank }\end{array}$ & V.18 \\
\hline 20-21 & $\mathbf{D E}$ & Standard uncertainty in $\mathbf{E}$ & V.11 \\
\hline $22-29$ & $\mathbf{R I}$ & Relative photon intensity ${ }^{1}$ & V.13 \\
\hline $30-31$ & DRI & Standard uncertainty in RI & V.11 \\
\hline $32-41$ & M & Multipolarity of transition & V.19 \\
\hline $42-49$ & $\mathbf{M R}$ & $\begin{array}{l}\text { Mixing ratio, } \delta \text {. (Sign must be shown } \\
\text { explicitly if known. If no sign is given, } \\
\text { it will be assumed to be unknown.) }\end{array}$ & V.10 \\
\hline $50-55$ & DMR & Standard uncertainty in $\mathbf{M R}$ & V.12 \\
\hline $56-62$ & $\mathbf{C C}$ & Total conversion coefficient & V.9 \\
\hline $63-64$ & DCC & Standard uncertainty in $\mathbf{C C}$ & V.11 \\
\hline $65-74$ & $\mathbf{T I}$ & Relative total transition intensity ${ }^{1}$ & V.13 \\
\hline $75-76$ & DTI & Standard uncertainty in TI & V.11 \\
\hline 77 & $\mathbf{C}$ & $\begin{array}{l}\text { Comment FLAG used to refer to } \\
\text { a particular comment record. The sym- } \\
\text { bol '*' denotes a multiply-placed } \gamma \text { ray. } \\
\text { The symbol ' } \& \text { ' denotes a multiply-placed } \\
\text { transition with intensity not divided. }\end{array}$ & V.8 \\
\hline & & $\begin{array}{l}\text { The symbol '@' denotes a multiply-placed } \\
\text { transition with intensity suitably divided. } \\
\text { The symbol '\%' denotes that the intensity given as } \\
\text { RI is the \% branching in the Super Deformed } \\
\text { Band. }\end{array}$ & \\
\hline 78 & COIN & $\begin{array}{l}\text { Letter 'C' denotes placement confirmed by } \\
\text { coincidence. Symbol '?' denotes questionable } \\
\text { coincidence. }\end{array}$ & V.15 \\
\hline
\end{tabular}



Field (Col.) Name Description 79 Blank
80 Q The character '?' denotes an uncertain placement of the transition in the level scheme Letter ' $\mathrm{S}$ ' denotes an expected, but as yet unobserved, transition

\title{
Reference
}

\section{The Reference Record}

Record can occur only in Reference data set.

The NNDC provides the Reference data set.

$\begin{array}{cllr}\text { Field (Col.) } & \text { Name } & \text { Description } & \text { Reference } \\ 1-3 & \text { MASS } & \text { Mass Number } & \\ 4-7 & & \text { Must be blank } & \\ 8 & \text { R } & \begin{array}{l}\text { Letter 'R' is required } \\ \text { Must be blank }\end{array} & \\ 9 & & \text { V.3 } \\ 10-17 & \text { KEYNUM } & \begin{array}{l}\text { Reference key number } \\ 18-80\end{array} & \text { REFERENCE } \\ & & \begin{array}{l}\text { Abbreviated reference } \\ \text { (from NSR file) }\end{array} & \end{array}$

\section{The End Record}

Required for all data sets.

Must be the last record in a data set.

\author{
Field (Col.) Description \\ 1-80 All columns are blank \\ C Summary
}

The following two pages summarize the standard one-card formats for all allowed record types. 


\section{SUMMARY Of STANDARD ONE-CARD RECORD FORMAT}

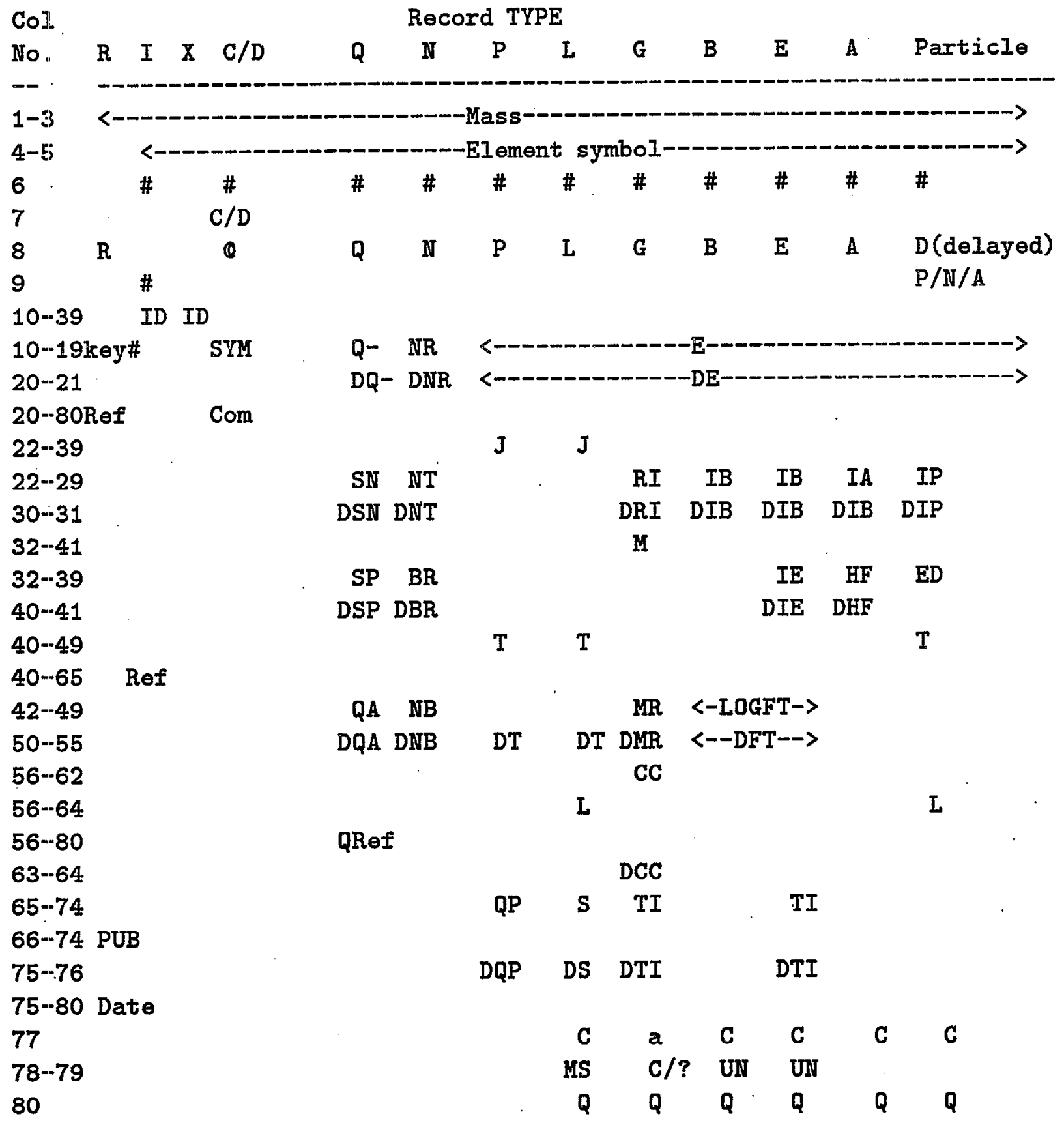

\# Any ASCII Character

( $L, G, B, A, E, N, Q, P$ for record comments following the respective record a * denotes multiply placed.

( denotes multiply placed, intensity sitably divided.

\& denotes multiply placed, undivided intensity given.

\% denotes that the intensity given is \% branching in SD band 
ENSDF Standard 80-character Formated Records

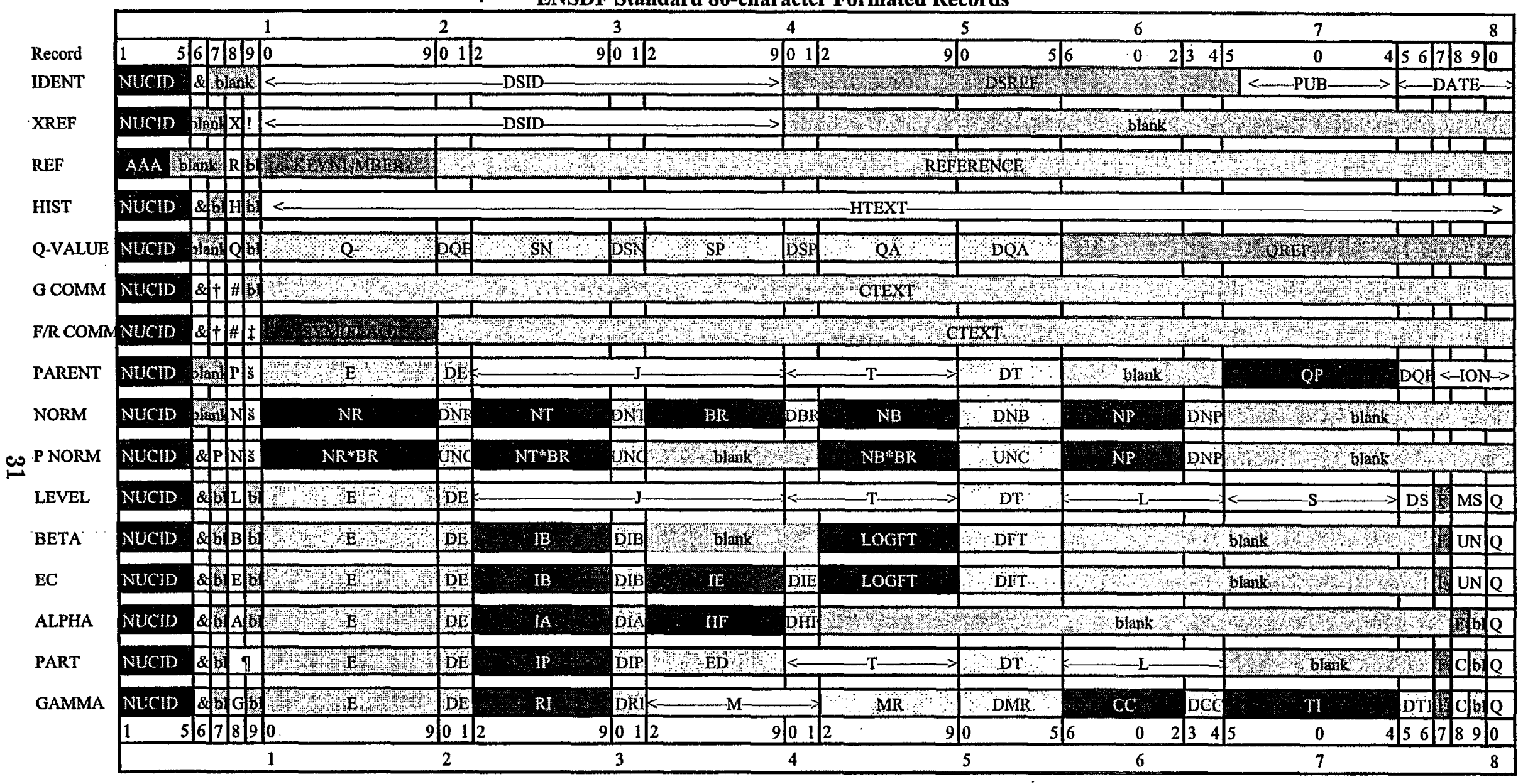

Notes:

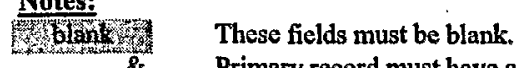

Primary record must have a blank or " 1 " in this field. Continuation records should have any printable ASCII character except for blank or "1" (one).

Unique alphanumeric character identifying the source data set.

Allowed characters for this field are $C, c, D, d, T$, and $t$.

Character identifying the record being commented on. Allowed characters for this field are $N, P, Q, L, G, B, E, A, D$, and blank.

Must be blank except for: 1) Particle code for a (delayed-)particle record. 2) Sequence number for normalization and parent records.

Must be blank except when there are multiple parent records then this field should contain an integer relating the parent record to the related normalization record.

Byte 8 must either be blank for a prompt particle radiation or $D$ for a delayed particle radiation. Byte 9 identifies the particle $(N, P, D$, or $T)$. 


\title{
Chapter IV
}

\section{RECORDS CONTAINING MORE THAN ONE CARD}

\section{A Card Enumeration}

Certain record types, namely, the Identification, History, Parent, Normalization records can have multiple occurrence of records with qualifications as indicated in the descriptions of these record types. For other record types if all the information cannot be contained on a single card, it is possible to use additional cards to describe the record fully. The first card of a record will have a blank in col. 6 and subsequent cards will have an ASCII character different from blank or 1 (usually running numbers: 2 to 9 or letters $A$ to $Z$ ).

\section{B Format for Continuation Cards}

\author{
THE CONTINUATION RECORD
}

Must follow the record of the same RTYPE.

\begin{tabular}{|c|c|c|}
\hline Field & Name & Description \\
\hline $1-5$ & NUCID & Nuclide identification \\
\hline 6 & & $\begin{array}{l}\text { Any alphanumeric character other than } 1 . \\
\text { Note: 'S' is reserved for computer-produced records which } \\
\text { will usually be suppressed in the Nuclear Data Sheets }\end{array}$ \\
\hline 7 & & Must be blank \\
\hline $\begin{array}{l}8 \\
9\end{array}$ & RTYPE & $\begin{array}{l}\text { Letter corresponding to the record type } \mathbf{L}, \mathbf{B}, \mathbf{E}, \mathbf{G} \text { or } \mathbf{H} \\
\text { Must be blank }\end{array}$ \\
\hline $10-80$ & Data & $<$ quant $><$ op $><$ value $>[<$ op $><$ value $>][<$ ref $>] \$$ \\
\hline
\end{tabular}


In the description of Data above the following abbreviations have been used:

$<$ quant >: Standard symbol for a quantity as defined in IV.C below.

Notes: 1. Ratios of more than two quantities should be indicated by colons and not by slashes (e.g., K:L1:L2:L3 and not $\mathrm{K} / \mathrm{L} 1 / \mathrm{L} 2 / \mathrm{L} 3)$.

2. See V.24 for description of $<$ value $>$ when $\langle$ quant $\rangle=$ XREF

3. See V.25 for description of items for $\mathbf{H}$ record

$<o p>: \quad=,<,>,<=,>=, \mathrm{EQ}, \mathrm{AP}, \mathrm{LT}, \mathrm{LE}, \mathrm{GT}, \mathrm{GE}$

Note: For the last 6 operators blanks before and after them are required.

$<$ value >: Numeric value with units as needed and optional uncertainty.

Uncertainty is as defined in Sections V.11 and V.12.

Note: For ranges, uncertainties should not be included.

To specify a bounded range of values a second operator

(note that $=, \mathrm{EQ}, \mathrm{AP}$ are not valid) and value are required.

See examples below.

[...]: Optional.

$<$ ref > : 8 character key numbers, KEYNUM (see V.3), separated by commas and enclosed within parentheses, e.g., (1976TU01,1981BO01).

$\$: \quad$ Delimiter (end of record is also a delimiter; thus ' $\$$ ' is not needed for the last item on a record)

Examples:

126TE $2 \mathrm{G}$ BE2W=25.3 7(1970LAZM)

$126 \mathrm{I} 2 \mathrm{~L} \% \mathrm{EC}+\% \mathrm{~B}+=56.320$ (1977JA04)\$\%B- EQ 43.720 (1977JA04)

$126 \mathrm{SN}$ S B EAV $=203060$

126TE 2 L G LE 0.19 GT 0.1 (1981SH15)\$MOME2 AP -0.20\$BE2=0.478 12

\section{Allowed Data Types on Continuation Records}

Each record type is permitted to contain only a limited (but extendable) set of data types. For example, a GAMMA record is not allowed to contain information of data type DTYPE = J (nuclear spin), similarly a LEVEL record is not allowed to contain LOGFT information.

For $\mathbf{A}$ and DP records only FLAG in addition to the quantities on the formatted records, can be given on a continuation record. The allowed data types for LEVEL, GAMMA, B-, and EC records are described below. 


\section{The Level Record}

Allowed data types E, DE, J, T, DT, L, S, DS, C, MS, Q, are described with the standard formats in Section III.B.9. Additional allowed data types are:

TYPE

Description

\%EC,\%B,$+ \% \mathrm{EC}+\% \mathrm{~B}+$, Percent decay of the level by $\epsilon, \beta^{+}, \epsilon+\beta^{+}$,

$\% \mathrm{~B}-, \% \mathrm{IT}, \% \mathrm{SF}$,

$\% \mathrm{~A}, \% \mathrm{P}, \% \mathrm{~N}, \ldots$;

$\% \mathrm{~B}-\mathrm{N} ; \% \mathrm{~B}-\mathrm{XN} ; \ldots$

$\beta^{-}$, isomeric transition, spontaneous fission,

$\alpha$, proton, or neutron decay, $\ldots$

Percent delayed decay through $\mathrm{n}, \mathrm{xn}$ emission,....

Similarly, for other particle emissions, e.g.,

$\mathrm{p}, \mathrm{xp}, \alpha, \mathrm{x} \alpha$, etc., following $\beta-, \beta+$, or $\epsilon$ decays.

Note: Decay modes must be given on ' $2 \mathbb{L}$ '

card in adopted set and on an ' $\mathrm{S} \mathrm{L}$ '

card in decay and $(n, \gamma)$ data sets

ION

CONF

BE1, BE2, ...

$\mathbf{B 2}, \mathbf{B 3}, \ldots$

FLAG

G

ISPIN

ISPINZ

MOME1, MOME2, ...

MOMM1, MOMM2,...

WIDTH,WIDTHG,

WIDTHGO,WIDTHN,

WIDTHP, WIDTHA

XREF
Ionization State (used in Ionized Atom Decay)

Nuclear configuration of the level

Reduced electric transition probability (upward)

given in units $e^{2} \times(\text { barns })^{L}$, where $\mathrm{L}=1,2, \ldots$

for the transition from the ground state to this level

$2^{L}$-pole $(L=2,3, \ldots)$ nuclear deformation

parameter

Additional footnote symbols

g-factor of the level

Isobaric spin

Z-component of Isobaric Spin

Electric moments: dipole, quadrupole, ...

Magnetic moments: dipole, quadrupole, ...

Level width, $\Gamma$, Partial- $\gamma,-\gamma 0,-n,-p,-\alpha$ widths, $\Gamma(\gamma), \Gamma(\gamma 0), \Gamma(\mathrm{n})$

$\Gamma(\mathrm{p}), \Gamma(\alpha)$, respectively

Cross-reference to other data sets for that nuclide, this is generally given only in the adopted set. 


\section{The Gamma Record}

Allowed data types, E, DE, RI, DRI, M, MR, DMR, CC, DCC, TI, DTI, C, COIN, $\mathbf{Q}$, are described with the standard formats in Section III.B.14. Additional allowed data types are:

DTYPE

BE1, BE2, ...

BE1W, BE2W, ..

$\mathbb{B M 1}, \mathbb{B M} 2, \ldots$

BM1W,BM2W, ...

CE

CEK,CEL,...

CEL1,...

ECC

EKC, ELC, EL1C, $\cdots$

FL

FLAG

$\mathrm{KC}, \mathrm{LC}, \mathrm{L} 1 \mathrm{C}, \ldots$

$\mathrm{K}: \mathrm{L}, \mathrm{M}: \mathrm{L}, \mathrm{L} 1: \mathrm{L} 2, \ldots$

$\mathrm{K}: \mathrm{T}, \mathrm{L}: \mathrm{T}, \ldots$

\section{Description}

Reduced electric transition probability (downward) given in units of $e^{2} \times(\text { barns })^{L}$; where $\mathrm{L}=1,2, \ldots$

Reduced electric transition probability

(downward) given in single-particle (Weisskopf)

units

Reduced magnetic transition probability (downward) given in units of $\mu_{N}^{2} \times(\text { barns })^{L-1}$, where $\mathrm{L}=1,2, \ldots$

Reduced magnetic transition probability .

(downward) given in single-particle (Weisskopf)

units

Total conversion electron intensity

Conversion-electron (ce) intensity for $K, L, \ldots$

$L_{1}, \ldots$ conversion

Measured total conversion coefficient

Measured K-, L-, $L_{1}-, \ldots$ conversion coefficient

Final level energy. It must be either identical to a level energy in the data set optionally followed by a '?' (latter expresses uncertain placement) or a '?' (if the final level is not known)

Additional footnote symbols

Theoretical K-, L-, $L_{1}-\ldots$ conversion coefficient

Conversion-electron intensity ratios

Ratio of $\mathrm{K}, \mathrm{L}, \ldots$... ce-intensity to total $(\gamma+\mathrm{ce})$

intensity 


\section{The Beta $\left(\beta^{-}\right)$Record}

Allowed data types E, DE, IB, DIB, LOGFT, DFT, C, UN, Q, are described with the standard formats in Section III.B.10. Additional allowed data types are:

DTYPE Description

EAV Average energy of the $\beta^{-}$spectrum

FLAG Additional footnote symbols

(Note: ' $\mathrm{C}$ ' and '?' may not be used -

see III.B.10 for their special meaning)

\section{The $\mathbb{P}$ C Record}

Allowed data types, E, DE, IB, DIB, IE, DIE, LOGFT, DFT, TI, DTI, C, UN, $\mathbf{Q}$, are described with the standard formats in Section III.B.11. Additional allowed data types are:

\begin{tabular}{|c|c|}
\hline DTYPE & Description \\
\hline EAV & Average energy of the $\beta^{+}$spectrum \\
\hline $\begin{array}{l}\mathrm{CK}, \mathrm{CL}, \mathrm{CM}, \\
\ldots, \mathrm{CL}+\end{array}$ & $\begin{array}{l}\text { Calculated fraction of decay by electron capture } \\
\text { from the } \mathbf{K}, \mathbf{L}, \mathbf{M}, \ldots, \mathrm{L}+\mathbf{M}+\ldots \text { shells }\end{array}$ \\
\hline $\begin{array}{l}\text { ECK,ECL,ECM, } \\
\ldots, \text { ECL }+\end{array}$ & $\begin{array}{l}\text { Measured fraction of decay by electron capture } \\
\text { from the } \mathbf{K}, \mathbf{L}, \mathbf{M}, \ldots, \mathrm{L}+\mathbf{M}+\ldots \text { shells }\end{array}$ \\
\hline $\mathrm{CK} / \mathrm{T}, \mathrm{CL} / \mathrm{T}, \ldots$ & $\begin{array}{l}\text { Ratio of } K, L, \ldots \epsilon \text {-intensity to total } \epsilon \\
\text { intensity }\end{array}$ \\
\hline FLAG & $\begin{array}{l}\text { Additional footnote symbols } \\
\text { (Note: 'C' and '?' may not be used - } \\
\text { see III.B.11 for their special meaning) }\end{array}$ \\
\hline
\end{tabular}




\section{Chapter V}

\section{DETAILED FIELD DESCRIPTIONS}

\section{NUCID}

The standard nuclide identification consists of two parts - mass number in cols. (1-3), right justified and element name (or $Z-100$ for $Z>109$ ) in (col. 4-5), left justified. The nuclide identification must be contained within the field defined for it (cols. 1-5). The nuclide identification must be included on every card of a data set except the END record. Comments and reference data sets pertaining to the whole A-(mass) chain evaluation contain only the A-value in the NUCID field.

\section{DSID}

Data Set ID for an ENSDF data set serves as a unique, computer recognizable identification for the data set. There can not be two data sets with identical DSID and NUCID. In the rare circumstance two data sets with same DSID for a given NUCID can be accomodated by ending DSID with a colon (:) and following it with a unique identifier which will then be different for the various data sets with that DSID.

The following rules for DSID should be strictly observed for ENSDF entries. Single blanks have meaning and should be used according to the formats below. In the description below the optional fields are given in italics. General categories are given in upper and lower cases and further defined. DSID must be confined to the 30 spaces allowed. The field may, however, be continued on to the DSID field on the second ID record as explained in Chapter III in which case the DSID on the first record must end with a ', '. 


\section{GENERAL ID'S}

REFERENCES

COMMENTS (see Appendix B for format for this data set)

ADOPTED LEVELS

ADOPTED LEVELS, GAMMAS

DECAY DATA SET ID'S

Parent Mode Decay (Half-life)

Parent should be the parent nuclide symbol, e.g., 52CR

For SF decay more than one parent can be given separated by commas

For Ionized Atom Decay parent nuclide symbol is followed by ionization state

in square brackets, e.g., $187 \mathrm{RE}[+75]$

Mode may be one of $\mathbb{B}+, \mathbb{B}-, \mathbf{E C}, \mathbf{I T}, \mathbf{A}, \mathbb{P}, \mathbf{B}-\mathbf{N}, \mathbf{E C P}, \mathbf{S F}, \ldots$

List of decay modes may be expanded.

Half-life can be of the form $\mathrm{T}$ defined in V.14.1

MUONIC ATOM

REACTION DATA SET ID'S

Target(Reaction), (Reaction), Target(Reaction) E=Energy Qualifier.

COULOMB EXCITATION

(HI,XNG)

Target should be the target (nuclide or element) symbol

Reaction should be given as (in,out), e.g., (N,P)

in is the incident particle, out are the outgoing particles

Energy may be one of the following

NUM, NUM Units (for definition of NUM see V.9.)

NUM-NUM Units

$\mathrm{TH}$ (for thermal)

RES (for resonance)

Qualifier may be one of the following

RES

IAR

IAS

EXAMPLES:

187RE B- DECAY

187RE[+75] B- DECAY

190PT A DECAY (6E11 Y)

186OS(N,G) $\mathrm{E}=$ THERMAL

$\mathrm{RE}\left(\mathrm{N}, \mathrm{N}^{\prime}\right): \mathrm{TOF}$

$186 \mathrm{~W}(\mathrm{~N}, \mathrm{G}) \mathrm{E}=\mathrm{RES}: \mathrm{AVG}$

$187 \mathrm{OS}\left(\mathrm{D}, \mathrm{D}^{\prime}\right) \mathrm{E}=12,17 \mathrm{MEV}$

187RE(D,2NG), 187RE(P,NG)

$\mathrm{PB}(238 \mathrm{U}, \mathrm{FXG})$
187OS IT DECAY (231 US)

187AU P DECAY:?

95RB B-N DECAY

$186 \mathrm{~W}(\mathrm{~N}, \mathrm{G}) \mathrm{E}=\mathrm{TH}:$ SECONDARY

$238 \mathrm{U}(\mathrm{N}, \mathrm{FG}) \mathrm{E}=\mathrm{TH}$

$1890 \mathrm{O}(\mathrm{P}, \mathrm{T}) \mathrm{E}=19 \mathrm{MEV}$

185RE(A,2NG) $\mathrm{E}=23-42.8 \mathrm{MEV}$

$44 \mathrm{CA}(\mathrm{P}, \mathrm{G}) \mathrm{E}=856,906 \mathrm{KEV}$ IAR

$\mathrm{PB}(238 \mathrm{U}, \mathrm{XG})$ 


\section{DSREF, KEYNUM, QREF}

The DSREF and QREF fields may include up to three key numbers (KEYNUM) each of which refers to a particular publication. Additional key numbers may be placed in COMMENT records. Key numbers must be left-justified and separated by commas with no blanks between the comma and the reference. A reference key number must be of the form YYYYAABB where YYYY is a four digit integer, AA are two alphabetic characters and $\mathbf{B B}$ is either a two digit integer or consists of two alphabetic characters. Examples: 1981TU01, 1981TUXY, etc.

\section{PUB}

Publication information generally consists of the year of the A-chain publication denoted by two digit year indicator followed by three-character code NDS for Nuclear Data Sheets and two-letter code NP for Nuclear Physics-A. This may optionally be followed by a comma and other updating information, e.g., the initials of the person modifying the data set after its publication. Example: 78NDS,TWB or 81NDS.

\section{DATE}

This field is of the form YYYYMM where YYYY and MM are four and two digit integers, respectively, within the following ranges:

$Y Y \geq 1900$ and $01 \leq M M \leq 12$

\section{RTYPE}

RTYPE is a two-letter code in col. 8-9 that gives a name to the RECORD type. Note that col. 9 is blank for most of the RTYPE

RTYPE

\begin{tabular}{ll}
\hline blank & May be IDENTIFICATION, general COMMENT, or END record \\
H & HISTORY record \\
N & NORMALIZATION record \\
& $\begin{array}{l}\text { Production Normalization record has 'P' in col } 7 . \\
\text { P }\end{array}$ \\
PARENT record \\
L & Q-VALUE record \\
G & LEVEL record \\
B & GAMMA record \\
& BETA $\left(\beta^{-}\right)$record
\end{tabular}


$\mathbf{E} \quad \mathbf{E C}\left(\right.$ for $\epsilon, \beta^{+}$or $\epsilon+\beta^{+}$) record
A ALPHA record
R REFERENCE record
$\mathrm{X}$ CROSS-REFERENCE record

DP DELAYED PARTICLE record, or

PARTICLE (col.8=blank) record

Particle symbol (e.g., ' $\mathrm{P}$ ' for proton) is given in col. 9.

\section{CTEXT}

This field consists of free text. The various expressions used in CTEXT can be translated via dictionary lookup. The translation dictionary is given in Appendix $F$. The unit expression used in translation is the string of characters between adjacent 'delimiters'. The characters presently used as 'delimiters' are:

$$
\begin{aligned}
& \mathrm{b}(\text { blank }),(\text { comma }) \cdot b(\text { period followed by a blank }) ;:()-= \\
& +<>/ \text { and } \$
\end{aligned}
$$

In some cases the dictionary lookup programs look beyond the next delimiter for proper translation.

\section{SYM(FLAG)}

The SYM(FLAG) field (with FLAG given) is valid only for records with RTYPE: L, G, B, E, A, DP. However, SYM (without FLAG) may additionally be used for record types $\mathbf{N}, \mathbf{P}$, and $\mathbf{Q}$.

FLAG can be a string of characters optionally separated by commas. Any character other than a comma and parentheses can be used as a FLAG symbol. For $B$ and $\mathbf{E}$ records ' $C$ ' can not be used for a FLAG as ' $C$ ' in column 77 of $\mathbf{B}, \mathbf{E}$, and $\mathbf{A}$ records denotes coincidence. Similarly '*', '@', ‘\%', and ' $\&$ ' for $\mathbf{G}$ records are reserved with special meaning (III.B.14). See notes on SYM and FLAG under description of COMMENT record. FLAG can be used only with SYMs which are valid data types on a formated card or with BAND. In fact, for BAND FLAG must be given.

Allowed symbols to be used as SYM for various RTYPE are currently limited to the fields allowed on the formatted records. 


\section{$9 \quad$ BR,CC,HF,LOGFT,NB,NP,NR,NT,QP}

These fields consist of either a blank or a single unsigned number (NUM) in one of the following forms:

1. An integer (e.g., 345)

2. A real number (e.g., 345.23)

3. An integer followed by an integer exponent (e.g., 345E-4, 4E+5)

4. A real number followed by an integer exponent (e.g., 345.E-4)

Note: It is desirable to write a number as ' 0.345 ' rather than '.345'.

\section{MR,Q-,QA,SN,SP}

These fields have the same form as the quantities in V.9. above with the difference that they are allowed to have signature (positive or negative).

\section{DBR,DCC,DE,DHF,DIA,DIB,DIE,DIP,DNB}

\section{Includes DNR,DNP,DNT,DQP,DQ-,DS,DSP,DTI}

These two character fields, represent uncertainty in the 'standard' form in the given quantity. The 'standard' numeric uncertainty denotes an uncertainty in the last significant figure(s), for example, $\mathrm{NR}=0.873, \mathrm{DNR}=11$ represent a normalization factor of $0.873 \pm 0.011$, similarly $\mathrm{QP}=2.3 \mathrm{E} 6, \mathrm{DQP}=10$ stand for a $\mathrm{Q}$-value of $(2.3 \pm 1.0) \times 10^{6}$ (see also General Policies given in Appendix H). The non-numeric uncertainty, e.g, $<,>$, or $\geq$, etc. is denoted by expressions LT, GT, and GE, etc.

The allowed forms for these fields are summarized below:

1. Blank

2. An integer $<99$, preferably $<25$, (left or right justified)

3. One of the following expressions:

LT, GT, LE, GE, AP, CA, SY

for $\langle\rangle,, \leq, \geq, \approx$, calculated, and from systematics, respectively. 


\section{DFT,DMR,DT,DNB,DQA}

These fields allow for the specification of 'standard' asymmetric uncertainty. For example, $\mathrm{T}=4.2 \mathrm{~S}, \mathrm{DT}=+8-10$, represent a half-life $=4.2_{-1}^{+0.8} \mathrm{~s}$, similarly $\mathrm{MR}=-3$, $\mathrm{DMR}=+1-4$ represent mixing ratio $=-3_{-4}^{+1}$ meaning a range from -7 to -2 . (Note: asymmetric uncertainties add algebraically.) When the $+/-$ construction is missing from this field, the digits or the expressions given in this field represent either the numeric 'standard' symmetric or the non-numeric uncertainty as described in V.11 above.

To summarize this field, there are two cases:

1. Symmetric uncertainty - the field consists of an integer number or an expression of the type described in V.11 above.

2. Asymmetric uncertainty - the field is of the form $+x-y$, where $\mathrm{x}$ and $\mathrm{y}$ are integers.

\section{IA, IB, IE, IP, RI, TI}

The following numbers/expressions are valid for these fields:

1. NUM (number as defined in V.9 above)

2. (NUM)

Note: Parentheses denote that the number given has been deduced (not directly measured) or taken from other experiment(s).

\section{$14 \mathrm{~T}$}

The field for half-life $\mathbf{T}$ must have one of the following forms:

1. NUM-Blank-Units (i.e., number as defined in V.9 above followed by a blank and its units)

Valid symbols for units are: Y, D, H, M, S, MS, US, NS, PS, FS, AS, EV, $\mathrm{KEV}$, and MEV, for year, day, hour, minute, second(s), $10^{-3} \mathrm{~s}, 10^{-6} \mathrm{~s}, 10^{-9}$ $\mathrm{s}, 10^{-12} \mathrm{~s}, 10^{-15} \mathrm{~s}, 10^{-18} \mathrm{~s}, \mathrm{eV}, 10^{3} \mathrm{eV}$, and $10^{6} \mathrm{eV}$, respectively.

2. Word 'STABLE'

Note: A question mark following half-life denotes that the assignment to that level is not certain. A comment should be given to explain the exact meaning intended. 


\section{COIN}

This one character field can either be blank or have character ' $C$ ' or '?'. The character ' $C$ ' denotes coincidence while '?' denotes questionable coincidence.

\section{UN}

This two character field can either be blank for allowed transitions or have an integer between 1 and 9 indicating order of forbiddeness' followed by a blank for 'non-unique' or a. ' $U$ ' for unique transition.

\section{MS}

This two character field can either be blank or have character ' $M$ ' followed by a blank or a digit between 1 and 9 .

\section{$18 \mathrm{E}$}

An energy field, $\mathbf{E}$, can have only one of the following forms:

1. NUM (as defined in V.9 above)

2. NUM+A or A+NUM, where $A=X, Y, Z, U, V, W, A, B, \ldots$ used in this order; i.e., for the first occurrence an ' $\mathrm{X}$ ' is used, for its. second occurrence a ' $\mathrm{Y}$ ' is used, and so on.

3. SN+NUM, SP+NUM. Resonance energies should be given in center-of-mass system, as far as possible.

4. A (as defined in 2. above)

Note: Parentheses are allowed for this field. They denote that the number given has been deduced (not directly measured) or taken from other experiment(s). Explanation as to what is intended should be given.

\section{$19 \mathbf{M}$}

The multipolarity field can be one of the following:

1. Mult 

2. Mult+Mult
3. Mult,Mult
4. NOT Mult

\section{MULT}
Where Mult $=E_{L}$ or $M_{L^{\prime}}$
(where $L, L^{\prime}$ are single digits $-L \geq 0, L^{\prime} \geq 1$ )
$M_{L^{\prime}}+E_{L}$ or
$E_{L}+M_{L^{\prime}}$ or
$D$ or $Q$

Note: Parentheses in the multipolarity field denote that the assignment is probable and not definite. Square brackets indicate assumed or derived assignment.

\section{J}

The spin-parity field can have only one of the following forms:

1. JPI (it can be $\mathrm{J}, \pi$, or $\mathrm{J} \pi$ )

2. JPI OR JPI (',' (comma) can be used in place of 'OR')

3. JPI AND JPI ('\&' (ampersand) can be used in place of 'AND')

4. OP JPI (where OP is AP, $\mathrm{LE}$, or $\mathrm{GE}$ )

Note: This will be interpreted as $\pi=\mathrm{PI}$ and $\mathrm{J}$ is $\mathrm{OP} \mathrm{J}$

Example: $\leq 5+$ means $\pi=+$ and $J \leq 5$

5. NOT JPI

6. JPI TO JPI (':' (colon) can be used in place of 'TO')

Note: If parity is given in the range it will be interpreted as follows:

(a) $J$ to $J^{\prime} P I$ means $J \leq J \leq J^{\prime}$ and $\pi=P I$

(b) $J P I$ to $J^{\prime} P I^{\prime}$ means JPI,J=J+1 $P I= \pm, \ldots, J=J^{\prime}-1 P I= \pm, J^{\prime} P I^{\prime}$

(c) $J P I$ to $J^{\prime}$ means $J P I, J=J+1 P I= \pm, \ldots, J=J^{\prime}-1 P I= \pm$, $J^{\prime} P I= \pm$ 
Examples:

(a) 3 to 6- means $\mathrm{J} \pi=3-, 4-, 5-, 6-$

(b) $3+$ to 6 - means $\mathrm{J} \pi=3+, 4 \pm, 5 \pm, 6-$

(c) $3+$ to 6 means $\mathrm{J} \pi=3+, 4 \pm, 5 \pm, 6 \pm$

7. NATURAL/UNNATURAL

8. A or A+JPI (where A is one of the characters, $J, K, L, M, N, O, P, \ldots$ )

In the above $\mathrm{J}=\mathrm{N}$ or $N / 2$ ( $\mathrm{N}$ is a positive integer or zero)

$\mathrm{PI}(\pi)=+$ or -

$\mathrm{JPI}=\mathrm{J}$ or PI or $\mathrm{J}$ followed by PI

Note:

1. Parentheses in the $J^{\pi}$ field indicate that the parenthesised value(s) is (are) based upon weak arguments. See 'Bases for Spin and Parity Assignments' in Appendix H. Note that JPI $=(3,4)$ - is interpreted as $J=(3)$ or $(4)$ and $\pi=-$.

2. As far as possible do not give more than three JPI values.

3. The ranges such as $3-$ to $5+$ are better written as $3-, 4,5+$.

4. Square brackets around $J^{\pi}$ value indicate assumed value.

\section{$21 S$}

This field may contain no more than three S-values, in the form of NUM defined in V.9, separated by a ' $t$ ' or a comma, for corresponding $L$-values given in the L-field (col. 65-74). Parentheses are allowed and will be interpreted to mean probable values.

\section{L}

This field may contain no more than three integer numbers optionally preceded by LE or GE and separated by a 't' or a comma. Parentheses are allowed and will be interpreted to mean probable values. Square brackets indicate assumed or derived values.

For certain reactions the $L$ value may be accompanied by its electric or magnetic character in the form similar to multipolarity (V.19). 


\section{ION}

This field is either blank or a signed integer, left justified, denoting order of ionization of the atom, e.g., +75 . It is used in Ionized Atom Decay data sets.

\section{Cross Reference}

The cross referencing of a record (currently allowed only for the ' $L$ ' record in an ADOPTED data set) is done through specification on the continuation record and it takes the following forms:

1. NUCID $2 \mathrm{~L} X R E F=A B C \$$

Above record indicates that the adopted level (specified by preceding ' $L$ ' record) has been seen in data sets ' $A$ ', ' $B$ ', and ' $C$ ' and that the corresponding levels are unambiguous.

2. NUCID $2 \mathrm{~L} \mathrm{XREF}=\mathrm{A}(\mathrm{E} 1) \mathrm{B}(\mathrm{E} 2) \mathrm{C}(\mathrm{E} 3) \$$

This record indicates that the adopted level is the same as the $\mathrm{E} 1$ level in data set ' $A$ ', the $E 2$ level in data set ' $B$ ', etc.

3. NUCID $2 \mathrm{~L}$ XREF $=\mathrm{A}(\mathrm{E} 1, \mathrm{E} 2) \mathrm{B}(\mathrm{E} 3) \$$

This record indicates that the adopted level is either the E1 or the E2 level in data set ' $A$ ', the $E 3$ level in data set ' $B$ '.

4. NUCID $2 \mathrm{~L} \mathrm{XREF}=\mathrm{A}\left({ }^{*} \mathrm{E} 1\right) \mathrm{B}(\mathrm{E} 2) \$$

This record indicates that a level with energy $E 1$ in data set ' $A$ ' is associated with more than one adopted level. An '*' must appear on all occurrences of a multiply assigned level. Alternatively, the notation $\mathrm{A}\left({ }^{*}\right)$ may be used if the energy is apparent.

5. NUCID 2 L XREF $=+\$$

This record indicates that the adopted level has been seen in all data sets.

6. NUCID $2 \mathrm{~L}$ XREF $=-(\mathrm{AB}) \$$

This record indicates that the adopted level has been seen in all data sets except the data sets ' $A$ ' and ' $B$ '.

Note: The symbols $\mathrm{A}, \mathrm{B}, \mathrm{C}$ relating to specific data sets must be defined through Cross-Reference records (see III.B.4). 


\section{History record}

1. In all individual data sets in ENSDF (excepting the REFERENCE and COMMENTS data sets) the following information will be presented (the information is required, unless indicated optional) on an $\mathbf{H}$ record every time changes are made to the data set (see III.B.2 for description of $\mathbf{H}$ record):

TYP Type of change/evaluation (required)

AUT Author's name (the person who makes or is responsible for the change not necessarily the evaluator of the data set) (required)

DAT Date of change (optional, if cutoff date given)

CUT Literature cutoff date (optional when changes do not involve fresh evaluation)

CIT Citation (optional, if not published)

COM Comments (optional)

2. Current list of evaluation types (can be expanded) are

FUL Complete revision of the nuclide based on all information to the cutoff date indicated. Cutoff date required

FMT Some format changes done

ERR Errata (Fix error(s) in the dataset, should be accompanied with COM)

MOD Modified dataset for partial update of nuclide. Kind of modification done should be indicated as comment. Cutoff date is optional.

UPD Update due to scan of new literature. Cutoff date is required.

EXP Experimental (not evaluated) data set.

There can be only one type specification per history record given.

3. Date and Cutoff date must be given as DD-MMM-YYYY (e.g., 31-MAY1996)

4. Citation (optional) gives the reference where the evaluation is published. CIT $=$ ENSDF means included in ENSDF but not published.

5. Comments (optional) may give general remarks about evaluation/update.

6. The fields can be in any order on an ' $\mathrm{H}$ ' record.

Note that history records indicate various revisions. These are wiped out at the next FULL evaluation.

For FULL evaluation NNDC will introduce ' $\mathrm{H}$ ' records based on the COMMENTS data set. 
Examples:

156DY H TYP=MOD $\$ A U T=B$. Singh $\$ D A T=31-D E C-1995 \$$

156DY2H COM=Updated SDB data only $\$$

156DY H TYP=UPD $\$ A U T=R$. Helmer $\$ C U T=15-D E C-1994 \$$

156DY2H COM=Updated data set since last full evaluation\$

156DY H TYP=FMT $\$ A U T=J$. Tuli $\$ D A T=1-D E C-1994 \$ C O M=F I X E D ~ T 1 / 2 \$$

156DY H TYP=FUL $\$ A U T=R$. Helmer $\$ C U T=01-$ May $-1991 \$$

156DY2H GIT $=$ NDS 65,65 (1992)\$ 


\section{Appendix A}

\section{Character Set}

The base character set is the standard 7-bit ASCII character set up. to octal 173 . Characters with octal values of 173 and greater are used as control characters. An alternate character set consists primarily of the Greek alphabet and some special symbols. The backslash character (octal 134) is interpreted as a backspace command. An alternate character in the input file consists of two characters, a control character and the standard character equivalent of the alternate character. All available alternate characters and their standard equivalents are given in the table on the follwing page.

There are four control characters, | (octal 176) ${ }^{-}$(octal 176),$\{$(octal 173), and $\}$ (octal 175). The vertical bar and the tilda are used to shift the next character into the first and second alternate character sets, respectively. The entire string of characters may also be modified from their standard form. In this case the string to be modified is enclosed by the open and close brace control characters. The character immediately following the open brace is interpreted as a control character. The available control character values and their meanings are given below. The modified character strings may be nested. The control characters may be in either upper or lower case.

\section{Examples}

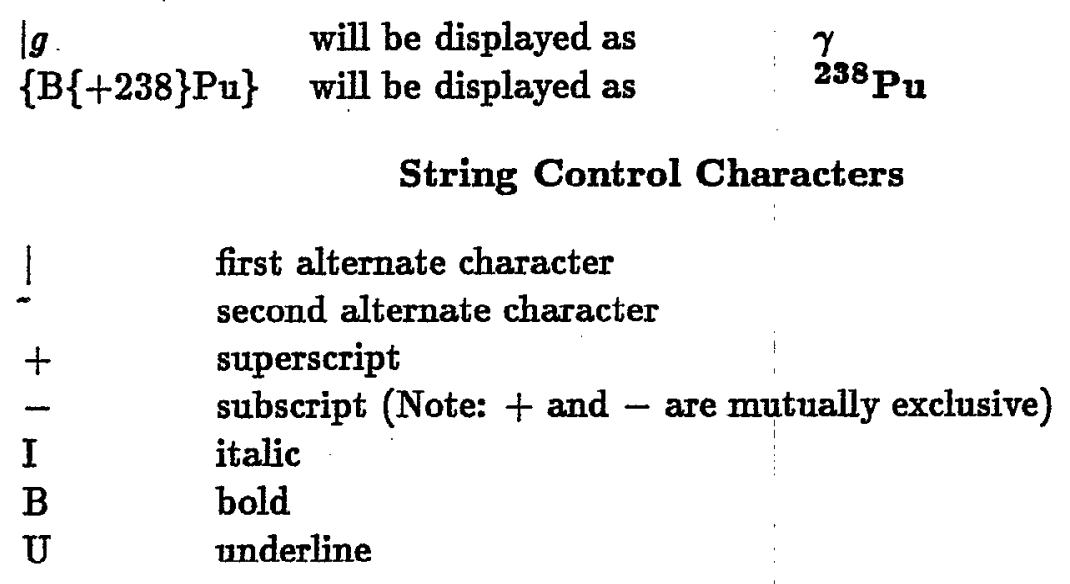

Note: The symbol ^ (caret) may be used before a character or a word to preserve its case, e.g., `A for A (and not a). 


\section{Alternate Character sets}

St

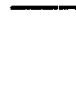

$!$
$\#$
$\$$
$\%$
$\&$

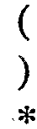

$\S$
e
$\sqrt{ }$
$\equiv$
$\circ$

)

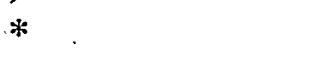

$+$

,

$-$

i

0

1

2

3

4

5

6

7

8 .

9

:

;

$<$

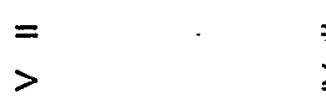

$?$

@

A

B

C

D

E

F

G

$\mathrm{H}$

I

J

$\mathrm{K}$

L

M

$$
\begin{aligned}
& \leftarrow \\
& \vec{x} \\
& \pm \\
& \pm \\
& \mp
\end{aligned}
$$$$
\infty
$$$$
\div
$$$$
\text { ( }
$$$$
\text { ) }
$$$$
\text { [ }
$$$$
\text { ] }
$$$$
>
$$$$
\sqrt{ }
$$$$
\text { j }
$$

$\Pi$

$\Sigma$

$t$

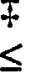

$\neq$

$\geq$

$\approx$

$\infty$

A

B

$\mathrm{H}$

$\Delta$

E

$\Phi$

$\Gamma$

X

I

-

$\mathrm{K}$

$\Lambda$

M

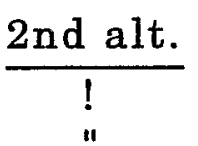

$\otimes$

$\$$

$\%$

\&

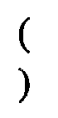

.

$+$

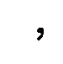

-$$
\text { j }
$$$$
0
$$

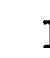

2

3

4
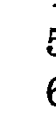

6

7

9

:

;

$<$

$=$

$>$

?

A

B

C

D

É

F

G

$\mathrm{H}$

I

J

K

L

M

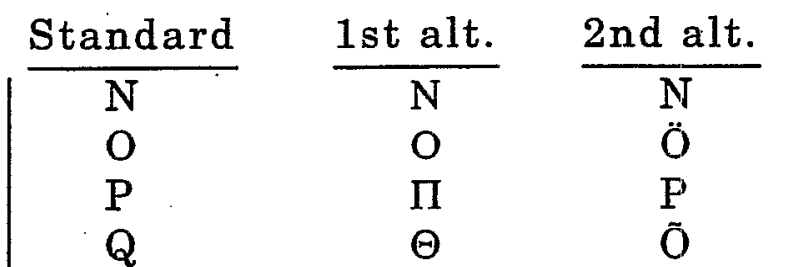

R

S

$\mathrm{T}$

U

V

W

$\mathrm{X}$

$\mathrm{Y}$

$\mathrm{Z}$

]

$\wedge$

$\overline{-}$

a

b

c

d

e

f

g

h

i

j

k

1

m

n

0

$\mathrm{p}$

q

$\mathbf{r}$

s

$\mathrm{t}$

u

$\mathrm{v}$

w

$\mathrm{w}$

$\mathrm{y}$

z
$\mathrm{R}$

$\mathrm{S}$

$\mathrm{T}$

Ü

V

W

$\mathrm{X}$

Y

Z

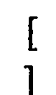

$\wedge$

7

ä

b

c

d

é

f

g

h

i

j

$\lambda$

m

$\mathrm{n}$

ö

$\mathrm{p}$

$\tilde{\text { o }}$

$\mathbf{r}$

s

$t$

ü

v

w

$\mathrm{x}$

$\mathbf{y}$
$\mathrm{z}$ 


\section{Appendix B}

\section{Format For Comments Data Set}

This data set consists only of general comment records (defined in III.B(4)). The format of the comment records is similar to general comments in other data sets except that the NUCID field will contain only the mass number, AAA, and that a SYM field is required as in a flagged comment. As in the flagged comments, the SYM field will either occupy, columns 10 to 19 with column 19 being blank or the SYM will be followed by a ' $\$$ '. Continuation records for a given comment are allowed with the additional feature that a new line will be started if the continuation character in column 6 is a '\#' and that a new paragraph will be started if the character is a '@'. This feature is intended to facilitate the entry of information into the COMM comments.

$\underline{\text { SYM } \quad \text { Meaning }}$

TITLE Title of evaluation. Required if the evaluation spans several masses.

AUTH Authors, a list of authors from the institution given in the following INST comment. A letter or number in parenthesis following an authors last name will signal a permanent address which is different from the institution. (See PERM)

INST Institution, name and address of the authors' institution. INST comment must follow the appropriate AUTH comment. The \# continuation character is used so the address does not run together into one line. More than one set of AUTH and INST comments can be given if more than one institution is involved.

ABST Abstract, should be terse and to the point. Additonal details should be given under COMM comments.

CUT Cutoff data and associated comments.

COMM General comments on techniques used in the evaluation or on other information common to many of the isotopes.

ACKN Acknowledgments.

PERM(a) Permanent address of an author. The letter or number 'a' within the parenthesis corresponds to the letter 
or number within the parenthesis which follows the authors last name in the AUTH comment.

FUND Funding, an acknowledgment of funding which will result in a footnote being added to the title.

CIT Citation. To be added by the NDS production staff so that the publication can be correctly cited by persons using a retrieval of the A chain. The authors may leave it out.

EXAMPLE of a COMMENTS data set

\begin{tabular}{|c|c|c|}
\hline 156 & & OMMENTS \\
\hline 156 & C & TITL\$ Nuclear Data Sheets for $A=156$ \\
\hline 56 & C & AUTH\$R. G. Helmer \\
\hline 156 & C & INST\$Idaho National Engineering Laboratory \\
\hline 56 & \#C & EG\&G Idaho, Inc. \\
\hline 56 & \#C & Idaho FaIls, Idaho 83415 USA \\
\hline 156 & $\mathbf{C}$ & ABST\$The experimental results from the various reaction and decay \\
\hline 56 & $2 \mathrm{C}$ & studies leading to nuclides in the $A=156$ mass chain, and ALPHA decays \\
\hline 156 & $3 \mathrm{C}$ & from it, have been reviewed. These data are summarized and presented, \\
\hline 156 & 4C & together with adopted levels schemes and properties. \\
\hline 156 & $\mathbf{C}$ & CUT\$Data available prior to May 1991 have been evaluated. \\
\hline 56 & C & ACKN\$The evaluator wishes to thank C. W. Reich, the reviever, and the \\
\hline 56 & $2 \mathrm{C}$ & editors for many helpful discussions. \\
\hline 56 & C & FUND\$Research sponsored by the U. S. Department of Energy. \\
\hline 56 & C & CIT\$R. G. Helmer, NDS 65,65 (1992) \\
\hline 56 & C & CoMM\$General Comments: In this evaluation, the following expression \\
\hline 56 & $2 \mathrm{C}$ & ras used to define the rotational-band parameters $a$ and $B$ : \\
\hline 56 & C & $E(J)=E\{-0\}+a[J(J+1)-K\{+2\}]+B[J(J+1)-K\{+2\}]\{+2\}$ \\
\hline 56 & C & with the following terms sometimes added for $K=1$ and 2 bands \\
\hline 156 & C & $+(-1)\{+J+1\} a\{-2\} J(J+1)$ for $K=1$ \\
\hline 156 & C & and \\
\hline 56 & C & $+(-1)\{+J\} a\{-4\}(J-1) J(J+1)(J+2)$ for $K=2$ \\
\hline 56 & $\mathbf{C}$ & In the determination of the values of these parameters, the energy \\
\hline 56 & $2 \mathrm{C}$ & spacings of only the lowest levels, and minimum number of levels, were \\
\hline 156 & $3 \mathbf{C}$ & used. \\
\hline 156 & C & The ENSDF file (the computer data base from which these Data Sheets \\
\hline 56 & 3C & are produced), contains some information that is not printed in these \\
\hline 156 & 4C & Data Sheets. This includes the theoretical internal-conversion \\
\hline 156 & 6C & coefficients for each shell, where the values are significant, for \\
\hline 156 & $8 \mathrm{C}$ & each Ig for wich a multipolarity is given in the Data Shoots. Also, a \\
\hline 56 & 9C & short comment is made about the experimental methods for each \\
\hline 56 & $\mathrm{BC}$ & reference. This information nould be available if a copy of the ENSDF \\
\hline 56 & DC & longentangt \\
\hline
\end{tabular}

Output for above COMMENTS data set is shown on the following page 


\title{
Nuclear Data Sheets for $A=156^{*}$
}

\author{
R. G. Helmer \\ Idaho National Engineéring Laboratory \\ EG\&G Idaho, Inc. \\ Idaho Falls, Idaho 83415 USA
}

(Received June 21. 1991; Revised August 20, 1991)

Abstract: The exporimontal resulte from the various reaction and decay etudios loading to nuelides in the $A=156$ mass chain, and $\alpha$ decays from it, have been reviewed. These data are summarized and presented, together with adopted levels schemes and properties.

Cutoff Date: Data available prior to May 1991 have been evaluated.

General Policies and Organization of Material: See the Jnnuary igsue of Nuclear Data Sheets.

Acknowledgments: The evaluator wishes to thank C. W. Reich, the reviewer, and the editors for many helpfu] discussions.

General Comments: In this ovaluation, the following expression was used to define the rotational-band parameters $A$ and $B$ :

$E(J)=E_{0}+A\left[J(J+1)-K^{2}\right]+B\left[J(J+1)-K^{2}\right]^{2}$.

with the following terms sometimes added for $K=1$ and 2 bands

$+(-1)^{3+1} A_{2} J(J+1)$ for $K=1$

and

$+(-1)^{\mathrm{J}} \mathrm{A}_{4}(\mathrm{~J}-1) \mathrm{J}(\mathrm{J}+1)(\mathrm{J}+2)$ for $\mathrm{K}=2$.

In the determination of the ralues of these parameters, the cnorgy spacings of ouly the lowest levels, and minimum number of lovels, wore used.

The ENSDF file (the computer data base from which these Data Sheets are produced), contains some information that is not printed in these Data Sheets. This includes the theoretical internal-conversion coefficients for each shell, where the values are significant, for each $\gamma$ for which a multipolarity is given in the Data Sheets. Also, a short comment is made about the experimental methods for each reference. This information would be available if a copy of the ENSDF file were obtained. 


\section{Appendix $\mathbf{C}$}

\section{Example of an adopted data set}

Example of an ADOPTED LEVELS, GAMMAS data set

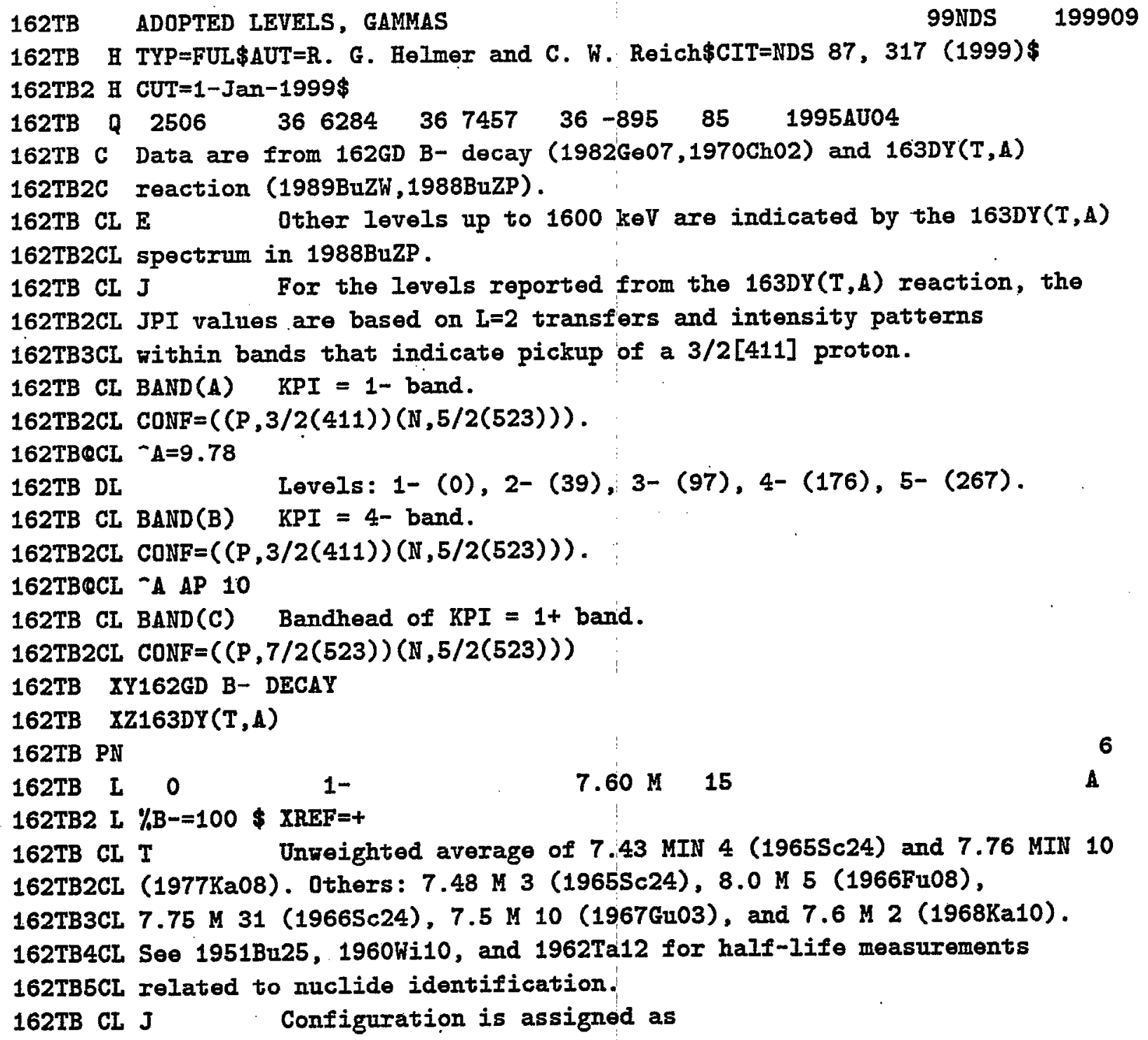


162TB2CL CONF $=((P, 3 / 2(411))(N, 5 / 2(523)))$ based on the ground-state 162TB3CL assignments of $\mathrm{CONF}=(\mathrm{P}, 3 / 2(411))$ for $161 \mathrm{~TB}$ and 162TB4CL CONF $=(N, 5 / 2(523))$ for $161 \mathrm{GD}$ and $163 \mathrm{DY}$.

162TB CL J LOGFT=4.95 of the B-transition to the 2- level at $1148 \mathrm{keV}$ 162TB2CL in 162DY indicates an allowed-unhindered B transition, which 162TB3CL must be $\operatorname{CONF}=(N, 5 / 2(523))$ to $C O N F=(P, 7 / 2(523))$. This confirms $162 T B 4 C L$ the configuration assignment to this ground state as well as 162TB5CL helping establish the configuration assignment to the 1148-keV 162TB6CL level in 162DY as $\mathrm{CONF}=((P, 3 / 2(411))(P, 7 / 2(523)))$. See 162DY 162TB6CL Adopted Levels and 1995Be02 for further discussion.

162TB I $39.10 \quad 9 \quad 2-$

$162 \mathrm{~TB} 2$ I XREF $=+$

$162 \mathrm{~TB}$ CL $\mathrm{J}$

From M1 component in $G$ to 1 - ground state, expected energy 162TB2CL spacing in rotational band, and $(T, A)$ reaction results.

$\begin{array}{llllll}162 \mathrm{~TB} & \mathrm{G} & 39.0 & 2 & 100 \quad \mathrm{M} 1+(\mathrm{E} 2)\end{array}$

162TB CG $M$ From intensity balance at 39 level in 162GD.B- decay, 162TB2CG transition is primarily M1 (1970Ch02); $x / G$ intensity ratio and 162TB3CG ' $L$ x-ray energy are consistent with this.

$\begin{array}{llc}162 \mathrm{~TB} & \text { I } & 97 \\ 162 \mathrm{~TB} 2 & \text { L } & \mathrm{XREF}=\mathrm{Z}\end{array}$

162TB I $176^{\circ}$

$13-$

A

162TB2 I XREF $=Z$

162TB I $216 \quad 1 \quad 4-$

$14-$

A

162TB2 L XREF=Z

162TB CL J

Configuration is assigned as that of the ground state, 162TB2CL namely, (PI 3/2[411]) (NU 5/2[523]) recoupled. The systematics 162TB3CL of 1998Ja07 suggest a "theoretical" Gallagher-Moszkorski splitting 162TB4CL of $82 \mathrm{keV}$ compared to the observed $216 \mathrm{keV}$, if this assignment 162TB5CL is correct.

$\begin{array}{lll}162 \mathrm{~TB} & \text { I } & 267 \\ 162 \mathrm{~TB} 2 & \text { I } & \mathrm{XREF}=\mathrm{Z}\end{array}$

$25-$

162TB I 310

$15-$

B

162TB2 L XREF=Z

162TB I 341.41

162TB2 L XREF $=Y$

$162 \mathrm{~TB}$ CL J

$9(0-, 1)$

162TB G 302.30

From IOGFT $=5.9$ in B- decay from $0+162 \mathrm{GD}$.

$162 \mathrm{~TB} G 341.42$

$162 \mathrm{~TB}$ I 442.11

$\begin{array}{lll}15 & 58 & 9\end{array}$

101009

162TB2 I $X R E F=Y$

162TB CL J

$81+$

c

162TB2CL 162GD ground state $(0+)$. This also uniquely establishes the

162TB3CL configuration of this level as $\operatorname{CONF}=((N, 5 / 2(523))(P, 7 / 2(523)))$.

162TB G $403.00 \quad 8 \quad 85 \quad 4$

162TB G $442.12 \quad 8 \quad 100$

Output for above data set is shown in the follwing pages 


\section{Adopted Levels, Gammas}

$Q\left(\beta^{-}\right)=2506$ 36; $S(n)=6284$ 36; $S(p)=7457 \quad 36 ; Q(\alpha)=-89585 \quad$ 1995Au04:

Data are from ${ }^{162} \mathrm{Gd} \beta^{-}$decay $\left(1982 \mathrm{Ge} 07,1970 \mathrm{ChO2}\right.$ ) and ${ }^{163} \mathrm{Dy}(\mathrm{t}, \alpha)$ reaction (1989BuzW,1988BuZP).

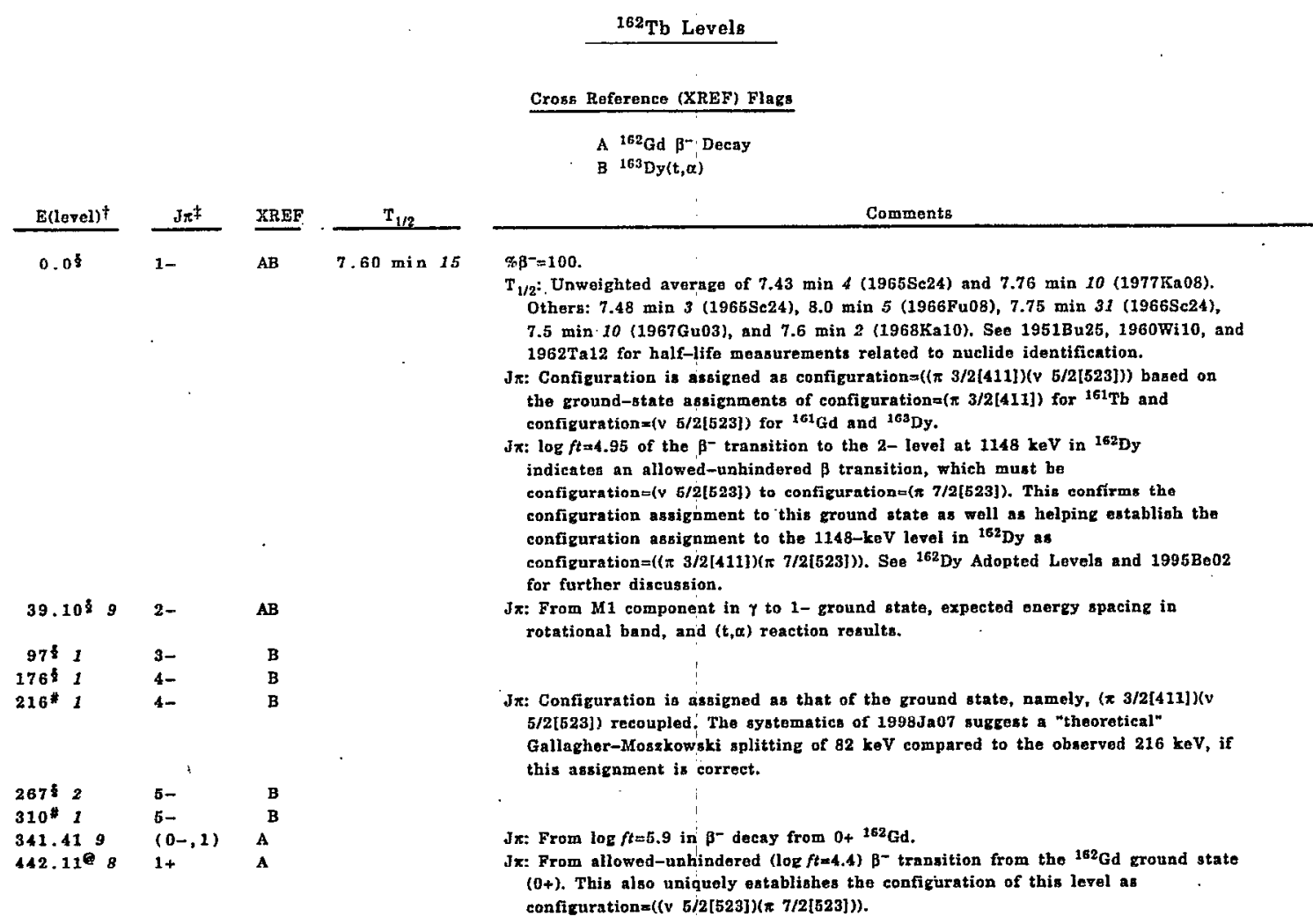

$\dagger$ Other levels up to $1600 \mathrm{keV}$ are indicated by the ${ }^{163} \mathrm{Dy}(t, \alpha)$ spectrum in $1988 \mathrm{BuZP}$.

\# For the levels reported from the ${ }^{163} \mathrm{Dy}(t, \alpha)$ reaction, the $\mathrm{J} \pi$ values are based on $\mathrm{L} \times 2$ transfers and intensity patterns within bands that indicate pickup of a $3 / 2[411]$ proton.

(A): K $\pi=1$ - band. Configurationz(( $3 / 2[411])(v$ 5/2[523])). A=9.78.

(B): K $\pi=4$ - band. Configuration= $((\pi, 3 / 2[411])(v 5 / 2[523]))$. A-10.

(C): Bandhead of $K_{\pi=1+b a n d}$. Conficuration=((x $\left.7 / 2[5231)(v 5 / 2[523])\right)$.

$$
\gamma\left({ }^{162} \mathrm{~Tb}\right)
$$

\begin{tabular}{|c|c|c|}
\hline E(level) & E $\gamma$ & $\mathrm{I} \gamma$ \\
\hline 39.10 & 39.02 & 100 \\
\hline \multirow[t]{2}{*}{341.41} & $302.30 \quad 15$ & 689 \\
\hline & 341.4210 & 1009 \\
\hline \multirow[t]{2}{*}{442.11} & 403.008 & 85 \\
\hline & 442.128 & 100 \\
\hline
\end{tabular}

$$
\text { Mult. }
$$$$
\mathbf{M 1}+(\mathrm{E2})
$$

Commenta

Mult.: From intensity balance at 39 level in ${ }^{162} \mathrm{Gd} \mathrm{g}^{-}$decay, trannition is primarily M1 (1970Ch02); $x / y$ intensity ratio and $L x-r a y$ energy are consistent with this. 


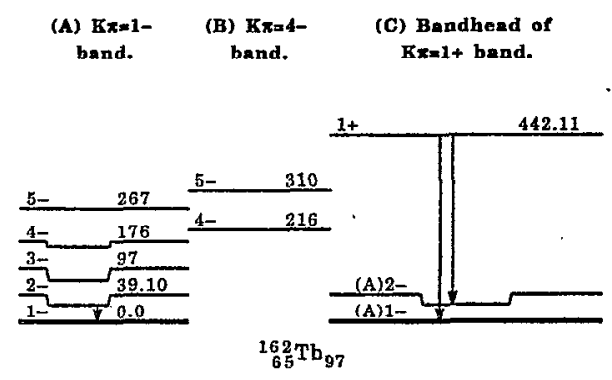




\section{Appendix D}

\section{Example of a decay data set}

Example of a DECAY data set

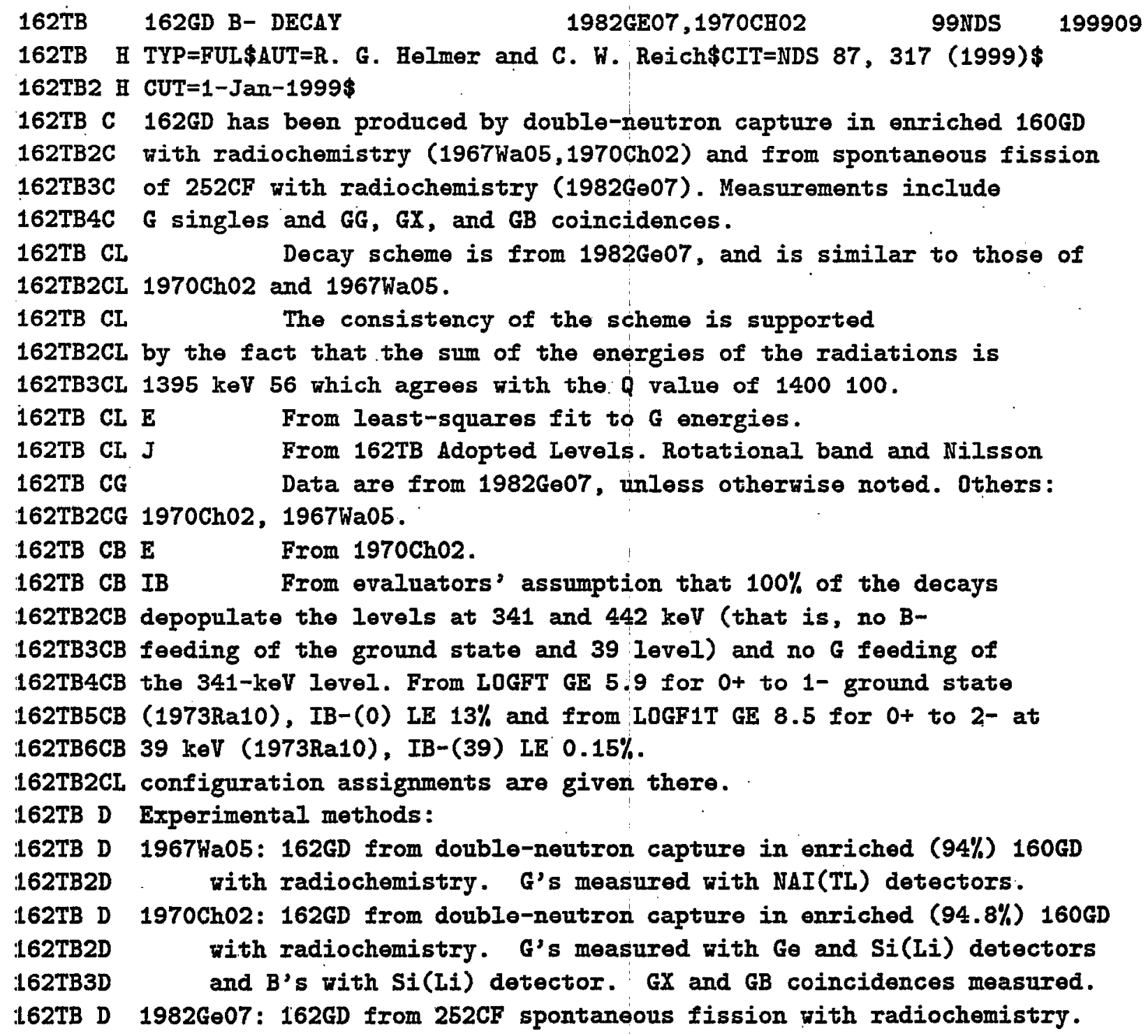




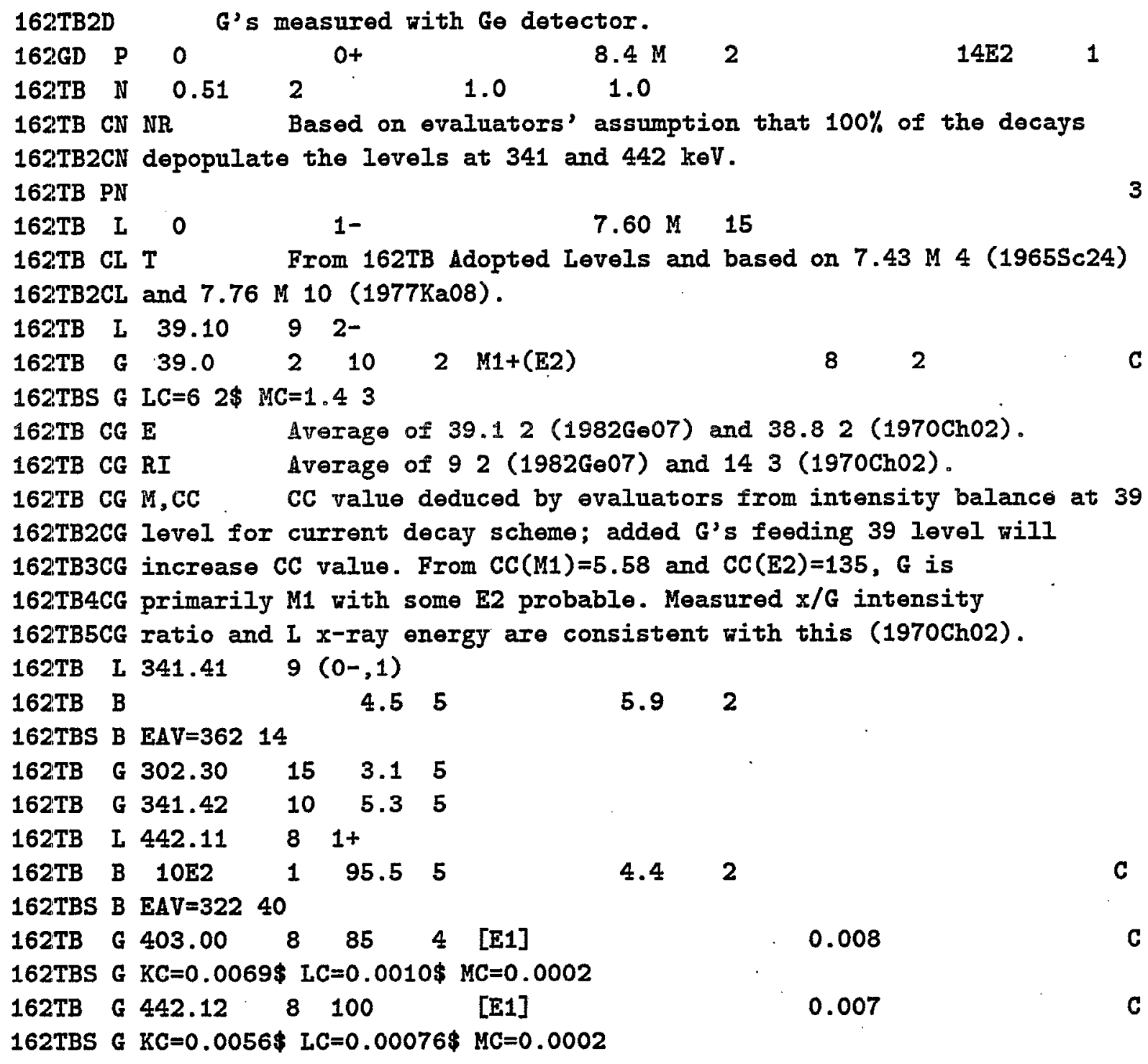

Output for above data set is shown in the follwing pages 
Parent ${ }^{162} \mathrm{Gd}: \mathrm{E}=0 ; \mathrm{J} \pi=0+; \mathrm{T}_{1 / 2}=8.4 \min 2 ; \mathrm{Q}(\mathrm{g} . \mathrm{B})=.14 \times 10^{2} 1 ; 9 \mathrm{~B}^{-}$decay $=100$,

${ }^{162} \mathrm{Gd}$ has been produced by double-neutron capture in enriched ${ }^{160} \mathrm{Gd}$ with radiochemistry $(1967 \mathrm{Wa05}, 1970 \mathrm{Ch02}$ ) and from spontancous fission of ${ }^{252} \mathrm{Cf}$ with radiochemistry (1982Ge07). Measurements include $\gamma$ singles and $\gamma$, $\mathrm{yX}$, and $\gamma \beta$ col ncldences.

\section{${ }^{162} \mathrm{~Tb}$ Levelg}

Decay scheme is from $1982 \mathrm{Ge07}$, and is similar to those of $1970 \mathrm{Ch} 02$ and $1967 \mathrm{Wa05}$

The consistency of the scheme is supported by the fact that the sum of the energies of the radiations is 1395 keV 56 which acrees with the $Q$ value of 1400100 .

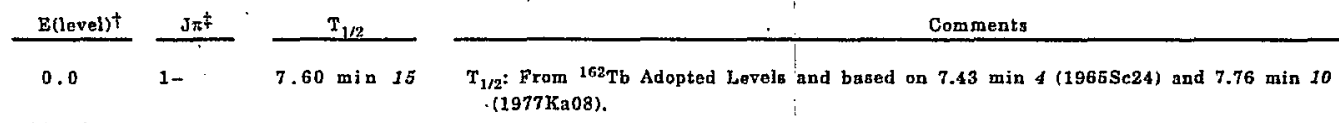

$39.1092-$ (1977Ka08).

$341.419 \quad(0-, 1)$

$142.1181+$

f From lenst-squares nit to $y$ energles.

$\mp$ From ${ }^{162} \mathrm{~Tb}$ Adopted Levels. Rotational band and Nilsson.

\begin{tabular}{|c|c|c|c|c|}
\hline$E B^{-\dagger}$ & E(level) & IB-75 & Log $f t$ & \\
\hline 1000100 & 442.11 & 95.55 & 4.42 & av $E \beta=32240$. \\
\hline 1060100$)$ & 341.41 & 4.55 & 5.92 & av $E \beta=96214$. \\
\hline
\end{tabular}

$\dagger$ From 1970Ch02.

F From evaluators' assumption that $100 \%$ of the decays depopulate the levels at 341 and $442 \mathrm{keV}$ (that is, no $\beta^{-}$foeding of the ground state and 39 level) and no $\gamma$ feeding of the $341-\mathrm{keV}$ level. From log $f t 25.9$ for $0+$ to $1-$ ground state (1973R210),

$1 \beta^{-}(0) \leq 13 \%$ and from $\log f^{t} t \geq 8.5$ for $0+$ to $2-$ at $39 \mathrm{keV}(1973 \mathrm{Ra} 10)$, $1 \beta^{-}(39) \leq 0.15 \%$. configuration assignments are given there.

For $\beta$ - intensity per 100 decays, multiply by 1.0 .

$$
\left.x^{162} \mathrm{~Tb}\right)
$$

Data are from 1982Gen7, unless atherwise noted, Others: 1970Ch02, 1967wa05.

IY normalization: Based on evaluators' anaumption that $100 \%$ of the decays dopopulate the levels at 341 and $442 \mathrm{keV}$.

$\frac{\text { Ey }}{39.02} \frac{\text { E(level) }}{39.10} \frac{\text { Iyt }}{102} \frac{\text { Mult. }}{M 1+(E 2)} \frac{\alpha}{82}$

302.3015

$403.008 \quad 442.11$

$142.128 \quad 442.11$

$$
\begin{array}{rl}
3.15 & 5 \\
5.3 & 5 \\
85 & 1 \\
100 &
\end{array}
$$

Comments

$\alpha(L)=62 ; \alpha(M)=1.43$

Eү: Averaze of 39.12 (1982Ge07) and 38.82 (1970Ch02).

I $\gamma$ : Averace of 92 (1982Go07) and 143 (1970Ch02).

Mult.,a: $\alpha$ ralue deduced by oraluators from intensity balance at 39

lovel for current decay schome; added $\gamma^{\prime} s$ feeding 39 lovel will increase $a$ value. From $\alpha(M 1) \times 5.58$ and $\alpha(E 2)=135, \gamma$ is primartly $M 1$

with some E2 probable. Measured $z / \gamma$ intensity ratio and $L$ x-ray enercy are consistent with this (1970Ch02).

$\alpha(K)=0.0069 ; \alpha(L)=0.0010 ; \alpha(M)=0.0002$.

$\alpha(K)=0.0056 ; \alpha(L)=0.00076 ; \alpha(M)=0.0002$.

† For absolute intensity per 100 decays, multiply by 0.512 
${ }_{65}^{162} \mathrm{~Tb}_{97}$

\section{${ }^{162} \mathrm{Gd}$ \&- Decay 1982Ge07,1970Ch02 (continued)}

Decay Scheme

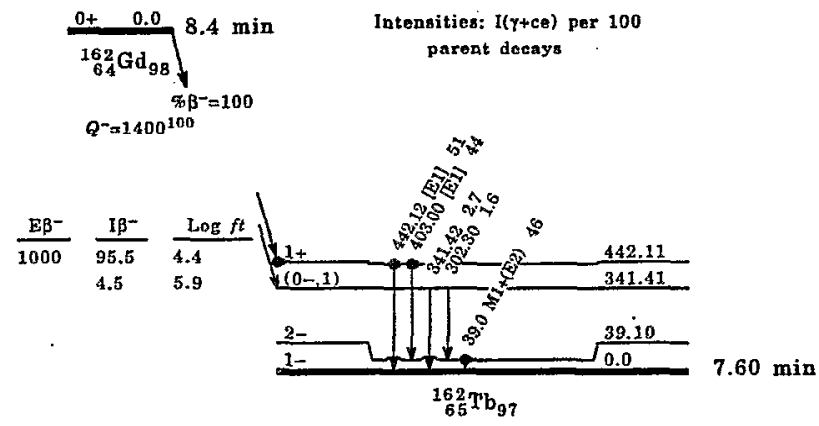




\section{Appendix E}

\section{ENSDF coding for Ionized Atom decay}

\section{Decay Data Set}

1. ID record

The ionization state of the atom would be in square brackets following the nuclide symbol in the DSID field.

2. Parent record

- Energy field: level energy of the parent nucleus

- Half-life field: half-life for the decay of the ionized itom

- Q-value field: nuclear ground-state to ground-state value

- New field (77-80): ionization state

3. Level records

- Energy field: level energy of the daughter nucleus

- MS field: atomic electron shell or subshell in which the emitted betaparticle is captured.

- A new quantity, "ION", giving the ionization state would be required on an "S L" record following the level record.

4. Daughter Adopted Levels, Gammas

The adopted levels would be cross-referenced to the observed states in the ionized atom decay dataset.

5. Parent Adopted Levels, Gammas

The half-life and decay branching of the ionized atom decay would be given as comments (analagous to the current practice for half-lifes which differ due to chemical effects). This should be regarded as an interim solution; after more experience is gained, methods of giving this data on level continuation records should be derived. 
Examples:

\section{$187 \mathrm{Re}$}

$1870 S$ 187RE [+75] B- DECAY 96B037

1870S C BOUND STATE B- DECAY OF BARE 187RE (75+ CHARGE STATE)

1870S C 96B037 (ALSO 97NO07,97KL06,97WE08): DECAY OF FULLY IONIZED 187RE

1870S2C NUCLEI CIRCULATING IN A STORAGE RING.

1870S. C T1/2 OF 187RE ION (75+ CHARGE STATE) $=32.9$ Y 20

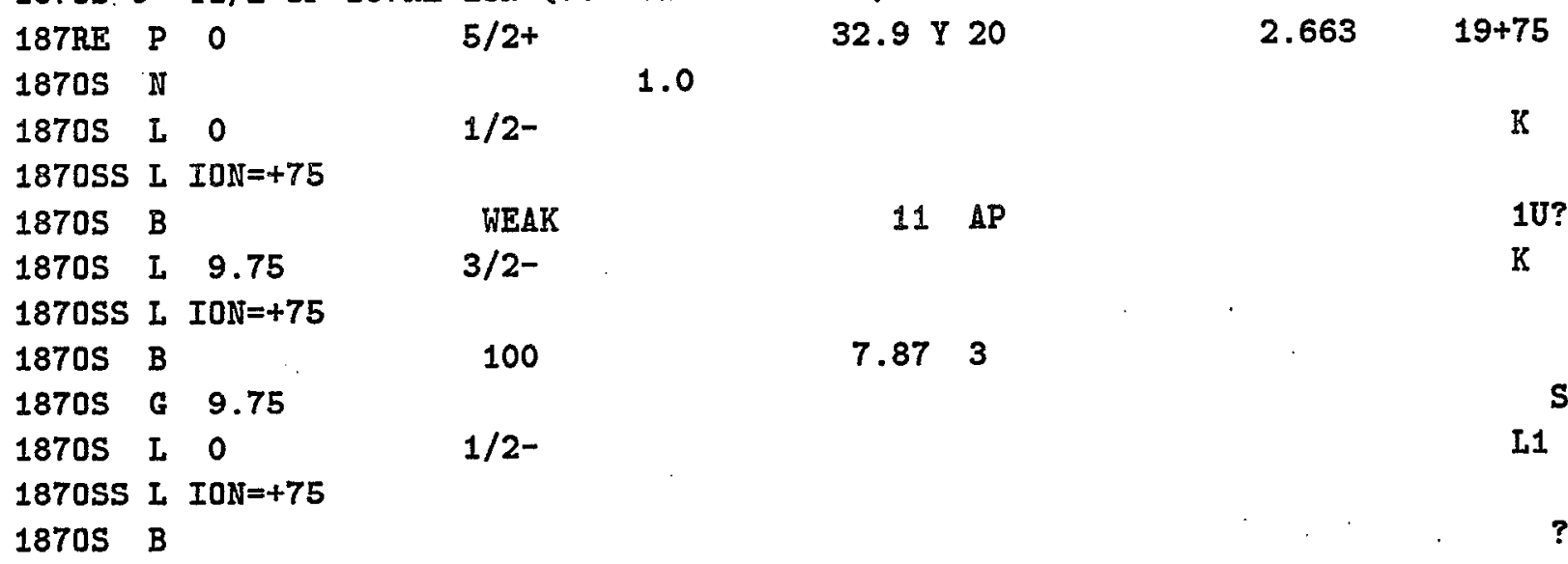

187RE ADOPTED LEVELS, GAMMAS

187RE CL BAND (A) $\$ 5 / 2[402]$ ?

187RE I $\quad 0.0 \quad 5 / 2+$

$4.35 E 10$ Y 13

A

187RE2 L $\%$ B-=100\$\% LT 0.0001

187RE CL $\$ \% B-(\{+187\}$ R $\theta\{++75\})=100 ; T 1 / 2(\{+187\}$ R $\theta\{++75\})=32.920 \mathrm{Y}$

$1870 S$ ADOPTED LEVELS, GAMMAS

1870S CL BAND (A) $\$ 1 / 2[501]$ BAND

1870S CL BAND(B) $\$ 3 / 2$ [512] BAND

1870S XA187RE B- DECAY

$1870 S$ XB187IR EC DECAY

1870S XC1860S(N,G) E=THERMAL

1870S XD187RE(D,2NG), 187RE (P,NG)

$1870 S$ XECOULOMB EXCITATION

$1870 S \mathrm{XF1890S}(\mathrm{P}, \mathrm{T})$

$1870 S$ XG1860S(D,P)

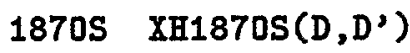

$1870 S \operatorname{XI1880S}(D, T),(T, A)$

1870S XJ187RE [+75] B- DECAY

$1870 \mathrm{~L} \quad 0.01 / 2-$

STABLE A

1870SX I XREF=ABCDEFGHIJ

$1870 S$ I $\quad 9.746243 / 2-$

2.38 NS 18

B

1870SX I XREF=BCDF J 


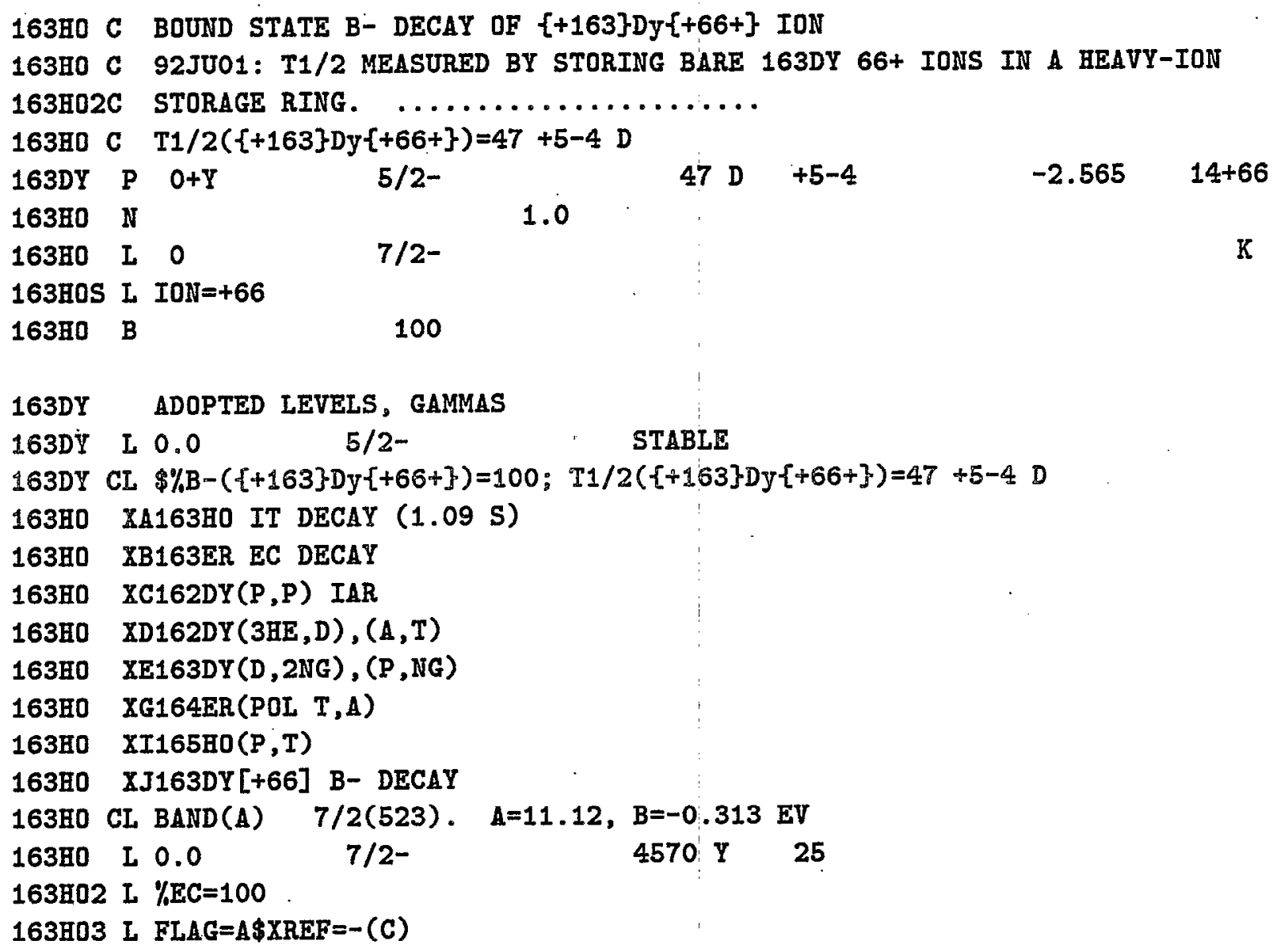


Appendix F

ENSDF Dictionary - Translation into true-type character set 


\begin{tabular}{|c|c|c|c|}
\hline ENSDF & Translation & ENSDF & TRANSLATION \\
\hline "A" & "A" & (UP) & $\left(1^{1}\right)$ \\
\hline$\% 12 \mathrm{C}$ & $\%\{+12\} C$ & * & $\backslash 1 * \backslash$ \\
\hline$\% 14 \mathrm{C}$ & $\%\{+14\} C$ & $* *(J+1 / 2)$ & $\{+(J+1)\}$, \\
\hline$\% 2 \mathrm{~B}-$ & $\% 2 \mid b\{+-\}$ & $* *-1$ & $\{t-1\}$ \\
\hline$\%$ A & $\% 1 \mathrm{a}$ & $* *-3$ & $\{+-3\}$ \\
\hline$\% B+A$ & $\%|b\{++\}| a$ & $* *-4$ & $\{t-4\}$ \\
\hline$\% B+N$ & $\% \mid b\{++\} n$ & $* * 1 / 2$ & $\{+1 / 2\}$ \\
\hline$\% B+P$ & $\% \mid b\{++\} p$ & $* * 1 / 3$ & $\{+1 / 3\}$ \\
\hline$\% \mathrm{~B}+$ & $\% \mid b\{t+\}$ & $* * 2$ & $\{+2\}$ \\
\hline$\% B-2 N$ & $\% \mid b\{+-\} 2 n$ & $* * 3$ & $\{+3\}$ \\
\hline$\% B-N$ & $\% \mid b\{+-\} n$ & $* * \mathrm{~L}$ & $\{+\mathrm{L}\}$ \\
\hline$\% B-P$ & $\% \mid b\{+-\}_{p}$ & $* A * *(1 / 3)$ & $|*| A\{+1 / 3\}$ \\
\hline$\% B-$ & $\% \mid b\{+-\}$ & *DS/DW & $\mathrm{d}|\mathrm{s} / \mathrm{d}| \mathrm{W}$ \\
\hline$\%$ BEC & $\%|b\{++\}| e$ & $* \mathrm{E}$ & $1 * \mathrm{E}$ \\
\hline$\%$ EO & $\%$ EO & $* \mathrm{EG}$ & $\mathrm{E} \mid \mathrm{g}$ \\
\hline$\%$ E2 & $\%$ \%2 & $* \mathrm{EKC}$ & $1 a(K) \exp$ \\
\hline$\% E C$. & $\% 10$ & $* \mathrm{G} * \mathrm{WIDTHGO} * * 2$ & $g \mid G\{+2\} \backslash\{-\mid g 0\}$ \\
\hline$\% \mathrm{ECA}$ & $\%$ lela & $* \mathrm{G} 2$ & $g\{-2\}$ \\
\hline$\%$ ECF & $\% \mid e F$ & $*$ IB- & $|* I| b\{+-\}$ \\
\hline$\%$ ECK & $\%$ lek & $* I E$ & $|* I|_{e}$ \\
\hline$\% \mathrm{ECP}$ & $\%$ lep & $* Q$ & $1 * Q$ \\
\hline \%EWSR & \%EWSR & $* \mathrm{R}$ & $\mathrm{R}$ \\
\hline$\% G$ & $\% / g$ & $* \mathrm{RI}$ & $I / g$ \\
\hline$\% I$ & $\% I$ & *SIGMA & $|*| \mathbf{s}$ \\
\hline$\%$ IB & $\% I \mid b$ & *SUMOF & is \\
\hline$\% I G$ & $\% I \mid g$ & $* \mathrm{~T} 1 / 2$ & $\mid * T\{-1 / 2\}$ \\
\hline$\% I T$ & $\%$ IT & $* \mathrm{TAU}$ & It \\
\hline$\%$ M1 & $\%$ M1 & *WIDTH & IG \\
\hline$\% \mathrm{~N}$ & $\% n$ & *WIDTHP & $\mid G\{-p\}$ \\
\hline$\% P$ & $\% p$ & $2 B-$ & $2 \mid b\{t-\}$ \\
\hline$\% R I$ & $\% I \mid g$ & $2 \mathrm{~J}$ & $2 \mathrm{~J}$ \\
\hline$\%$ SF & $\%$ SF & $2 \mathrm{~N} *$ SIGMA & $2 \mathrm{~N} / \mathrm{s}$ \\
\hline (A) & (la) & 4PI & $4 \mid p$ \\
\hline (B) & $(\mid b)$ & 4PIB & $4|p| b$ \\
\hline (COUL.) & (Coul.) & 4PIBG & $4|p| b \mid g$ \\
\hline (CV) & (CV) & 4PIG & $4|p| g$ \\
\hline (DOWN) & $\left(I_{-}\right)$ & A DECAY & la decay \\
\hline$(H, T)$ & $(H, T)$ & A DECAYS & la decays \\
\hline (IT) & (IT) & A SYST & la syst \\
\hline$(\mathrm{T})$ & $(t)$ & $A^{\prime}$ & $\mid a^{\prime}$ \\
\hline (THETA, H) & $(\mathrm{lq}, \mathrm{H})$ & A (THETA) & $A(\mid q)$ \\
\hline (THETA, H, T, T) & $(\mathrm{I}, \mathrm{H}, t, \mathrm{~T})$ & $A * * 1 / 3$ & $A\{+1 / 3\}$ \\
\hline (THETA, $\mathrm{T}, \mathrm{H})$ & $(\mid \mathrm{q}, \mathrm{T}, \mathrm{H})$ & $A * * 2 / 3$ & $A\{+2 / 3\}$ \\
\hline
\end{tabular}




\begin{tabular}{|c|c|c|c|}
\hline ENSDF & TRANSLATION & ENSDF & TRANSLATION \\
\hline$A-D E C A Y$ & la-decay & $\mathrm{B}(\mathrm{E} 4$ & $\mathrm{B}(\mathrm{E} 4$ \\
\hline$A-N$ & $A-N$ & $B(I S$ & $\mathrm{lb}(\mathrm{IS}$ \\
\hline A-SYST & la-syst & $\mathrm{B}(\mathrm{J}$ & $B(J)$ \\
\hline AO & $A\{-0\}$ & $\mathrm{B} * \mathrm{R}$ & IbR \\
\hline A1 & $A\{-1\}$ & $\mathrm{B} * \mathrm{RHO}$ & $\mathrm{B}|*| \mathrm{r}$ \\
\hline A11 & $A\{-11\}$ & $B+$ & $\mid b\{t+\}$ \\
\hline A2 & $A\{-2\}$ & $B-2 N$ & $1 \mathrm{~b}\{+-\} 2 \mathrm{n}$ \\
\hline $\mathrm{A} 2 / \mathrm{AO}$ & $A\{-2\} / A\{-0\}$ & $\mathrm{B}-\mathrm{N}$ & $\mid b\{t-\} n$ \\
\hline A22 & $\mathrm{A}\{-22\}$ & B-VIBRATIONAL & |b-vibrational \\
\hline A $2 \mathrm{P} 2$ & $A\{-2\} P\{-2\}$ & $B-$ & $\mid b\{t-\}$ \\
\hline A3 & $A\{-3\}$ & $\mathrm{B} / \mathrm{A}$ & $B / A$ \\
\hline A4 & $A\{-4\}$ & BO & $\mid b\{-0\}$ \\
\hline A44 & $A\{-44\}$ & BOO & $\mathrm{lb}\{-00\}$ \\
\hline A5 & $A\{-5\}$ & $\mathrm{BO} 2$ & $\mid b\{-02\}$ \\
\hline A6 & $A\{-6\}$ & B03 & $\mid b\{-03\}$ \\
\hline A7 & $\mathrm{A}\{-7\}$ & B04 & $\mid b\{-04\}$ \\
\hline$A=$ & $\mathrm{A}=$ & B1: & $\mid b\{-1\}$ \\
\hline $\mathrm{AA}$ & $|a| a$ & B12 & $\mid b\{-12\}$ \\
\hline AAO & $\operatorname{Aa}\{-0\}$ & B2 & $\mathrm{Ib}\{-2\}$ \\
\hline AAS & AAS & $\mathrm{B} 2 * \mathrm{R}$ & $\mathrm{Ib}\{-2\} \mathrm{R}$ \\
\hline $\mathrm{AB}$ & $A B$ & B2O & $\mathrm{lb}\{-20\}$ \\
\hline$A C E$ & $(l a)(c e)$ & B22 & $\mid b\{-22\}$ \\
\hline AG & la $\mid g$ & B24: & $\operatorname{lb}\{-24\}$ \\
\hline $\mathrm{AJ}$ & $\mathrm{AJ}$ & B3 ! & $\mid b\{-3\}$ \\
\hline ALAGA & Alaga & B3*R & $\mathrm{lb}\{-3\} \mathrm{R}$ \\
\hline ALPHA & la & B30 & $\mathrm{lb}\{-30\}$ \\
\hline ALPHAO & $\mid a\{-0\}$ & B4 & $\mathrm{Ib}\{-4\}$ \\
\hline ALPHA1 & $\mid a\{-1\}$ & $\mathrm{B} 4 * \mathrm{R}$ & $\mathrm{Ib}\{-4\} \mathrm{R}$ \\
\hline ALPHA2 & $\mid a\{-2\}$ & B42 & $\mathrm{Ib}\{-42\}$ \\
\hline ALPHA3 & $\mid a\{-3\}$ & B4C & $B\{-4\} C$ \\
\hline ALPHAS & la's & B5 & $\mathrm{lb}\{-5\}$ \\
\hline AP & I? & B5*R & $\mathrm{lb}\{-5\} \mathrm{R}$ \\
\hline APRIL & April & B6 & $\mathrm{lb}\{-6\}$ \\
\hline AUGER & Auger & $\mathrm{B} 6 * \mathrm{R}$ & $\mid b\{-6\} R$ \\
\hline AUGUST & August & B7 & $\mathrm{lb}\{-7\}$ \\
\hline AVRSQ & $\{\langle I\{+2\}\rangle\}$ & $B=$ & $B=$ \\
\hline $\mathrm{AXK}$ & $(\mid a)(k \times$ ray $)$ & BA & $|b| a$ \\
\hline AY & Ay & BAVRSQ & $\{\langle\mid b\{+2\}\rangle\{+1 / 2\}\}$ \\
\hline B & $\mathrm{lb}$ & BB & $|b| b$ \\
\hline$B(E O$ & $\mathrm{B}$ (EO & BC & lbc \\
\hline $\mathrm{B}(\mathrm{E} 1$ & $B(E 1$ & BCE & Ibce \\
\hline $\mathrm{B}(\mathrm{E} 2$ & B(E2 & BCS & $\mathrm{BCS}$ \\
\hline B (E3 & B (E3 & $\mathrm{BE}(\mathrm{L})$ & $\mathrm{BE}(\mathrm{L})$ \\
\hline
\end{tabular}




\begin{tabular}{|c|c|c|c|}
\hline ENSDF & TRANSLATION & ENSDF & TRANSLATION \\
\hline$---\infty$ & 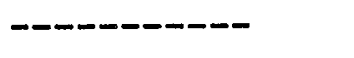 & ---- & - - - - \\
\hline $\mathrm{BE}-$ & Ibe $\{t-\}$ & $\mathrm{BL} * * 2$ & $\mid b\{-L\}\{+2\}$ \\
\hline BEO & $B(E 0)$ & $\mathrm{BL} * \mathrm{R}$ & $\mid b\{-L\} R$ \\
\hline BEOW & $B(E O)($ W.u. $)$ & $\mathrm{BL} * \mathrm{R} * \mathrm{~A} * *(1 / 3)$ & $\mid b\{-I\} R A\{+1 / 3\}$ \\
\hline $\mathrm{BE} 1$ & $\dot{B}(E 1)$ & BLAIR & Blair \\
\hline BE1UP & $\left.B(E 1)\right|^{-}$ & $\mathrm{BM}(\mathrm{L})$ & $\mathrm{BM}(\mathrm{L})$ \\
\hline $\mathrm{BE} 1 \mathrm{~W}$ & $B(E 1)$ (h.u.) & BM1 & $B(\mathrm{M} 1)$ \\
\hline BE2 & $\mathrm{B}(\mathrm{E} 2)$ & BM1UP & $\left.B(\mathrm{M} 1)\right|^{-}$ \\
\hline BE2DWN & $\left.\mathrm{B}(\mathrm{E} 2)\right|_{-}$ & BM1W & $B(M 1)$ (H.u.) \\
\hline BE2UP & $B(E 2) 1^{-}$ & BM2 & $B(M 2)$ \\
\hline $\mathrm{BE} 2 \mathrm{~W}$ & $B(E 2)$ (H.u.) & BM2UP & $\left.\mathrm{B}(\mathrm{M} 2)\right|^{-}$ \\
\hline BE3 & $B(E 3)$ & BM2W & B (M2) (W.u.) \\
\hline BE3UP & $\left.B(E 3)\right|^{\wedge}$ & BM3 & $B(M 3)$ \\
\hline BE3W & $B($ E3) (W.u.) & BM3W & $B(M 3)(H . u)$. \\
\hline BE3WUP & $\left.B(E 3)($ W.u. $)\right|^{-}$ & $\mathrm{BM} 4$ & $\mathrm{~B}(\mathrm{M} 4)$ \\
\hline $\mathrm{BE} 4$ & $B(E 4)$ & $\mathrm{BM} 4 \mathrm{H}$ & $B(M 4)$ (W.u.) \\
\hline BE4UP & $\left.B(E 4)\right|^{-}$ & BM5W & $B(M 5)$ (W.u.) \\
\hline $\mathrm{BE} 4 \mathrm{~W}$ & $B(E 4)$ (H.u.) & BM8UP & $\mathrm{B}(\mathrm{M} 8) \mathrm{I}^{-}$ \\
\hline BE5 & $B(E 5)$ & BML & $B(M L)$ \\
\hline BE5W & $B(E 5)$ (H.u.) & BML $\mathrm{H}$ & $B(M L)($ W.u. $)$ \\
\hline BE6 & $B(E 6)$ & $\mathrm{BN}$ & Ibn \\
\hline BE6UP & $\left.B(E 6)\right|^{\sim}$ & BOHR & Bohr \\
\hline BE6W & $B(E 6)$ (H.u.) & BORN & Born \\
\hline $\mathrm{BE} 7$ & $B(E 7)$ & $\mathrm{BP}$ & Ibp \\
\hline BE7W & $B(E 7)$ (ห.u.) & $\mathrm{BR}$ & Branching \\
\hline BE8 & $B(E 8)$ & BREIT & Breit \\
\hline BEC DECAY & $|\mathrm{b}\{++\}|_{e}$ Decay & BRINK & Brink \\
\hline BEL & $B(E L)$ & $\mathrm{Be}$ & $\mathrm{Be}$ \\
\hline BELK & $B(E L)$ (W.u.) & C & C \\
\hline BERKELEY & Berkeley & C.M. & c.m. \\
\hline BESSEL & Bessel & C12G & $\{+12\} \mathrm{C} / \mathrm{g}$ \\
\hline BETA & Ib & $\mathrm{C2S}$ & $C\{+2\} S$ \\
\hline $\mathrm{BETA} * \mathrm{R}$ & $\mathrm{lbR}$ & $\mathrm{CA}(\mathrm{OH})$ & $\mathrm{Ca}(\mathrm{OH})$ \\
\hline BETAS & Ib's & $\mathrm{CC}$ & la \\
\hline BETHE & Bethe & CCBA & CCBA \\
\hline BF3 & $B F\{-3\}$ & $\operatorname{ccc}$ & $\mathrm{CCC}$ \\
\hline BG & $|\mathbf{b}| \mathbf{g}$ & $\mathrm{CE}$ & $c \theta$ \\
\hline BGG. & $|\mathrm{b} / \mathrm{g}| \mathrm{g}$ & CEB & $c \theta \mid b$ \\
\hline BGI & $|b| g n$ & CEG & $\mathrm{celg}$ \\
\hline$B G O$ & BGD & CEK & $\mathrm{C \theta}(\mathrm{K})$ \\
\hline BGT & $\mid \mathrm{b}(\mathrm{GT})$ & CEL & $\operatorname{ce}(\mathrm{I})$ \\
\hline BIEDENHARN & Biedenharn & CEL1 & $c \theta(L 1)$ \\
\hline $\mathrm{BJ} * * 2$ & $B J\{+2\}$ & CEL12 & $c \theta(L 12)$ \\
\hline BL & $\mid \mathrm{b}\{-L\}$ & CEL2 & $c \theta(L 2)$ \\
\hline
\end{tabular}




\begin{tabular}{|c|c|c|c|}
\hline ENSDF & TRANSLATION & ENSDF & TRANSLATION \\
\hline$\overline{\text { CEL } 23}$ & ce(L23) & CURIE & Gurie \\
\hline CEL3 & $C \theta(I, 3)$ & $\mathrm{Cm}$ & $\mathrm{Cm}$ \\
\hline CEM & $c_{\theta}(\mathrm{M})$ & D) & D) \\
\hline CEM1 & $c e$ (M1) & $D+(Q)$ & $D+(Q)$ \\
\hline CEM2 & $\mathrm{Ce}(\mathrm{H} 2)$ & $D+Q$ & $D+Q$ \\
\hline CEM23 & $\mathrm{Ce}$ (M23) & D3HE & $\mathrm{d}\{+3\} \mathrm{He}$ \\
\hline CEM3 & $\mathrm{ce}(\mathrm{M} 3)$ & DA & IDA \\
\hline CEM4 & $\mathrm{ce}(\mathrm{M} 4)$ & DA2 & $\operatorname{IDA}\{-2\}$ \\
\hline CEM45 & $\mathrm{c \theta}(\mathrm{M} 45)$ & DA4 & $\mid D A\{-4\}$ \\
\hline CEM5 & $\mathrm{ce}(\mathrm{M} 5)$ & DAVRSQ & $\{\mid D<r\{+2\}>\}$ \\
\hline CEN & $c \theta(N)$ & DAVRSQ4 & $\{\mid D<r\{+4\}>\}$ \\
\hline CEN1 & $\mathrm{ce}(\mathrm{N} 1)$ & DAVRSQ6 & $\{\mid D<r\{+6\}>\}$ \\
\hline CEN2 & $c \theta(N 2)$ & DAVYDOV & Davydoy \\
\hline CEN3 & $\mathrm{C \theta}(\mathrm{N} 3)$ & DBR & branching uncertainty \\
\hline CEN4 & $\operatorname{ce}(\mathbb{N} 4)$ & DCC & $|D| a$ \\
\hline CEN45 & $\mathrm{ce}(\mathbb{N} 45)$ & $\mathrm{DCO}$ & $\mathrm{DCO}$ \\
\hline CEN5 & $c \theta(N 5)$ & DCOQ & $\mathrm{DCOQ}$ \\
\hline CED & $c \theta(0)$ & $\mathrm{DE}$ & $\mid D E$ \\
\hline CEO+CEP & $c \theta(0)+c \theta(P)$ & $\mathrm{DE} / \mathrm{DX}$ & $d E / d x$ \\
\hline CE01 & $\mathrm{ce}(01)$ & DECEMBER & December \\
\hline CERENKOV & Cerenkov & $\mathrm{DEG}$ & 11 \\
\hline CERN & CERN & DELTA & $|D|$ \\
\hline CHI & lh & DFT & $\mid D(\log f t)$ \\
\hline CHI**2 & $\ln \{+2\}$ & DG & $\mathrm{d} / \mathrm{g}$ \\
\hline $\mathrm{CK}$ & leK & $\mathrm{DHF}$ & $\mid D(H F)$ \\
\hline CL & leL & DIA & $|D I| a$ \\
\hline CLEBSCH & Clebsch & DIB & $|D I| b$ \\
\hline CM & leM & DIE & $|D I|_{\theta}$ \\
\hline CM2 & $\operatorname{cm}\{+2\}$ & DISPIN & IDT \\
\hline CM3 & $\operatorname{cm}\{+3\}$ & DJ & IDJ \\
\hline $\mathrm{CN}$ & leN & DJPI & $|D J| p$ \\
\hline $\mathrm{CD}$ & Co & DK & IDK \\
\hline COMPTON & Compton & DL & IDL \\
\hline CONF & configuration & DMR & $|D| d$ \\
\hline $\mathrm{CONF}=$ & configuration= & DN & IDN \\
\hline CORIOLIS & Coriolis & DNB & |D (|b-normalization $)$ \\
\hline COS2TH . & $\cos \{+2\} \mid q$ & DNR & ID (Ig-normalization $)$ \\
\hline COSTER & Coster & DNT & ID $($ lgtce-normalization $)$ \\
\hline COUL & Coul 1 & DOMEGA & $d \mid W$ \\
\hline COULOMB & Coulomb & DOPPLER & Doppler \\
\hline CP & CP & DPAC & DPAC \\
\hline CRC & CRC & DPAD & DPAD \\
\hline CSI & CsI & DPI & $|D| p$ \\
\hline
\end{tabular}




\begin{tabular}{|c|c|c|c|}
\hline ENSDF & TRANSLATION & ENSDF & TRANSLATIDN \\
\hline---- & - - - - - - - & $-\infty--$ & $-\infty-\infty$ \\
\hline $\mathrm{DQ}+$ & $\mid D Q(\mid \theta)$ & E7 & E7 \\
\hline $\mathrm{DQ}-$ & $\operatorname{IDQ}(\operatorname{Ib}\{+-\})$ & E8 & E8 \\
\hline$D Q A$ & $\operatorname{IDQ}(\mid a)$ & E9 & E9 \\
\hline DRI & $|D I| g$ & $\mathrm{EA}$ & Ela \\
\hline DS & IDS & EAV & av $E / b$ \\
\hline DS/DW & $d|s / d| h$ & $\mathrm{~EB}$ & $E / b$ \\
\hline DSA & DSA & $\mathrm{EB}-$ & $E \mid b\{+-\}$ \\
\hline DSAM & DSAM & EBE2UP & $|e B(E 2)|^{\circ}$ \\
\hline DSIGMA & $\mathrm{d} \mid \mathrm{s}$ & EBE3UP & $|e B(E 3)|^{-}$ \\
\hline DSN & $\operatorname{lDS}(n)$ & EB_ & $E / b$ \\
\hline DSP & $\operatorname{IDS}(\mathrm{p})$ & EC & le \\
\hline $\mathrm{DT}$ & $\mid D T\{-1 / 2\}$ & EC2P & le2p \\
\hline $\mathrm{DT} 1 / 2$ & $\operatorname{IDT}\{-1 / 2\}$ & $\mathrm{ECA}$ & lela. \\
\hline DTI & $\operatorname{lDI}(\mid g+c \theta)$ & ECC & la $(e x p)$ \\
\hline DUBNA & Dubna & $\mathrm{ECE}$ & $E(c \theta)$ \\
\hline DWBA & DWBA. & ECK & leK $(\exp )$ \\
\hline DHIA & DWIA & ECL & leL (exp) \\
\hline DWUCK & DWUCK & ECL1 & leL1 (exp) \\
\hline $\mathbf{E}$ & $\mathrm{E}$ & ECL2 & leL2(exp) \\
\hline$E^{\prime}$ (THETA) & $\theta^{\prime}(\mid q)$ & ECL3 & leL3 $(\exp )$ \\
\hline$E(A)$ & $E(\mid a)$ & ECM & IjM(exp) \\
\hline$E(D)$ & $E(d)$ & $\mathrm{ECN}$ & $\mid j N(\exp )$ \\
\hline$E(E)$ & $E(\theta)$ & ECP & lep \\
\hline$E(\pi)$ & $E(n)$ & ED & $E(d)$ \\
\hline$E(P)$ & $E(p)$ & EDE & $E \mid D E$ \\
\hline$E(P 1)$ & $E(p\{-1\})$ & $\mathrm{EE}$ & Eө \\
\hline$E(P 2)$ & $E(p\{-2\})$ & EEC & $E \mid \theta$ \\
\hline$E(T)$ & $E(t)$ & EG & Elg \\
\hline$E * * 1 / 2$ & $E\{+1 / 2\}$ & $\mathrm{EG} * * 3$ & $E \mid g\{+3\}$ \\
\hline$E * * 2$ & $\mathrm{E}\{+2\}$ & $\mathrm{EG} * * 5$ & $E \mid g\{+5\}$. \\
\hline $\mathrm{E}+$ & $e\{t+\}$ & EKC & la(K) $\exp$ \\
\hline $\mathrm{E}+-$ & $\theta\{+1+\}$ & EL & EI \\
\hline $\mathbf{E}-\mathbf{E}$ & $E-E$ & EL12C & $\mathrm{la}(\mathrm{I} 12) \exp$ \\
\hline E.G. & $\{I \otimes \cdot g \cdot\}$ & EL1C & la (L1) $\exp$ \\
\hline$E / D E$ & $E / \mid D E$ & EL23C & la(L23) exp \\
\hline EO & EO & EL2C & la(L2) exp \\
\hline E1 & E1 & EL3C & la (L3) $\exp$ \\
\hline E10 & E10 & ELC & $\mid a(L) \exp$ \\
\hline E2 & E2 & EM1C & la (M1) exp \\
\hline E3 & E3 & EM2C & la (M2) exp \\
\hline E4 & E4 & EM3C & $I_{a}(\mathrm{MB}) \exp$ \\
\hline E5 & E5 & EM4C & la (M4) exp \\
\hline E6 & E6 & EM5C & la (M5) exp \\
\hline
\end{tabular}




\begin{tabular}{|c|c|c|c|}
\hline ENSDF & TRANSLATION & ENSDF & TRANSLATION \\
\hline EMC & la $(M) \exp$ & $G *$ W $*$ WIDTHGO $* * 2$ & $2 \mathrm{gW} \mid G\{-0\} \backslash\{+2\}$ \\
\hline EN & $E(n)$ & G*VIDTH & gIG \\
\hline EN1C & la(N1) exp & G*WIDTHGO & $g \mid G\{-\mid g 0\}$ \\
\hline EN23C & $\mathrm{a}(\mathrm{N} 23) \exp$ & G*WIDTHGO**2 & $g \mid G\{+2\} \backslash\{-\mid g 0\}$ \\
\hline EN2C & la(N2) $\exp$ & G*WIDTHN & $g \mid G\{-n\}$ \\
\hline EN3C & la(N3) exp & G+- & $\lg \{+1+\}$ \\
\hline EN4C & $\mathrm{la}(\mathrm{N} 4) \exp$ & G-FACTOR & $g$-factor \\
\hline ENC & la $(N) \exp$ & G-FACTORS & g-factors \\
\hline ENDF / B-V & ENDF/B-V & G-M! & G-M \\
\hline ENDF/B_ & ENDF/B & $G / A_{1}$ & $|g /| a$ \\
\hline ENDOR & ENDOR & GO & $\lg \{-0\}$ \\
\hline ENGE & Enge & GI & $g\{-1\}$ \\
\hline EP & $E(p)$ & GI*WIDTH & $g\{-1\} \mid G$ \\
\hline EPR & EPR & G2 & $g\{-2\}$ \\
\hline EPSILON & le & G2*WIDTH & $g\{-2\} \mid G$ \\
\hline EPSILONB & $l_{e B}$ & $G=$ & $g=$ \\
\hline ESR & ESR & GA & $|?\rangle$ \\
\hline ET & $E(t)$ & GA2 & $g\{-A\} \backslash\{+2\}$ \\
\hline $\mathrm{EV}$ & $\mathrm{eV}$ & GALLAGHER & Gallagher \\
\hline EVEN-A & even-A & GAMMA & $\lg$ \\
\hline EWSR & EWSR & GAMOW & Gamor \\
\hline EX. & ex. & GARVEY & Garvey \\
\hline$E\{$ & $\mathrm{E}\{$ & GAUSSIAN & Gaussian \\
\hline$F+B$ & $F+B$ & GB & $|g| b$ \\
\hline $\mathrm{F}-\mathrm{K}$ & $F-K$ & GB- & $|g| b\{t-\}$ \\
\hline$F / B$ & $F / B$ & GCE & Igce \\
\hline FEBRUARY & February & GDR & GDR \\
\hline FERMI & Fermi & GE & $\mid>$ \\
\hline FESHBACH & Feshbach & $G E(L I)$ & $G_{\theta}(L i)$ \\
\hline FG & (fragment) $\mid g$ & GE- & $\lg \theta\{t-\}$ \\
\hline FM & $\mathrm{fm}$ & GEIGER & Geiger \\
\hline FM**-1 & $\operatorname{fm}\{t-1\}$ & GEIGER-MULLER & Geiger-Muller \\
\hline FM**2 & $\operatorname{fm}\{+2\}$ & GELI & $\mathrm{Ge}(\mathrm{L} i)$ \\
\hline FH**4 & $f m\{+4\}$ & GEV & GeV \\
\hline FM-1 & $\operatorname{fm}\{t-1\}$ & GG & $\lg \mid g$ \\
\hline FOCK & Fock & GGG & $|g| g \mid g$ \\
\hline FOURIER & Fourier & GGN & $\lg \lg n$ \\
\hline FWHM & FWHY & GGT & $|g| g \mid t$ \\
\hline G FACTOR & $g$ factor & GM & GM \\
\hline G FACTORS & $g$ factors & GMR & GMR \\
\hline$G(2+$ & $g(2+$ & GN & $\operatorname{lgn}$ \\
\hline $\mathbf{G} * \mathbf{T}$ & gT & GP & $\operatorname{lgP}$ \\
\hline G*W*WIDTHGO & $g \mathbb{D} \mid G\{-\mid g 0\}$ & GP' & lgp' \\
\hline
\end{tabular}




\begin{tabular}{|c|c|c|c|c|}
\hline ENSDF & TRANSLATION & . & ENSDF & TRANSLATION \\
\hline $\mathrm{GP}(\mathrm{T})$ & $\operatorname{lgp}(t)$ & & IMPAC & IMPAC \\
\hline GQR & GQR & & $\operatorname{INC}$ & $\operatorname{In}($ \\
\hline GS & g.s. & & INFNT & 10 \\
\hline GSI & GSI & & IPAC & IPAC \\
\hline GT & $>$ & & IS $D$ & is $D$ \\
\hline GT1/2 & $\operatorname{gT}\{-1 / 2\}$ & & ISOLDE & ISOLDE \\
\hline GTOL & GTOL & & ISPIN & $T$ \\
\hline GWIDTHOWIDTHG & $g|G\{-0\}| G \mid g$ & & ISPINZ & $T\{-z\}$ \\
\hline GX & $\lg x$ & & IT BRANCHING & IT branching \\
\hline$G_{-}$ & $\lg$ & & IT DECAY & IT decay \\
\hline $\mathrm{HC}$ & $\mathrm{HC}$ & & IT DECAYS & IT decays \\
\hline $\mathrm{H} * * 2$ & $h\{+2\}$ & & IT TRANSITION & IT transition \\
\hline H, & $\mathrm{H}$, & & IT- & IT- $\quad$. \\
\hline $\mathrm{H}=$ & $\mathrm{H}=$ & & $I T=$ & $I T=$ \\
\hline HAGER & Hager & & $I X$ & $I(x$ ray $)$ \\
\hline HARTREE & Hartree & & $\mathrm{J}$ & $\mathrm{J}$ \\
\hline HAUSER & Hauser & & $\mathrm{J} * * 2$ & $J\{+2\}$ \\
\hline HERA & HERA & & Jo & $J\{-0\}$ \\
\hline $\mathrm{HF}$ & $\mathrm{HF}$ & & $\mathrm{J} 1$ & $J\{-1\}$ \\
\hline HI & $\mathrm{HI}$ & & J2 & $J\{-2\}$ \\
\hline HOMEGA & $h \backslash l^{\prime} \mid r$ & & JANUARY & January \\
\hline $\mathrm{HP}$ & HP & & JF & $J\{-f\}$ \\
\hline HPGE & HPGE & & JI & $J\{-i\}$ \\
\hline I & $I$ & & $\mathrm{JKP}$ & $\mathrm{JK} \mid \mathrm{p}$ \\
\hline I.E. & $\{\mathrm{Ii} \cdot \bullet\}$. & & JMAX & $J \max$ \\
\hline IA & Ila & & JMIN & Jmin \\
\hline IAR & IAR . & & JOSEF & JOSEF \\
\hline IAS & IAS & & JPI & $J \mid p$ \\
\hline IB & $I \mid b$ & & JULIE & JULIE \\
\hline $\mathrm{IB}+$ & $I \mid b\{++\}$ & & JULY & July \\
\hline IB- & $I \mid b\{+-\}$ & & JUNE & June \\
\hline IBA & IBA & & $\mathbb{K}$ & $\mathrm{K}$ \\
\hline IBM & IBM & & $\mathrm{K} / \mathrm{L}+\mathrm{M}$ & $\mathrm{K} / \mathrm{L}+\mathrm{M}$ \\
\hline IBS & IBS & & $\mathrm{K} / \mathrm{LM}$ & K/LM \\
\hline ICC & la & & $\mathrm{K} / \mathrm{T}$ & $c \theta(K) /(\lg +c \theta)$ \\
\hline ICE & Ice & & KAPPA & lk \\
\hline ICE (K) & $\operatorname{Ic\theta }(\mathrm{K})$ & & $\mathrm{KC}$ & $\mathrm{la}(\mathrm{K})$ \\
\hline $\operatorname{ICE}(\mathrm{N})$ & $\operatorname{Ic\theta }(N)$ & & KELSON & Kelson \\
\hline IE & Ile & & $\mathrm{KEV}$ & $\mathrm{keV}$ \\
\hline IEC & Ile & & KEVIN & Kelvin \\
\hline IG & Ilg & & KG & $\mathbf{K G}$ \\
\hline$I G * E G$ & I $|g E| g$ & & KL1L1 & $\operatorname{KL}\{-1\} L\{-1\}$ \\
\hline IGISOL & IGISOL & & KL1L2 & $\operatorname{KL}\{-1\} L\{-2\}$ \\
\hline
\end{tabular}




\begin{tabular}{|c|c|c|c|}
\hline ENSDF & TRANSLATION & ENSDF & TRANSLATION \\
\hline$-\infty-\infty$ & $-\cdots-m-\cdots$ & ---- & --ー-ー-ー-ー-- \\
\hline KL1L3 & $K L\{-1\} L\{-3\}$ & LARMOR & Larmor \\
\hline KL1M1 & $K L\{-1\} M\{-1\}$ & LASER & LASER \\
\hline KL1M2 & $K L\{-1\} M\{-2\}$ & LBL & LBL \\
\hline KL1M3 & $K L\{-1\} M\{-3\}$ & LC & $\mid a(L)$ \\
\hline $\mathrm{KL} 2 \mathrm{~L} 2$ & $K L\{-2\} L\{-2\}$ & LE & $1<$ \\
\hline KL2L3 & $\mathrm{KL}\{-2\} L\{-3\}$ & LEGENDRE & Legendre \\
\hline $\mathrm{KL} 2 \mathrm{M} 1$ & $K L\{-2\} M\{-1\}$ & LI & Li \\
\hline KL2M3 & $K L\{-2\} M\{-3\}$ & IITHERLAND & Litherland \\
\hline KL2M4 & $\mathrm{KL}\{-2\} \mathrm{M}\{-4\}$ & LM : & LM \\
\hline KL3L3 & $\operatorname{KL}\{-3\} L\{-3\}$ & LMI & IMN \\
\hline KL3LM1 & $\operatorname{KL}\{-3\} \operatorname{LM}\{-1\}$ & LNT & $I(n)$ \\
\hline KL3M2 & $K L\{-3\} M\{-2\}$ & LOGF1T & $\operatorname{Iog} \mid\{\operatorname{If}\{+1\} t\}$ \\
\hline KI.3M3 & $K L\{-3\} M\{-3\}$ & LOGF1UT & $\operatorname{Iog} \mid\{\operatorname{If}\{+1 u\} t\}$ \\
\hline KL3N & $\mathrm{KL}\{-3\} \mathrm{N}$ & LOGF 2UT & $\log \mid\{\operatorname{If}\{+2 u\} t\}$ \\
\hline KLI & KLL & LOGF3UT & $\log \mid\{\operatorname{If}\{+3 u\} t\}$ \\
\hline KLM & KLM & LDGFT & $\log \mid\{$ Ift $\}$ \\
\hline KM2M3 & $\operatorname{KM}\{-2\} M-3\}$ & LOHENGRIN & LDHENGRIN \\
\hline KM2N2 & $\mathrm{KM}\{-2\} \mathrm{N}\{-2\}$ & LORENTZIAN & Lorentzian \\
\hline KM3M3 & $\mathrm{KM}\{-3\} \mathrm{M}\{-3\}$ & LP & $L(p)$ \\
\hline RNIGHT & Knight & $\mathbf{L T}$ & $<$ \\
\hline $\mathrm{KOE}$ & $\mathrm{kOe}$ & $\mathbf{M}$ & $M$ \\
\hline $\mathrm{KPI}$ & $K / p$ & $M+/ T$ & $c \theta(M+) /(\lg +c \theta)$ \\
\hline KRANE & Krane & $\mathbf{M}+=$ & $\mathbf{M}+=$ \\
\hline KRONIG & Kronig & M-SHELL & M-shell \\
\hline KUD-BROWN & Kuo-Brown & M-SUBSHELL & M-subshell \\
\hline KURIE & Kurie & $\mathrm{M} / \mathrm{CE}$ & $M /$ total ce \\
\hline $\mathrm{KXY}$ & $\mathbf{K X Y}$ & $M / T$ & $\operatorname{co}(M) /(\lg +c \theta)$ \\
\hline L & L & M1 & M1 \\
\hline $\mathrm{L}+/ \mathrm{T}$ & $c \theta(L+) /(\mid g+c \theta)$ & M12 & M12 \\
\hline $\mathrm{L} / \mathrm{T}$ & $c \theta(L) /(\mid g+c \theta)$ & M1C & la(M1) \\
\hline L1 & L1 & M2 & M2 \\
\hline L12 & L12 & M23 & N23 \\
\hline L12C & $\mathrm{la}(\dot{\mathrm{L}} 12)$ & $\mathrm{M} 2 \mathrm{C}$ & la(M2) \\
\hline L1C & $\mathrm{la}(\mathrm{L} 1)$ & M3 & H3 \\
\hline L2 & L2 & M3C & la(M3) \\
\hline L23 & L23 & M4 & M4 \\
\hline L23C & $\mathrm{la}(\mathrm{L23})$ & H45 & M45 \\
\hline L2C & $\mathrm{la}(\mathrm{L} 2)$ & M4C & la $(M 4)$ \\
\hline L3 & L3 & H5 & M5 \\
\hline L3C & $\mathrm{Ia}(\mathrm{L} \cdot 3)$ & M5C & $\mathrm{la}(\mathrm{M} 5)$ \\
\hline IA & I?< & M6 & M6 \\
\hline LAMBDA & 11 & M8 & M8 \\
\hline LAMPF & LAMPF & MARCH & March \\
\hline
\end{tabular}




\begin{tabular}{|c|c|c|c|}
\hline ENSDF & TRANSLATION & ENSDF & TRANSLATION \\
\hline$--\infty$ & - - - - - & ---- & 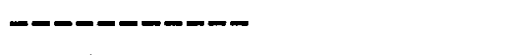 \\
\hline MB & $\mathrm{mb}$ & $\mathrm{N} 4 \mathrm{C}$ & la(N4) \\
\hline $\mathrm{MB} / \mathrm{SR}$ & $\mathrm{mb} / \mathrm{sr}$ & N5 & N5 \\
\hline MC & $\mathrm{a}(\mathrm{M})$ & $\mathrm{N} 5 \mathrm{C}$ & $\mathrm{Ia}(\mathrm{N} 5)$ \\
\hline $\mathrm{MC}+$ & $\mid a(M+\ldots)$ & $\mathrm{N} 6 \mathrm{C}$ & $\mathrm{la}(\mathrm{N} 6)$ \\
\hline MEDLIST & MEDLIST & $\mathbb{N}<$ & $\mathbb{N}<$ \\
\hline $\mathrm{MEV}$ & $\mathrm{MeV}$ & $\mathrm{N}=$ & $\mathrm{N}=$ \\
\hline MEV**-4 & $M e V\{E 4-4\}$ & NAI & $\mathrm{NaI}$ \\
\hline MG/CM2 & $\mathrm{mg} / \mathrm{cm}\{+2\}$ & $\mathbb{N B}$ & Ilb normalization \\
\hline MHZ & MHZ & $\mathrm{NB} / \mathrm{SR}$ & $\mathrm{nb} / \mathrm{sr}$ \\
\hline MILLI-EV & $\mathrm{meV}$ & NBS & NBS \\
\hline MIT & MIT & NC & $\mathrm{la}(\mathrm{N})$ \\
\hline ML & $M+L$ & $\mathrm{NC}+$ & $1 a(N+\ldots)$ \\
\hline MNO & $\mathrm{M}+\mathrm{N}+\mathrm{O}$ & NC2S & $\mathrm{NC}\{+2\} S$ \\
\hline MDME2 & $\mathbf{Q}$ & NDS & Nuclear Data Sheөts \\
\hline MOME3 & Dctupole mom(el) & $\mathrm{NE}$ & $1=$ \\
\hline MOMM1 & Im & $\operatorname{NE} 213$ & NE213 \\
\hline MDMM3 & Dctupole mom(mag) & NG & $\mathrm{n} / \mathrm{g}$ \\
\hline MOMM5 & $2\{+5\} \operatorname{mom}(\mathrm{mag})$ & NIGG & $n \lg \mid g$ \\
\hline MOMM7 & $2\{+7\}$ mom (mag) & NILSSON & Nilsson \\
\hline MOSSBAUER & Mossbauer & NMR & NMR \\
\hline MOSZKOWSKI & Moszkorski & NOTE: & Note: \\
\hline MR & Id & NOVEMBER & November \\
\hline MR**2 & $\mid d\{+2\}$ & NP & Particle normaljzation \\
\hline MS & ms & INQR & INQR \\
\hline MU & lm & NR & I/g normalization \\
\hline MU- & $\operatorname{lm}\{t-\}$ & NS*SIGMA & NSIs \\
\hline N*SIGMA & $N|*| \mathbf{s}$ & NT & $I(\mid g+c \theta)$ normalization \\
\hline $\mathrm{N}+/ \mathrm{T}$ & $c \theta(N+) /(\lg +c \theta)$ & NU & $\ln$ \\
\hline N-SHELL & $\mathrm{N}-\operatorname{sh} \theta 11$ & $\mathrm{NX}$ & $\mathrm{NX}$ \\
\hline N-SUBSHELL & N-subshe11 & $\mathrm{Ne}$ & $\mathrm{Ne}$ \\
\hline $\mathbf{N}-\mathbf{Z}$ & $N-Z$ & D & 0 \\
\hline $\mathrm{N} / \mathrm{T}$ & $\operatorname{co}(\mathrm{N}) /(\mathrm{g} g+\mathrm{c \theta})$ & $0 / Q$ & $0 / Q$ \\
\hline N1 & N1 & $0 / T$ & $c \theta(0) /\left(\lg +c_{\theta}\right)$ \\
\hline $\mathrm{N} 12$ & N12 & 01 & 01 \\
\hline N123 & N123 & 0123 & 0123 \\
\hline $\mathrm{N} 1 \mathrm{C}$ & $\mathrm{la}(\mathrm{N} 1)$ & 01C & $\operatorname{la}(01)$ \\
\hline N2 & N2 & 02 & 02 \\
\hline N23 & N23 & $02 \mathrm{C}$ & la(02) \\
\hline N2C & $\mathrm{la}(\mathrm{N} 2)$ & 03 & 03 \\
\hline N3 & N3 & O3C & $\mathrm{la}(03)$ \\
\hline N3C & la (N3) & $04 \mathrm{C}$ & $\mathrm{la}(04)$ \\
\hline N4 . & N4 & OCTOBER & Dctober \\
\hline N45 & N45 & DDD-A & odd-A \\
\hline
\end{tabular}




\begin{tabular}{|c|c|c|c|}
\hline ENSDF & TRANSLATION & ENSDF & TRANSLATION \\
\hline$-\infty-\infty$ & - & ----- & -ー-ーーーーーーー- \\
\hline OMEGA & 10 & QA & $Q(\mid a)$ \\
\hline OMEGA**2*TAU & $|\nabla\{+2\}| t$ & QDD & QDD \\
\hline OMEGA*T & $|\nabla| t$ & QDDM & QDDH \\
\hline ORNL & ORNL & QDMDQ & QDMDQ \\
\hline OSIRIS & DSIRIS & QMG : & QMG \\
\hline P DECAY & $\mathrm{p}$ decay & $\mathbf{Q P}:$ & $Q(g . s)$. \\
\hline P (THETA) & $p(\mid q)$ & QQSP & QQSP \\
\hline $\mathrm{P}+/ \mathrm{T}$ & $c \theta(P+) /(\lg +c \theta)$ & QS & $Q\{-s\}$ \\
\hline P-WIDTH & p-width & QSD & QSD \\
\hline Po & $\mathrm{P}\{-0\}$ & R & R \\
\hline P1 & P1 & $R(D C D)$ & $\mathrm{R}(\mathrm{DCO})$ \\
\hline $\mathrm{P} 1 / 2$ & $\mathrm{p} 1 / 2$ & $R * * 2$ & $r\{+2\}$ \\
\hline P1C & la $(P 1)$ & $\mathrm{R} * * 4$ & $r\{+4\}$ \\
\hline P2NG & $\mathrm{p} 2 \mathrm{n} / \mathrm{g}$ & $\mathrm{R} * * 6$ & $r\{+6\}$ \\
\hline PAC & PAC & RO & $r\{-0\}$ \\
\hline PAD & PAD & RDDS & RDDS \\
\hline PALPHA & $\mathbf{p} \mid \mathbf{a}$ & RDM & RDM \\
\hline PG & $\mathrm{p} / \mathrm{g}$ & RHO & Ir \\
\hline PGG & $\mathrm{p} / \mathrm{g} / \mathrm{g}$ & $\mathrm{RHO} * * 2$ & $\operatorname{lr}\{+2\}$ \\
\hline PHI & $\mid F$ & RI & $I \lg$ \\
\hline PHI (P1) & $\mid F(p\{-1\})$ & RITZ & Ritz \\
\hline PHI (P2) & $\mid F(p\{-2\})$ & ROSE & Rose \\
\hline PI & Ip & RPA & RPA \\
\hline PI- & $\operatorname{lp}\{+-\}$ & RUL & RUL \\
\hline PIB & $|p| b$ & RUTHERFORD & Rutherford \\
\hline PIBG & $|p| b \mid g$ & RYTZ & Rytz \\
\hline PIG & $|p| g$ & S VALUE & S value \\
\hline PN & $P\{-n\}$ & S VALUES & S values \\
\hline PNG & $\mathrm{pn} / \mathrm{g}$ & $\mathbf{S}^{\prime}$ & $S^{\prime}$ \\
\hline PRI & $|D I| g(\%)$ & $S(2 N)$ & $s(2 n)$ \\
\hline PSI & $\mid Y$ & $S(2 P)$ & $s(2 p)$ \\
\hline PWBA & PWBA & $s(C E)$ & $s(c \theta)$ \\
\hline PWIA & PWIA & $S-1$ & $s\{t-1\}$ \\
\hline$Q$ & $Q$ & S-FACTOR & s-factor \\
\hline$Q C$ & $Q($ & S-FACTORS & s-factors \\
\hline$Q+0$ & $Q+0$ & S-VALUE & S-value \\
\hline$Q+\ldots$ & $Q(\mid \theta)$ & S-VALUES & S-values \\
\hline$Q-$ & $Q(\mid b\{+-\})$ & S-WAVE & s-nave \\
\hline $\mathrm{Q} / \mathrm{D}$ & $\mathrm{Q} / \mathrm{D}$ & $\mathbf{S} /$ & $s /$ \\
\hline Q22 & $Q\{-22\}$ & $S=$ & $S=$ \\
\hline Q2D & Q2D & SA : & $s(\mid a)$ \\
\hline Q2DM & Q2DM & SAXON & Saxon \\
\hline Q3D & Q3D & SCHMIDT & Schmidt \\
\hline
\end{tabular}




\begin{tabular}{|c|c|c|c|}
\hline ENSDF & TRANSLATION & ENSDF & TRANSLATION \\
\hline SD & SD & THETA2 & $\mid q\{-2\}$ \\
\hline $\mathrm{SDB}$ & $\mathrm{SDB}$ & THETAA & $|q| a$ \\
\hline$S E(L I)$ & $\mathrm{Se}(\mathrm{L} i)$ & THETAA $* * 2$ & $|q| a\{+2\}$ \\
\hline SELTZER & Seltzer & THETAG & $|q| g$ \\
\hline SEPTEMBER & September & THETAP $1 * * 2$ & $\mid q\{-p 1\}\{+2\}$ \\
\hline SF & $\mathrm{SF}$ & THETAP $2 * * 2$ & $\mid q\{-p 2\}\{+2\}$ \\
\hline $\operatorname{SI}(L I)$ & $\mathrm{Si}(\mathrm{L} i)$ & TI & $I(\mid g+c \theta)$ \\
\hline SIGMA & Is & TOF & tof \\
\hline SIGMA (0) & $\mid s\{-0\}$ & TPAD & TPAD \\
\hline SIGMA *DE & $|s| * \mid D E$ & TRISTAN & TRISTAN \\
\hline SIGMAG & $\mid s\{-\mid g\}$ & TRIUMPH & TRIUMPH \\
\hline SIGMAN & $\mid s\{-n\}$ & $\mathrm{Ti}$ & $\mathrm{Ti}$ \\
\hline SIGMANO & $|s| n$ & U & $\mathrm{U}$ \\
\hline SIGNA & $\mid s(n \mid a)$ & $\mathrm{U} 2 \mathrm{~A} 2$ & $U\{-2\} A\{-2\}$ \\
\hline SIGNG & $\mid s(n \mid g)$ & UB & $\mathrm{Imb}$ \\
\hline SILI & $\operatorname{Si}\left(L_{i}\right)$ & $\mathrm{UB} * \mathrm{MEV}$ & $|\mathrm{mb}| * \mathrm{MeV}$ \\
\hline SID & Sio & $\mathrm{UB} / \mathrm{SR}$ & $\mathrm{mb} / \mathrm{sr}$ \\
\hline SLIV-BAND & Sliv-Band & UG & lmg \\
\hline SN & $S(n)$ & UG/CM & $\mathrm{mg} / \mathrm{cm}$ \\
\hline SOREQ & SOREQ & UK & UK \\
\hline $\mathrm{SP}$ & $s(p)$ & UNISOR & UNISOR \\
\hline STEFFEN & Steffen & UNIV & Univ \\
\hline STOCKHOLM & Stockholm & UNIVERSITY & University \\
\hline SUMOF & $|s|$ & US & Ims \\
\hline SY & syst & USA & USA \\
\hline $\mathrm{Sn}$ & $\mathrm{Sn}$ & USSR & USSR \\
\hline $\mathbf{T}$ & $T\{-1 / 2\}$ & $\mathrm{v}$ & v \\
\hline T) & t) & VAP & VAP \\
\hline$T$, & $t$, & พ & W \\
\hline $\mathrm{T} /$ & $\mathrm{T} /$ & W $($ THETA $) * G$ & DTH $\bar{v}(\mid q) g \mid G\{-\mid g 0\}$ \\
\hline $\mathrm{T} 1 / 2$ & $T\{-1 / 2\}$ & พ.บ. & ท.น. \\
\hline T20 & T20 & WEISSKOPF & Weisskopf \\
\hline T21 & $\mathrm{T} 21$ & WIDTH & IG \\
\hline T22 & T22 & WIDTH**2 & $\mid G\{+2\}$ \\
\hline TAU & lt & WIDTHA & $|G| a$ \\
\hline TDPAD & TDPAD & WIDTHAO & $\mid G\{-\mid a 0\}$ \\
\hline TELLER & Teller & WIDTHA1 & $\mid G\{-\mid a 1\}$ \\
\hline TEMP & $T$ & WIDTHA2 & $\mid G\{-\mid a 2\}$ \\
\hline TG & $t \lg$ & WIDTHA3 & $\mid G\{-\mid a 3\}$ \\
\hline TH & th & WIDTHA4 & $\mid G\{-\mid a 4\}$ \\
\hline THETA & $\mathrm{Iq}$ & WIDTHG & $\mid G\{-\mid g\}$ \\
\hline THETA**2 & $\mid q\{+2\}$ & WIDTHGO & $\mid G\{-\mid g 0\}$ \\
\hline THETA1 & $\operatorname{lq}\{-1\}$ & WIDTHGO $* * 2$ & $\mid G\{+2\} \backslash\{-\mid g 0\}$ \\
\hline
\end{tabular}




\begin{tabular}{|c|c|c|c|}
\hline ENSDF & TRANSLATIDN & ENSDF & TRANSLATION \\
\hline WIDTHG1 & $\mid G\{-\mid g 1\}$ & XLB15 & $L|b\{-15\}| x$ ray \\
\hline WIDTHN & $G\{-n\}$ & XLB2 & $L|b\{-2\}| \times$ ray \\
\hline WIDTHNO & $\mid G\{-n O\}$ & XLB215 & $\mathrm{L}|\mathrm{b}\{-215\}| \mathrm{x}$ ray \\
\hline WIDTHP & $\mid G\{-p\}$ & XLB3 & $L|b\{-3\}| x$ ray \\
\hline WIDTHP & $\mid G\left\{-p^{\prime}\right\}$ & XIBA & $L|b\{-4\}| x$ ray \\
\hline WIDTHPO & $\mid G\{-\mathrm{p} 0\}$ & XLB5 & $L|b\{-5\}| x$ ray \\
\hline WIDTHP1 & $\mid G\{-p 1\}$ & XLB6 & $L|b\{-6\}| x$ ray \\
\hline WIDTHP2 & $\mid G\{-\mathrm{p} 2\}$ & XLB9 & $L|b\{-9\}| x$ ray \\
\hline WIGNER & Higner & XLC & $L\{-\mid c\} \times$ ray \\
\hline HINTHER & Winther & ILG & $L\{-\mid g\} x$ ray \\
\hline $\mathrm{XC}$ & $\mathrm{XC}$ & XLG1 & $\operatorname{L}|g\{-1\}| x$ ray \\
\hline $\mathrm{X}-\mathrm{RAY}$ & $x$-ray & $\mathrm{XLG2}$ & $\operatorname{Llg}\{-2\} \mid \times$ ray \\
\hline X-RAYS & $x$-rays & XLG3 & $\operatorname{Llg}\{-3\} \mid x$ ray \\
\hline$X G$ & $X / g$ & $\mathrm{XLG4}$ & $\operatorname{Llg}\{-4\} \mid x$ ray \\
\hline $\mathrm{XK}$ & $\mathrm{KI} \times$ ray & XLG5 & L $|g\{-5\}| x$ ray \\
\hline $\mathrm{XKA}$ & $\mathrm{K}|\mathrm{a}| \mathrm{x}$ ray & XLG6 & $L|g\{-6\}| \times$ ray \\
\hline XKA1 & $\mathrm{K}|\mathrm{a}\{-1\}| \mathrm{x}$ ray & $X L L$ & $L\left\{-\left\{S_{1}\right\}\right\} \times$ ray \\
\hline $\mathrm{XKA2}$ & $\mathrm{K}|\mathrm{a}\{-2\}| \mathrm{x}$ ray & $\mathbf{X M}$ & $M \times$ ray \\
\hline $\mathrm{XKB}$ & $\mathrm{K}|\mathrm{b}| \mathrm{x}$ ray & XPYNG & xpynlg \\
\hline XKB1 & $K \mid b\{-1\} \times$ ray & $X X$ & $\mathrm{xx}$ \\
\hline XKB13 & $K / b\{-13\} x$ ray & YTTRIUM & $\mathrm{Y}$ \\
\hline XKB1P & $\mathrm{K}|\mathrm{b}\{-1\}|$,$x ray$ & $\mathbf{Z}:$ & $\mathbf{z}$ \\
\hline XKB2 & $\mathrm{K} \mid \mathrm{b}\{-2\} \times$ ray & $\mathbf{Z}>\mathbb{N}$ & $\mathrm{Z}>\mathbb{N}$ \\
\hline XKB2P & $\mathrm{K}|\mathrm{b}\{-2\}|$,$x ray$ & [E2] & [E2] \\
\hline XKB3 & $K / b\{-3\} \times$ ray & [RI. & {$[I / g$} \\
\hline XKB4 & $\mathrm{K} / \mathrm{b}\{-4\} \times$ ray & ao & $a\{-0\}$ \\
\hline XKB5 & $K \mid b\{-5\} \times$ ray & ID & ID \\
\hline XKB5I & $\mathrm{K} \mid \mathrm{b}\{-5\} \backslash\{+I\} \times$ ray & & \\
\hline XKB5II & $\mathrm{K} / \mathrm{b}\{-5\} \backslash\{+I I\} \times$ ray & & \\
\hline XKG & $(K \mid x$ ray $) \mid g$ & & \\
\hline $\mathrm{XKO2}$ & $K-0\{-2\} \times$ ray & & \\
\hline XK023 & $\mathrm{K}-0\{-23\} \times$ ray & & \\
\hline XKO3 & $\mathrm{K}-0\{-3\} \times$ ray & & \\
\hline $\mathrm{XL}$ & LI $x$ ray & & \\
\hline $\mathrm{XL1}$ & $L\{-1\} \times$ ray & & \\
\hline XL2 & $L\{-2\} x$ ray & & \\
\hline XI3 & $L\{-3\} \times$ ray & & \\
\hline XLA & $L\{-\mid a\} \times$ ray & & \\
\hline XLA1 & $L|a\{-1\}| x$ ray & & \\
\hline XLA2 & $L|a\{-2\}| \times$ ray & & \\
\hline XIB & $L\{-\mid b\} \times$ ray & & \\
\hline XLB1 & L $|b\{-1\}| x$ ray & & \\
\hline XLB10 & $L|b\{-10\}| x$ ray & & \\
\hline
\end{tabular}


Appendix G

ENSDF Dictionary - ordered by output 


\section{ENSDF Dictionary - ordered by output}

\begin{tabular}{|c|c|c|c|}
\hline Translation & ENSDF & Translation & ENSDF \\
\hline$(\alpha)(c e)$ & $\mathrm{ACE}$ & $B(E 0)$ & BE0 \\
\hline$(\beta)$ & (B) & $B(E 0)(W$. u. $)$ & BEOW \\
\hline$(\theta, \mathrm{H}, \mathrm{t}, \mathrm{T})$ & (THETA,H,T,T) & $\mathrm{B}(\mathrm{E} 1$ & $\mathrm{B}(\mathrm{E} 1$ \\
\hline$(\theta, \mathrm{H})$ & $($ THETA,H) & $B(E 1)(W . u)$. & BE $1 W$ \\
\hline$(\theta, \mathrm{T}, \mathrm{H})$ & (THETA,T,H) & $\mathrm{B}(\mathrm{E} 1) \uparrow$ & BE1UP \\
\hline $2 J$ & $2 \mathrm{~J}$ & $B(E 1)$ & $\mathrm{BE} 1$ \\
\hline $2 \mathrm{~N} \sigma$ & $2 N * S I G M A$ & $\mathrm{~B}(\mathrm{E} 2$ & $\mathrm{B}(\mathrm{E} 2$ \\
\hline $2^{5} \mathrm{mom}$ (mag) & MOMM5 & $\mathrm{B}(\mathrm{E} 2)$ & $\mathrm{BE} 2$ \\
\hline $2^{7} \mathrm{mom}(\mathrm{mag})$ & MOMM7 & $\mathrm{B}(\mathrm{E} 2) \uparrow$ & BE2UP \\
\hline $2 \beta^{-}$ & $2 \mathrm{~B}-$ & $\mathrm{B}(\mathrm{E} 2) \downarrow$ & BE2DWN \\
\hline $4 \pi$ & $4 P I$ & $\mathrm{~B}(\mathrm{E} 2)(\mathrm{W} . \mathrm{u})$. & $\mathrm{BE} 2 \mathrm{~W}$ \\
\hline $4 \pi \beta \gamma$ & 4PIBG & $\mathrm{B}(\mathrm{E} 3$ & $\mathrm{B}(\mathrm{E} 3$ \\
\hline $4 \pi \beta$ & $4 \mathrm{PIB}$ & $\mathrm{B}(\mathrm{E} 3) \uparrow$ & BE3UP \\
\hline $4 \pi \gamma$ & $4 \mathrm{PIG}$ & $\mathrm{B}(\mathrm{E} 3)(\mathrm{W} . \mathrm{u}.) \uparrow$ & BE3WUP \\
\hline$<$ & $\mathrm{LT}$ & $\mathrm{B}(\mathrm{E} 3)$ & BE3 \\
\hline$>$ & GT & $\mathrm{B}(\mathrm{E} 3)(\mathrm{W} . \mathrm{u})$ & BE3W \\
\hline$A(\theta)$ & A(THETA) & $\mathrm{B}(\mathrm{E} 4$ & $\mathrm{B}(\mathrm{E} 4$ \\
\hline$A-N$ & $A-N$ & $\mathrm{~B}(\mathrm{E} 4) \uparrow$ & BE4UP \\
\hline$A=$ & $A=$ & $\mathrm{B}(\mathrm{E} 4)(\mathrm{W} . \mathrm{u})$. & $\mathrm{BE} 4 \mathrm{~W}$ \\
\hline AA.S & AAS & $\mathrm{B}(\mathrm{E} 4)$ & BE4 \\
\hline $\mathrm{AB}$ & $\mathrm{AB}$ & $B(E 5)$ & BE 5 \\
\hline AJ & AJ & B(E5)(W.u.) & BE5W \\
\hline $\mathrm{Aa}_{0}$ & $\mathrm{AAO}$ & $\mathrm{B}(\mathrm{E} 6)(\mathrm{W} . \mathrm{u})$. & $\mathrm{BE} 6 \mathrm{~W}$ \\
\hline Alaga & ALAGA & $B(E 6) \uparrow$ & BE6UP \\
\hline April & APRIL & $B(E 6)$ & BE 6 \\
\hline Auger & AUGER & $B(E 7)(W . u)$. & BE7W \\
\hline August & AUGUST & $\mathrm{B}(\mathrm{E} 7)$ & BE7 \\
\hline $\mathrm{Ay}$ & $\mathrm{AY}$ & $B(E 8)$ & BE 8 \\
\hline$A^{1 / 3}$ & $A * * 1 / 3$ & $B(E L)\left(W . u_{.}\right)$ & BELW \\
\hline$A^{2 / 3}$ & $A^{* * 2 / 3}$ & $B(E L)$ & BEL \\
\hline $\mathrm{A}_{0}$ & AO & $\mathbf{B}(\mathbf{J}$ & $\mathrm{B}(\mathrm{J}$ \\
\hline$A_{11}$ & A11 & $\mathrm{B}(\mathrm{M} 1)$ & BM1 \\
\hline$A_{1}$ & A1 & $\mathrm{B}(\mathrm{M} 1) \uparrow$ & BM1UP \\
\hline$A_{22}$ & A22 & $B(M 1)(W . u)$. & BM1W \\
\hline $\mathrm{A}_{2} / \mathrm{A}_{0}$ & $\mathrm{~A} 2 / \mathrm{A} 0$ & $\mathrm{~B}(\mathrm{M} 2)$ & $\mathrm{BM} 2$ \\
\hline$A_{2}$ & A2 & $\mathrm{B}(\mathrm{M} 2) \uparrow$ & BM2UP \\
\hline $\mathrm{A}_{2} \mathbb{P}_{2}$ & $\mathrm{~A} 2 \mathrm{P2}$ & B(M2)(W.u.) & BM2W \\
\hline$A_{3}$ & A3 & $B(M 3)(W . u)$. & BM3W \\
\hline $\mathrm{A}_{44}$ & $\mathrm{~A} 44$ & $\mathrm{~B}(\mathrm{M} 3)$ & BM3 \\
\hline $\mathrm{A}_{4}$ & A4 & $\mathrm{B}(\mathrm{M} 4)$ & BM4 \\
\hline$A_{5}$ & A5 & $\mathrm{B}(\mathrm{M} 4)(\mathrm{W} . \mathrm{u})$. & $\mathrm{BM} 4 \mathrm{~W}$ \\
\hline$A_{6}$ & A6 & $B(M 5)(W . u)$. & BM5W \\
\hline $\mathrm{A}_{7}$ & $\mathrm{~A} 7$ & $\mathrm{~B}(\mathrm{M} 8) \uparrow$ & BM8UP \\
\hline $\mathrm{B}(\mathrm{E} 0$ & $\mathrm{B}(\mathrm{E} 0$ & $\mathrm{B}(\mathrm{ML})$ & BML \\
\hline
\end{tabular}


ENSDF Dictionary - ordered by output

\begin{tabular}{|c|c|c|c|c|}
\hline Translation & & ENSDF & Translation & ENSDF \\
\hline$B(M L)(W . u)$. & & BMLW & $\mathrm{DCO}$ & $\mathrm{DCO}$ \\
\hline $\mathrm{B} / \mathrm{A}$ & & $\mathrm{B} / \mathrm{A}$ & $\mathrm{DCOQ}$ & $\mathrm{DCOQ}$ \\
\hline$B=$ & & $\mathrm{B}=$ & DPAC & DPAC \\
\hline $\mathrm{BCS}$ & & $\mathrm{BCS}$ & DPAD & DPAD \\
\hline $\mathrm{BE}(\mathrm{L})$ & & $\mathrm{BE}(\mathrm{L})$ & DSA & DSA \\
\hline $\mathrm{BF}_{3}$ & & BF 3 & DSAM & DSAM \\
\hline $\mathrm{BGO}$ & & BGO & DWBA & DWBA \\
\hline $\mathrm{BJ}^{2}$ & & $\mathrm{BJ} * * 2$ & DWIA & DWIA \\
\hline $\mathrm{BM}(\mathrm{L})$ & & $\mathrm{BM}(\mathrm{L})$ & DWUCK & DWUCK \\
\hline $\mathrm{Be}$ & & $\mathrm{Be}$ & Davydov & DAVYDOV \\
\hline Berkeley & & BERKELEY & December & DECEMBER \\
\hline Bessel & & BESSEL & Doppler & DOPPLER \\
\hline Bethe & & BETHE & Dubna & DUBNA \\
\hline Biedenharn & & BIEDENHARN & $\mathbf{E}$ & $\mathbf{E}$ \\
\hline Blair & & BLAIR & $E(c e)$ & $\mathrm{ECE}$ \\
\hline Bohr & & BOHR & $E(d)$ & ED \\
\hline Born & & BORN & $E(d)$ & $\mathbf{E}(\mathrm{D})$ \\
\hline Branching & . & BR & $\mathbf{E}(\mathbf{e})$ & $\mathbf{E}(\mathbf{E})$ \\
\hline Breit & & BREIT & $E(\mathbf{n})$ & $E(N)$ \\
\hline Brink & & BRINK & $E(\mathbf{n})$ & EN \\
\hline $\mathrm{B}_{4} \mathrm{C}$ & & $\mathrm{B} 4 \mathrm{C}$ & $E(p)$ & EP \\
\hline $\mathrm{B} \times p$ & & $\mathrm{~B} * \mathrm{RHO}$ & $\mathrm{E}(\mathrm{p})$ & $\mathbf{E}(\mathbf{P})$ \\
\hline C & & $\mathrm{C}$ & $E\left(\mathrm{p}_{2}\right)$ & $E(P 2)$ \\
\hline CCBA & & CCBA & $E\left(p_{1}\right)$ & $E(P 1)$ \\
\hline $\mathrm{CCC}$ & & $\mathrm{CCC}$ & $E(t)$ & $\mathrm{ET}$ \\
\hline CERN & & CERN & $E(t)$ & $\mathbf{E}(\mathrm{T})$ \\
\hline $\mathrm{CP}$ & $\cdot$ & $\mathrm{CP}$ & $E(\alpha)$ & $\mathbf{E}(\mathbf{A})$ \\
\hline CRC & $\cdot$ & $\mathrm{CRC}$ & $\mathrm{E}-\mathrm{E}$ & $E-E$ \\
\hline $\mathrm{Ca}(\mathrm{OH})$ & & $\mathrm{CA}(\mathrm{OH})$ & $\mathrm{E} / \Delta \mathrm{E}$ & $\mathrm{E} / \mathrm{DE}$ \\
\hline Cerenkov & & CERENKOV & EO & E0 \\
\hline Clebsch & & CLEBSCH & E1 & $\mathrm{E} 1$ \\
\hline $\mathrm{Cm}$ & & $\mathrm{Cm}$ & E10 & E10 \\
\hline $\mathrm{Co}$ & & $\mathrm{CO}$ & E2 & E2 \\
\hline Compton & .. & COMPTON & E3 & E3 \\
\hline Coriolis & & CORIOLIS & E4 & E4 \\
\hline Coster & & COSTER & E5 & E5 \\
\hline Coul & & COUL & E6 & E6 \\
\hline Coulomb & & COULOMB & E7 & E7 \\
\hline CsI & & CSI & E8 & E8 \\
\hline Curie & & CURIE & E9 & E9 \\
\hline$C^{2} S$ & & $\mathrm{C} 2 \mathrm{~S}$ & EL & $\mathrm{EL}$ \\
\hline D) & & D) & ENDF/B-V & ENDF/B-V \\
\hline$D+(Q)$ & & $D+(Q)$ & ENDF/B & ENDF/B_ \\
\hline$D+Q$ & & $\mathrm{D}+\mathrm{Q}$ & ENDOR & ENDOR \\
\hline
\end{tabular}


ENSDF Dictionary - ordered by output

\begin{tabular}{|c|c|c|c|}
\hline Translation & ENSDF & Translation & ENSDF \\
\hline EPR & EPR & $\mathrm{H}$, & $\mathrm{H}$, \\
\hline ESR & ESR & $\mathrm{H}=$ & $\mathrm{H}=$ \\
\hline EWSR & EWSR & HERA & HERA \\
\hline Ee & $\mathbf{E E}$ & HF & $\mathrm{HF}$. \\
\hline Enge & ENGE & $\mathrm{HI}$ & HI \\
\hline $\mathbf{E}$ & $\mathbf{E}$ & $\mathrm{HP}$ & HP \\
\hline$E^{1 / 2}$ & $\mathrm{E}^{* * 1 / 2}$ & HPGE & HPGE \\
\hline $\mathrm{E}^{2}$ & $\mathrm{E}^{* * 2} 2$ & Hager & HAGER \\
\hline $\mathrm{E} \Delta \mathrm{E}$ & EDE & Hartree & HARTREE \\
\hline $\mathrm{E} \alpha$ & $\mathrm{EA}$ & Hauser & HAUSER \\
\hline $\mathbb{E} \beta$ & $\mathrm{EB}$ & I & I \\
\hline$E \beta$ & $\mathrm{EB}_{-}$ & $I(x$ ray $)$ & IX \\
\hline $\mathbf{E} \beta^{-}$ & $\mathrm{EB}-$ & $\mathrm{I}(\gamma+\mathrm{ce})$ & $\mathrm{TI}$ \\
\hline $\mathrm{E} \varepsilon$ & EEC & $I(\gamma+c e)$ normalization & NT \\
\hline $\mathbf{E} \gamma$ & $* \mathbf{E G}$ & IAR & IAR \\
\hline $\mathbf{E} \gamma$ & EG & IAS & IAS \\
\hline$E \gamma^{3}$ & $\mathrm{EG} * * 3$ & IBA & IBA \\
\hline $\mathrm{E} \gamma^{5}$ & $\mathbf{E G * * 5}$ & IBM & IBM \\
\hline$F+B$ & $F+B$ & IBS & IBS \\
\hline $\mathrm{F}-\mathrm{K}$ & $\mathrm{F}-\mathrm{K}$ & IGISOL & IGISOL \\
\hline $\mathrm{F} / \mathrm{B}$ & $\mathrm{F} / \mathrm{B}$ & IMPAC & IMPAC \\
\hline FWHM & FWHM & IPAC & IPAC \\
\hline February & FEBRUARY & ISOLDE & ISOLDE \\
\hline Fermi & FERMI & IT branching & IT BRANCHING \\
\hline Feshbach & FESHBACH & IT decay & IT DECAY \\
\hline Fock & FOCK & IT decays & IT DECAYS \\
\hline Fourier & FOURIER & $I T=$ & $\mathrm{IT}=$ \\
\hline G-M & $\mathrm{G}-\mathrm{M}$ & Ice & ICE \\
\hline GDR & GDR & $\operatorname{Ice}(\mathrm{K})$ & $\operatorname{ICE}(\mathrm{K})$ \\
\hline GM & GM & $\operatorname{Ice}(N)$ & $\operatorname{ICE}(N)$ \\
\hline GMR & GMR & $\operatorname{In}($ & IN ( \\
\hline GQR & GQR & $I \alpha$ & IA \\
\hline GSI & GSI & $I \beta$ & IB \\
\hline GTOL & GTOL & I $\beta$ normalization & NB \\
\hline Gallagher & GALLAGHER & $I \beta^{-}$ & IB- \\
\hline Gamow & GAMOW & $I \beta^{+}$ & $\mathrm{IB}+$ \\
\hline Garvey & GARVEY & $\mathrm{I} \varepsilon$ & $\mathrm{IE}$ \\
\hline Gaussian & GAUSSIAN & $\mathrm{I} \varepsilon$ & IEC \\
\hline $\mathrm{Ge}(\mathrm{Li})$ & $\mathrm{GE}(\mathrm{LI})$ & $\mathrm{I} \gamma$ & IG \\
\hline $\mathrm{Ge}(\mathrm{Li})$ & GELI & I $\gamma$ & $*$ RI \\
\hline $\mathrm{GeV}$ & GEV & $\mathrm{I} \gamma$ & $\mathrm{RI}$ \\
\hline Geiger-Muller & GEIGER-MULLER & 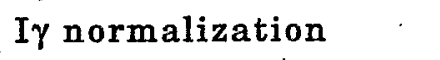 & NR \\
\hline Geiger & GEIGER & $\mathrm{I} \gamma \mathrm{E} \gamma$ & $\mathrm{IG} * \mathrm{EG}$ \\
\hline $\mathrm{H}($ & $\mathrm{H}($ & $J$ & $\mathrm{~J}$ \\
\hline
\end{tabular}




\section{ENSDF Dictionary - ordered by output}

\begin{tabular}{|c|c|c|c|}
\hline Translation & ENSDF & Translation & ENSDF \\
\hline$J K \pi$ & JKP & Kelvin & KEVIN \\
\hline JOSEF & JOSEF & Knight & KNIGHT \\
\hline JULIE & JULIE & Krane & KRANE \\
\hline January & JANUARY & Kronig & KRONIG \\
\hline$J \max$ & JMAX & Kuo-Brown & KUO-BROWN \\
\hline$J \min$ & JMIN & Kurie & KURIE \\
\hline July & JULY & $\mathrm{KX}$ ray & XK \\
\hline June & JUNE & $\mathrm{K} \alpha_{2} \times$ ray & XKA2 \\
\hline $\mathrm{J}^{2}$ & $\mathrm{~J} * * 2$ & $\mathrm{~K} \alpha_{1} \times \mathrm{ray}$ & $\mathrm{XKA1}$ \\
\hline $\mathrm{J}_{0}$ & Jo & $\mathrm{K} \alpha \mathrm{x}$ ray & XKA \\
\hline$J_{1}$ & J1 & $\mathrm{K} \beta_{2}^{\prime} \times$ ray & XKB2 \\
\hline $\mathrm{J}_{2}$ & J2 & $\mathrm{K} \beta_{2}^{\prime}$ x ray & XKB2P \\
\hline$J_{f}$ & JF & $\mathrm{K} \beta_{4} \times \mathrm{ray}$ & XKB4 \\
\hline $\mathrm{J}_{\mathrm{i}}$ & JI & $\mathrm{K} \beta_{3} \times$ ray & XKB3 \\
\hline$J \pi$ & JPI & $\mathrm{K} \beta_{1} \times$ ray & XKB1 \\
\hline $\mathbf{K}$ & $\mathbf{K}$ & $\mathrm{K} \beta_{1}^{\prime} \times$ ray & XKB1P \\
\hline $\mathrm{K}-\mathrm{O}_{2} \times$ ray & $\mathrm{XKO} 2$ & $K \beta_{5}^{I} x$ & XKB5I \\
\hline $\mathrm{K}-\mathrm{O}_{3}$ x ray & XKO3 & $K \beta_{5}^{I I} x$ & XKB5II \\
\hline $\mathrm{K}-\mathrm{O}_{23} \times$ ray & $\mathrm{XKO} 23$ & $\mathrm{~K} \beta_{13} \times$ ray & XKB13 \\
\hline $\mathrm{K} / \mathrm{L}+\mathrm{M}$ & $\mathrm{K} / \mathrm{L}+\mathrm{M}$ & $\mathrm{K} \beta_{5} \mathrm{x}$ ray & XKB5 \\
\hline $\mathrm{K} / \mathrm{LM}$ & $\mathrm{K} / \mathrm{LM}$ & $\mathrm{K} \beta \mathrm{x}$ ray & $\mathrm{XKB}$ \\
\hline KLL & KLL & $\mathbf{K} \boldsymbol{\pi}$ & KPI \\
\hline $\mathrm{KLM}$ & KLM & $\mathbf{L}$ & $\mathrm{L}$ \\
\hline $\mathrm{KL}_{1} \mathrm{~L}_{1}$ & $\mathrm{KL} 1 \mathrm{~L} 1$ & $L(n)$ & $\mathrm{LN}$ \\
\hline $\mathrm{KL}_{1} \mathrm{M}_{2}$ & KL1M2 & $L(p)$ & LP \\
\hline $\mathrm{KL}_{1} \mathrm{~L}_{3}$ & KL1L3 & L1 & L1 \\
\hline $\mathrm{KL}_{1} \mathrm{M}_{3}$ & KL $1 \mathrm{M} 3$ & $\mathrm{~L} 12$ & $\mathrm{~L} 12$ \\
\hline $\mathrm{KL}_{1} \mathrm{M}_{1}$ & $\mathrm{KL} 1 \mathrm{M} 1$ & L2 & L2 \\
\hline $\mathrm{KL}_{1} \mathrm{~L}_{2}$ & KL1L2 & L23 & $\mathrm{L} 23$ \\
\hline $\mathrm{KL}_{2} \mathrm{M}_{1}$ & $\mathrm{KL} 2 \mathrm{M} 1$ & L3 & L3 \\
\hline $\mathrm{KL}_{2} \mathrm{~L}_{2}$ & KL2L2 & LAMPF & LAMPF \\
\hline $\mathrm{KL}_{2} \mathrm{~L}_{3}$ & KL2L3 & LASER & LASER \\
\hline $\mathrm{KL}_{2} \mathrm{M}_{3}$ & KL2M3 & LBL & LBL \\
\hline $\mathrm{KL}_{2} \mathrm{M}_{4}$ & KL 2M4 & LM: & $\mathbf{L M}$ \\
\hline $\mathrm{KL}_{3} \mathrm{~L}_{3}$ & KL3L3 & LMN & LMN \\
\hline $\mathrm{KL}_{3} \mathrm{LM}_{1}$ & KL3LM1 & LOHENGRIN & LOHENGRIN \\
\hline $\mathrm{KL}_{3} \mathrm{~N}$ & KL3N & Larmor & LARMOR \\
\hline $\mathrm{KL}_{3} \mathrm{M}_{3}$ & KL3M3 & Legendre & LEGENDRE \\
\hline $\mathrm{KL}_{3} \mathrm{M}_{2}$ & KL3M2 & $\mathrm{Li}$ & $\mathbf{L I}$ \\
\hline $\mathrm{KM}_{2} \mathrm{M}_{3}$ & KM2M3 & Litherland & LITHERLAND \\
\hline $\mathrm{KM}_{2} \mathrm{~N}_{2}$ & KM2N2 & Lorentzian & LORENTZIAN \\
\hline $\mathrm{KM}_{3} \mathrm{M}_{3}$ & KM3M3 & $L_{1} \times$ ray & XL1 \\
\hline $\mathrm{KXY}$ & $\mathrm{KXY}$ & $\mathrm{L}_{2} \times$ ray & $\mathrm{XL2}$ \\
\hline Kelson & KELSON & $\mathrm{L}_{3} \times$ ray & XL3 \\
\hline
\end{tabular}


ENSDF Dictionary - ordered by output

\begin{tabular}{|c|c|c|c|}
\hline Translation & ENSDF & Translation & ENSDF \\
\hline $\mathrm{L}_{1} \times$ ray & XLL & MIT & $\mathrm{MIT}$ \\
\hline$L_{\alpha} \times$ ray & XLA & March & MARCH \\
\hline$L_{\beta} \times$ ray & XLB & $\mathrm{MeV}$ & $\mathrm{MEV}$ \\
\hline$L_{\eta} \times$ ray & $\mathrm{XLC}$ & $\mathrm{MeV}^{-4}$ & $\mathrm{MEV}^{* *}-4$ \\
\hline $\mathrm{L}_{\gamma} \mathrm{x}$ ray & $\mathrm{XLG}$ & Mossbauer & MOSSBAUER \\
\hline Lx ray & $\mathrm{XL}$ & Moszkowski & MOSZKOWSKI \\
\hline $\mathrm{L} \alpha_{1} \times$ ray & XLA1 & $\mathrm{N}-\mathrm{Z}$ & $\mathrm{N}-\mathrm{Z}$ \\
\hline $\mathrm{L} \alpha_{2} \times$ ray & XLA2 & N-shell & N-SHELL \\
\hline $\mathrm{L} \beta_{3} \times$ ray & XLB3 & N-subshell & N-SUBSHELL \\
\hline $\mathrm{L} \beta_{4} \times$ ray & XLB 4 & $\mathrm{~N} 1$ & N1 \\
\hline $\mathrm{L} \beta_{1} \times$ ray & XLB 1 & N12 & $\mathrm{N} 12$ \\
\hline $\mathrm{L} \beta_{5} \times$ ray & XLB5 & N123 & N123 \\
\hline$L \beta_{2} \times$ ray & XLB2 & $\mathrm{N} 2$ & N2 \\
\hline $\mathrm{L} \beta_{215} \times \mathrm{ra}$ & XLB215 & N23 & $\mathrm{N} 23$ \\
\hline$L \beta_{9} \times$ ray & XLB9 & N3 & N3 \\
\hline$L \beta_{15} \times$ ray & XLB15 & $\mathrm{N} 4$ & N4 \\
\hline $\mathrm{L} \beta_{6} \times$ ray & XLB6 & $\mathrm{N} 45$ & N45 \\
\hline $\mathrm{L} \beta_{10} \times \mathrm{ray}$ & XLB10 & N5 & N5 \\
\hline $\mathrm{L} \gamma_{3} \times$ ray & XLG3 & $\mathrm{N}<$ & $\mathrm{N}<$ \\
\hline $\mathrm{L} \gamma_{4} \times$ ray & $\mathrm{XLG} 4$ & $N=$ & $N=$ \\
\hline $\mathrm{L} \gamma_{6} \mathrm{x}$ ray & XLG6 & NBS & NBS \\
\hline $\mathrm{L} \gamma_{5} \times$ ray & XLG5 & $\mathrm{NC}^{2} \mathrm{~S}$ & NC2S \\
\hline$L \gamma_{2} \times$ ray & XLG2 & NE213 & NE213 \\
\hline $\mathrm{L} \gamma_{1} \times$ ray & XLG1 & NMR & NMR \\
\hline $\mathbf{M}$ & $\mathbf{M}$ & NQR & NQR \\
\hline M x ray & $\mathrm{XM}$ & $\mathrm{NS} \sigma$ & NS*SIGMA \\
\hline $\mathbf{M}+=$ & $M+=$ & $\mathrm{NX}$ & $\mathrm{NX}$ \\
\hline $\mathrm{M}+\mathrm{L}$ & ML & $\mathrm{NaI}$ & NAI \\
\hline $\mathrm{M}+\mathrm{N}+\mathrm{O}$ & MNO & $\mathrm{Ne}$ & $\mathrm{Ne}$ \\
\hline M-shell & M-SHELL & Nilsson & NILSSON \\
\hline M-subshell & M-SUBSHELL & Note: & NOTE: \\
\hline M/total ce & $\mathrm{M} / \mathrm{CE}$ & November & NOVEMBER \\
\hline Mi & M1 & Nuclear Data Sheets & NDS \\
\hline M12 & M12 & $N \times \sigma$ & $N^{*}$ SIGMA \\
\hline M2 & M2 & 0 & $\mathrm{O}$ \\
\hline M23 & M23 & $\mathrm{O} / \mathrm{Q}$ & $\mathrm{O} / \mathrm{Q}$ \\
\hline M3 & M3 & 01 & $\mathrm{O} 1$ \\
\hline M4 & M4 & 0123 & 0123 \\
\hline M45 & M45 & 02 & $\mathrm{O} 2$ \\
\hline M5 & M5 & 03 & O3 \\
\hline M6 & M6 & ORNL & ORNL \\
\hline M8 & M8 & OSIRIS & OSIRIS \\
\hline MIEDLIST & MEDLIST & October & OCTOBER \\
\hline $\mathrm{M}] \mathrm{HZ}$ & MHZ & Octupole mom(mag) & MOMM3 \\
\hline
\end{tabular}


ENSDF Dictionary - ordered by output

\begin{tabular}{|c|c|c|c|}
\hline Translation & ENSDF & Translation & ENSDF \\
\hline Octupole $\operatorname{mom}(\mathrm{el})$ & MOME3 & $S(2 p)$ & $\mathrm{S}(2 \mathrm{P})$ \\
\hline $\mathrm{P} 1$ & $P 1$ & $S(n)$ & SN \\
\hline PAC & PAC & $S(p)$ & $\mathbf{S P}$ \\
\hline PAD & PAD & $S(\alpha)$ & $\mathrm{SA}$ \\
\hline PWBA & PWBA & S-factors & S-FACTORS \\
\hline PWIA & PWIA & S-factor & S-FACTOR \\
\hline Particle normalization & NP & S-value & S-VALUE \\
\hline$P_{0}$ & Po & S-values & S-VALUES \\
\hline$P_{n}$ & PN & $\mathbf{S} /$ & S/ \\
\hline$Q^{\mathrm{n}}$ & MOME2 & $S=$ & $S=$ \\
\hline $\mathrm{Q}$ & Q & $S D$ & $S D$ \\
\hline Q( & $Q($ & $\mathrm{SDB}$ & SDB \\
\hline$Q(g . s)$. & QP & $\mathrm{SF}$ & $\mathrm{SF}$ \\
\hline$Q(\alpha)$ & QA & SOREQ & SOREQ \\
\hline$Q\left(\beta^{-}\right)$ & Q- & Saxon & SAXON \\
\hline$Q(\varepsilon)$ & $\mathrm{Q+}+$ & Schmidt & SCHMIDT \\
\hline $\mathrm{Q}+\mathrm{O}$ & $Q+O$ & $\operatorname{Se}(\mathrm{Li})$ & $\mathrm{SE}(\mathrm{LI})$ \\
\hline Q/D & $\mathrm{Q} / \mathrm{D}$ & Seltzer. & SELTZER \\
\hline Q2D & $\mathrm{Q} 2 \mathrm{D}$ & September & SEPTEMBER \\
\hline Q2DM & Q2DM & $\mathrm{Si}\left(\mathrm{Li}_{\mathrm{i}}\right)$ & $\mathrm{SI}(\mathrm{LI})$ \\
\hline Q3D & Q3D & $\mathrm{Si}(\mathrm{Li})$ & SILI \\
\hline QDD & QDD & $\mathrm{SiO}$ & SIO \\
\hline QDDM & QDDM & Sliv-Band & SLIV-BAND \\
\hline QDMDQ & QDMDQ & $\mathrm{Sn}$ & Sn \\
\hline QMG & QMG & Steffen & STEFFEN \\
\hline QQSP & QQSP & Stockholm & STOCKHOLM \\
\hline QSD & QSD & $\mathbf{T}$ & TEMP \\
\hline $\mathrm{Q}_{22}$ & Q22 & $\mathbf{T}$ & ISPIN \\
\hline$Q_{\mathrm{s}}$ & QS & $\mathrm{T} /$ & $\mathrm{T} /$ \\
\hline $\mathrm{R}$ & $* \mathrm{R}$ & T20 & $\mathrm{T} 20$ \\
\hline $\mathrm{R}$ & $\mathbf{R}$ & $\mathrm{T} 21$ & $\mathrm{~T} 21$ \\
\hline$R(D C O)$ & $\mathrm{R}(\mathrm{DCO})$ & $\mathrm{T} 22$ & $\mathrm{~T} 22$ \\
\hline RDDS & RDDS & TDPAD & TDPAD \\
\hline RDM & $\mathrm{RDM}$ & TPAD & TPAD \\
\hline RPA & RPA & TRISTAN & TRISTAN \\
\hline RUL & RUL & TRIUMPH & TRIUMPH \\
\hline Ritz & RITZ & Teller & TELLER \\
\hline Rose & ROSE & Ti & $\mathrm{Ti}$ \\
\hline Rutherford & RUTHERFORD & $\mathrm{T}_{1 / 2}$ & $\mathrm{~T} 1 / 2$ \\
\hline Rytz & RYTZ & $\mathrm{T}_{1 / 2}$ & $\mathbf{T}$ \\
\hline S values & S VALUES & $\mathrm{T}_{\mathrm{z}}$ & ISPINZ \\
\hline S value & S VALUE & $\mathrm{U}$ & $\mathrm{U}$ \\
\hline$S^{\prime}$ & $\mathbf{S}^{\prime}$ & UK & UK \\
\hline$S(2 n)$ & $S(2 N)$ & UNISOR & UNISOR \\
\hline
\end{tabular}


ENSDF Dictionary - ordered by output

\begin{tabular}{|c|c|c|c|}
\hline Translation & ENSDF & Translation & ENSDF \\
\hline USA & USA & $\operatorname{ce}(\mathbf{M} 45)$ & CEM45 \\
\hline USSR & USSR & $\operatorname{ce}(\mathrm{M} 4)$ & CEM4 \\
\hline Univ & UNIV & $\operatorname{ce}(\mathrm{M} 5)$ & CEM5 \\
\hline University & UNIVERSITY & $\operatorname{ce}(\mathrm{N}) /(\gamma+\mathrm{ce})$ & $\mathrm{N} / \mathrm{T}$ \\
\hline $\mathrm{U}_{2} \mathrm{~A}_{2}$ & U2A2 & $\operatorname{ce}(\mathrm{N})$ & CEN \\
\hline$v^{2}$ & $\mathrm{~V}$ & $\operatorname{ce}(\mathrm{N}+) /(\gamma+\operatorname{ce})$ & $\mathrm{N}+/ \mathrm{T}$ \\
\hline VAP & VAP & $\operatorname{ce}(\mathrm{N} 1)$ & CEN1 \\
\hline $\mathrm{W}$ & $\mathrm{W}$ & $\operatorname{ce}(\mathrm{N} 2)$ & CEN2 \\
\hline W.u. & W.U. & $\operatorname{ce}(\mathrm{N} 3)$ & CEN3 \\
\hline Weisskopf & WEISSKOPF & $\operatorname{ce}(\mathrm{N} 45)$ & CEN45 \\
\hline Wigner & WIGNER & $\operatorname{ce}(\mathrm{N} 4)$ & CEN4 \\
\hline Winther & WINTHER & $\operatorname{ce}(N 5)$ & CEN5 \\
\hline $\mathrm{X}($ & $\mathrm{X}($ & $\operatorname{ce}(0)$ & CEO \\
\hline $\mathrm{xx}$ & $\mathrm{xx}$ & $\operatorname{ce}(O) /(\gamma+c e)$ & $\odot / \mathrm{T}$ \\
\hline $\mathrm{X} \gamma$ & $\mathrm{XG}$ & $\operatorname{ce}(O)+\operatorname{ce}(P)$ & $\mathrm{CEO}+\mathrm{CEP}$ \\
\hline $\mathrm{Y}$ & YTTRIUM & $\operatorname{ce}(01)$ & $\mathrm{CEO} 1$ \\
\hline Z & $\mathbf{Z}$ & $\operatorname{ce}(\mathrm{P}+) /(\gamma+c e)$ & $\mathrm{P}+/ \mathrm{T}$ \\
\hline $\mathrm{Z}>\mathrm{N}$ & $\mathrm{Z}>\mathrm{N}$ & $\operatorname{ce} \beta$ & CEB \\
\hline$[E 2]$ & [E2] & $\operatorname{ce\gamma }$ & CEG \\
\hline$[\mathrm{I} \gamma$ & {$[\mathrm{RI}$} & $\mathrm{cm}^{2}$ & CM2 \\
\hline - & $\mathrm{DEG}$ & $\mathrm{cm}^{3}$ & CM3 \\
\hline$x$ & $*$ & configuration= & $\mathrm{CONF}=$ \\
\hline av $\mathbf{E} \beta$ & EAV & configuration & CONF \\
\hline$a_{0}$ & $\mathrm{a} 0$ & $\cos ^{2} \theta$ & COS2TH \\
\hline branching uncertainty & $\mathrm{DBR}$ & $\mathrm{dE} / \mathrm{dx}$ & $\mathrm{DE} / \mathrm{DX}$ \\
\hline c.m. & C.M. & $\mathrm{d}^{3} \mathrm{He}$ & $\mathrm{D} 3 \mathrm{HE}$ \\
\hline $\mathrm{ce}$ & $\mathrm{CE}$ & $d \Omega$ & DOMEGA \\
\hline $\operatorname{ce}(\mathrm{K}) /(\gamma+c \mathrm{e})$ & $\mathrm{K} / \mathrm{T}$ & $\mathrm{d} \gamma$ & $\mathrm{DG}$ \\
\hline $\operatorname{ce}(\mathrm{K})$ & CEK & $d \sigma$ & DSIGMA \\
\hline $\operatorname{ce}(L) /(\gamma+\operatorname{ce})$ & $\mathrm{L} / \mathrm{T}$ & $\mathrm{d} \sigma / \mathrm{d} \Omega$ & $\mathrm{DS} / \mathrm{DW}$ \\
\hline $\operatorname{ce}(L)$ & CEL & $\mathrm{d} \sigma / \mathrm{d} \Omega$ & $* \mathrm{DS} / \mathrm{DW}$ \\
\hline $\operatorname{ce}(L+) /(\gamma+c e)$ & $\mathrm{L}+/ \mathrm{T}$ & $e^{\prime}(\theta)$ & E'(THETA) \\
\hline $\operatorname{ce}(\mathrm{L} 1)$ & CEL1 & $\mathrm{eV}$ & EV \\
\hline $\operatorname{ce}(\mathrm{L} 12)$ & CEL12 & even-A & EVEN-A \\
\hline $\operatorname{ce}(\mathrm{L} 23)$ & CEL23 & ex. & EX. \\
\hline $\operatorname{ce}(\mathrm{L} 2)$ & CEL2 & $e^{+}$ & $\mathrm{E}+$ \\
\hline $\operatorname{ce}(\mathrm{L} 3)$ & CEL3 & $\mathrm{e}^{ \pm}$ & $\mathbf{E}+-$ \\
\hline $\operatorname{ce}(\mathrm{M}) /(\gamma+\mathrm{ce})$ & $\mathrm{M} / \mathrm{T}$ & $\mathrm{fm}$ & FM \\
\hline $\operatorname{ce}(\mathrm{M})$ & CEM & $\mathrm{fm}^{-1}$ & FM-1 \\
\hline $\operatorname{ce}(\mathrm{M}+) /(\gamma+\mathrm{ce})$ & $\mathrm{M}+/ \mathrm{T}$ & $f m^{-1}$ & $\mathbf{F M} * *-1$ \\
\hline $\operatorname{ce}(\mathrm{M} 1)$ & CEM1 & $\mathrm{fm}^{2}$ & $\mathbf{F M} * 2$ \\
\hline $\operatorname{ce}(\mathrm{M} 2)$ & CEM2 & $\mathrm{fm}^{4}$ & $\mathbf{F M} * 4$ \\
\hline $\operatorname{ce}(\mathrm{M} 23)$ & CEM23 & $g$ factor & G FACTOR \\
\hline $\operatorname{ce}(\mathrm{M} 3)$ & CEM3 & g factors & G FACTORS \\
\hline
\end{tabular}


ENSDF Dictionary - ordered by output

\begin{tabular}{|c|c|c|c|}
\hline Translation & ENSDF & Translation & ENSDF \\
\hline$g(2+$ & $\mathrm{G}(2+$ & $\mathrm{p} 1 / 2$ & $\mathrm{P} 1 / 2$ \\
\hline g-factors & G-FACTORS & $\mathrm{p} 2 \mathrm{n} \gamma$ & P2NG \\
\hline g-factor & G-FACTOR & $\operatorname{pn} \gamma$ & PNG \\
\hline g.s. & GS & $\mathrm{p} \alpha$ & PALPHA \\
\hline$g=$ & $\mathrm{G}=$ & $\mathrm{p} \gamma$ & $\mathrm{PG}$ \\
\hline $\mathrm{gT}$ & $\mathrm{G}^{*} \mathrm{~T}$ & $\mathrm{p} \gamma \gamma^{\prime}$ & PGG \\
\hline $\mathrm{gT}_{1 / 2}$ & $\mathrm{GT} 1 / 2$ & $r^{2}$ & $\mathrm{R} * * 2$ \\
\hline $\mathrm{gW} \Gamma_{0}^{2}$ & $\mathrm{G} * \mathrm{~W} * \mathrm{WIDTHGO}{ }^{* *}$ & $r^{4}$ & $\mathrm{R} * * 4$ \\
\hline$g w \Gamma_{\gamma 0}$ & $\mathrm{G}^{*} \mathrm{~W}^{*} \mathrm{WIDTHGO}$ & $r^{6}$ & $\mathrm{R} * * 6$ \\
\hline$g_{1} \Gamma$ & G1*WIDTH & $\mathbf{r}_{0}$ & Ro \\
\hline$g_{1}$ & G1 & $s(c e)$ & $\mathrm{S}(\mathrm{CE})$ \\
\hline $\mathrm{g}_{2} \Gamma$ & G2*WIDTH & s-wave & S-WAVE \\
\hline $\mathrm{g}_{2}$ & $* \mathrm{G} 2$ & syst & SY \\
\hline$g_{2}$ & G2 & $\mathrm{s}^{-1}$ & $S-1$ \\
\hline $\mathrm{g}_{\mathrm{A}}^{\overline{2}}$ & GA2 & t) & $\mathrm{T})$ \\
\hline$g \Gamma$ & G*WIDTH & $t$ & $\mathrm{~T}$ \\
\hline$g \Gamma_{\gamma 0}^{2}$ & ${ }^{*} \mathrm{G} *$ WIDTHG $0 * * 2$ & th & $\mathrm{TH}$ \\
\hline $\mathrm{g} \Gamma_{\gamma 0}^{20}$ & $\mathrm{G} * \mathrm{WIDTHGO}{ }^{* * 2} 2$ & tof & TOF \\
\hline $\mathrm{g} \Gamma_{\mathrm{n}}$ & G*WIDTHN & $\mathrm{t} \gamma$ & TG \\
\hline $\mathrm{g} \Gamma_{\gamma 0}$ & $\mathrm{G}^{*}$ WIDTHGO & $\mathrm{w}(\theta) \mathrm{g} \Gamma_{\gamma 0}$ & $\mathrm{~W}(\mathrm{THETA}) * \mathrm{G} * \mathrm{WID}$ \\
\hline$g \Gamma_{0} \Gamma \gamma$ & GWIDTHOWIDTHC & $x-r a y$ & $\mathrm{X}-\mathrm{RAY}$ \\
\hline $\mathrm{h} \omega$ & HOMEGA & $x$-rays & X-RAYS \\
\hline$h^{2}$ & $\mathrm{H}^{* * 2}$ & xpyn $\gamma$ & XPYNG \\
\hline is $D$ & IS D & $\left.<r^{2}\right\rangle$ & AVRSQ \\
\hline $\mathrm{kG}$ & $\mathrm{KG}$ & $\left\langle\beta^{2}\right\rangle^{1 / 2}$ & BAVRSQ \\
\hline $\mathrm{kOe}$ & $\mathrm{KOE}$ & $\Delta<\mathbf{r}^{4}>$ & DAVRSQ4 \\
\hline $\mathrm{keV}$ & KEV & $\Delta<\mathrm{r}^{2}>$ & DAVRSQ \\
\hline $\log f^{1 u_{t}}$ & LOGF1UT & $\Delta<r^{6}>$ & DAVRSQ6 \\
\hline $\log f^{3 u_{t}}$ & LOGF3UT & $(\mathrm{J}+1 / 1 / 2)$ & $* *(J+1 / 2)$ \\
\hline $\log f^{2 u} t$ & LOGF2UT & -1 & $* *_{-1}$ \\
\hline $\log f^{1} t$ & LOGF $1 T$ & -3 & $* *-3$ \\
\hline $\log f t$ & LOGFT & -4 & $* *-4$ \\
\hline $\mathrm{mb}$ & MB & $1 / 2$ & $* * 1 / 2$ \\
\hline $\mathrm{mb} / \mathrm{sr}$ & $\mathrm{MB} / \mathrm{SR}$ & $1 / 3$ & $* * 1 / 3$ \\
\hline $\mathrm{meV}$ & MILLI-EV & ${ }^{12} \mathrm{C} \gamma$ & $\mathrm{C} 12 \mathrm{G}$ \\
\hline $\mathrm{mg} / \mathrm{cm}^{2}$ & $\mathrm{MG} / \mathrm{CM} 2$ & 2 & $* * 2$ \\
\hline $\mathrm{ms}$ & MS & $3:$ & $* * 3$ \\
\hline $\mathrm{nb} / \mathrm{sr}$ & NB/SR & $\mathbf{L}$ & $* * \mathrm{~L}$ \\
\hline $\mathrm{n} \gamma$ & NG & e.g: & E.G. \\
\hline $\mathrm{n} \gamma \gamma$ & NGG & i.e. & I.E. \\
\hline odd-A & ODD-A & $\times \mathbf{E}$ & $* \mathbf{E}$ \\
\hline p decay & P DECAY & $\times \mathbf{I} \boldsymbol{\beta}^{-}$ & *IB- \\
\hline$p(\theta)$ & P(THETA) & $\times I \varepsilon$ & $* \mathrm{IE}$ \\
\hline $\mathrm{p}-\mathrm{width}$ & P-WIDTH & $\times Q$ & $* \mathbf{Q}$ \\
\hline
\end{tabular}


ENSDF Dictionary - ordered by output

\begin{tabular}{|c|c|c|c|}
\hline Translation & ENSDF & Translation & ENSDF \\
\hline$\times \mathrm{T}_{1 / 2}$ & $* \mathrm{~T} 1 / 2$ & $\Phi$ & PHI \\
\hline$\times \mathrm{A}^{1 / 3}$ & $* A^{* *}(1 / 3)$ & $\Phi\left(p_{2}\right)$ & PHI(P2) \\
\hline$\times \sigma$ & *SIGMA & $\Phi\left(p_{1}\right)$ & $\mathrm{PHI}(\mathrm{P} 1)$ \\
\hline$\leq$ & LE & $\Gamma$ & *WIDTH \\
\hline$\neq$ & $\mathrm{NE}$ & $\Gamma$ & WIDTH \\
\hline$\geq$ & GE & $\Gamma_{\gamma 0}^{2}$ & WIDTHGO**2 \\
\hline$\approx$ & AP & $\Gamma^{2}$ & WIDTH**2 \\
\hline$\approx<$ & LA & $\Gamma_{\mathrm{n}}$ & WIDTHN \\
\hline$\Rightarrow$ & GA & $\Gamma_{\mathrm{n} 0}$ & WIDTHNO \\
\hline$\infty$ & INFNT & $\Gamma_{\mathrm{p} 0}$ & WIDTHPO \\
\hline$\Delta$ & $\Delta$ & $\Gamma_{\mathrm{p} 1}$ & WIDTHP 1 \\
\hline$\Delta(\mathrm{HF})$ & $\mathrm{DHF}$ & $\Gamma_{\mathrm{p}}$ & *WIDTHP \\
\hline$\Delta(\log \mathrm{ft})$ & $\mathrm{DFT}$ & $\Gamma_{\mathrm{p}^{\prime}}^{r}$ & WIDTHP' \\
\hline$\Delta(\beta-$ normalization & DNB & $\Gamma_{\mathrm{p} 2}$ & WIDTHP2 \\
\hline$\Delta(\gamma-$ normalization & DNR & $\Gamma_{\mathrm{p}}$ & WIDTHP \\
\hline$\Delta(\gamma+$ ce-normalization & DNT & $\Gamma_{\alpha 4}$ & WIDTHA4 \\
\hline$\Delta \mathrm{A}$ & $\mathrm{DA}$ & $\Gamma_{\alpha 1}$ & WIDTHA1 \\
\hline$\Delta \mathrm{A}_{2}$ & DA2 & $\Gamma_{\gamma}$ & WIDTHG \\
\hline$\Delta \mathrm{A}_{4}$ & DA4 & $\Gamma_{\gamma 1}$ & WIDTHG1 \\
\hline$\Delta \mathbf{E}$ & $\mathrm{DE}$ & $\Gamma_{\alpha 2}^{r 1}$ & WIDTHA2 \\
\hline$\Delta \mathrm{I}(\gamma+c e)$ & DTI & $\Gamma_{\alpha 0}$ & WIDTHAO \\
\hline$\Delta \mathrm{I} \alpha$ & DIA & $\Gamma_{\gamma 0}^{\infty 0}$ & WIDTHGO \\
\hline$\Delta \mathbf{I} \beta$ & DIB & $\Gamma_{\alpha 3}$ & WIDTHA3 \\
\hline$\Delta \mathrm{I} \varepsilon$ & DIE & $\Gamma \alpha$ & WIDTHA \\
\hline$\Delta \mathrm{I} \gamma$ & DRI & $\Sigma$ & *SUMOF \\
\hline$\Delta \mathrm{I} \gamma(\%)$ & PRI & $\Sigma$ & SUMOF \\
\hline$\Delta \mathrm{J}$ & DJ & $\Psi$ & PSI \\
\hline$\Delta \mathrm{J} \pi$ & DJPI & $\alpha$ & ICC \\
\hline$\Delta \mathrm{K}$ & $\mathrm{DK}$ & $\alpha$ & ALPHA \\
\hline$\Delta \mathrm{L}$ & DL & $\alpha$ & $\mathrm{CC}$ \\
\hline$\Delta \mathrm{N}$ & DN & $\alpha$ decay & A DECAY \\
\hline$\Delta Q(\varepsilon)$ & DQ+ & $\alpha$ decays & A DECAYS \\
\hline$\Delta Q\left(\beta^{-}\right)$ & DQ- & $\alpha$ syst & A SYST \\
\hline$\Delta Q(\alpha)$ & DQA & $\alpha^{\prime}$ & $A^{\prime}$ \\
\hline$\Delta \mathbf{S}$ & DS & $\alpha$ 's & ALPHAS \\
\hline$\Delta S(n)$ & DSN & $\alpha(\mathrm{K}) \exp$ & $* \mathrm{EKC}$ \\
\hline$\Delta \mathbf{S}(\mathbf{p})$ & DSP & $\alpha(\mathrm{K}) \exp$ & EKC \\
\hline$\Delta T$ & DISPIN & $\alpha(\mathrm{K})$ & $\mathrm{KC}$ \\
\hline$\Delta \mathrm{T}_{1 / 2}$ & DT & $\alpha(L) \exp$ & ELC \\
\hline$\Delta \mathrm{T}_{1 / 2}$ & $\mathrm{DT} 1 / 2$ & $\alpha(L)$ & LC \\
\hline$\Delta^{10 \Delta}$ & DELTA & $\alpha(L 12) \exp$ & EL12C \\
\hline$\Delta \alpha$ & DCC & $\alpha(\mathrm{L} 12)$ & $\mathrm{L} 12 \mathrm{C}$ \\
\hline$\Delta \delta$ & DMR & $\alpha(L 1) \exp$ & EL1C \\
\hline$\Delta \pi$ & DPI & $\alpha(\mathrm{L} 1)$ & L1C \\
\hline
\end{tabular}


ENSDF Dictionary - ordered by output

\begin{tabular}{|c|c|c|c|}
\hline Translation & ENSDF & Translation & ENSDF \\
\hline$\alpha(\mathrm{L} 2)$ & $\mathrm{L} 2 \mathrm{C}$ & $\alpha_{3}$ & ALPHA3 \\
\hline$\alpha(\mathrm{L} 23) \exp$ & EL23C & $\alpha \alpha$ & $\mathrm{AA}$ \\
\hline$\alpha($ L23 $)$ & $\mathrm{L} 23 \mathrm{C}$ & $\alpha \gamma^{i}$ & $\mathrm{AG}$ \\
\hline$\alpha(\mathrm{L} 2) \exp$ & EL2C & $\beta:$ & BETA \\
\hline$\alpha($ L3) exp & EL3C & $\beta$ & $\mathrm{B}$ \\
\hline$\alpha(\mathrm{L} 3)$ & $\mathrm{L} 3 \mathrm{C}$ & $\beta ' s:$ & BETAS \\
\hline$\alpha(M) \exp$ & EMC & $\beta(G T)$ & BGT \\
\hline$\alpha(\mathrm{M})$ & $\mathrm{MC}$ & $\beta(I S$ & $\mathrm{B}(\mathrm{IS}$ \\
\hline$\alpha(\mathbf{M}+.)$. & $\mathrm{MC}+$ & $\beta$-vibrational & B-VIBRATIONAL \\
\hline$\alpha(\mathbf{M} 1)$ & $\mathrm{M} 1 \mathrm{C}$ & $\beta R$ & $\mathrm{~B} * \mathrm{R}$ \\
\hline$\alpha($ M1) $\exp$ & $\operatorname{EM} 1 \mathrm{C}$ & $\beta \mathrm{R}$ & $\mathrm{BETA} * \mathbf{R}$ \\
\hline$\alpha(\mathbf{M} 2)$ & M2C & $\beta \mathbf{c}$ & $\mathrm{BC}$ \\
\hline$\alpha($ M2)exp & EM2C & $\beta c e$ & $\mathrm{BCE}$ \\
\hline$\alpha(\mathrm{M} 3)$ & M3C & $\mathrm{Be}^{-}$ & $\mathrm{BE}-$ \\
\hline$\alpha(\mathrm{M} 3) \exp$ & EM3C & $\beta \mathrm{n}$ & $\mathrm{BN}$ \\
\hline$\alpha(\mathbf{M} 4)$ & $\mathrm{M} 4 \mathrm{C}$ & $\beta p$ & $\mathbf{B P}$ \\
\hline$\alpha(\mathrm{M} 4) \exp$ & EM4C & $\beta^{+}$ & $\mathrm{B}+$ \\
\hline$\alpha($ M5) & M5C & $\beta^{+} \varepsilon_{i}$ Decay & BEC DECAY \\
\hline$\alpha(\mathrm{M} 5) \exp$ & EM5C & $\beta^{-2 n}$ & $\mathrm{~B}-2 \mathrm{~N}$ \\
\hline$\alpha(N) \exp$ & ENC & $\beta^{-}:$ & B-_ \\
\hline$\alpha(N)$ & $\mathrm{NC}$ & $\beta^{-} n$ & $\mathrm{~B}-\mathrm{N}$ \\
\hline$\alpha(N+.)$. & $\mathrm{NC}+$ & $\beta_{0}$ & BO \\
\hline$\alpha(N 1) \exp$ & EN1C & $\beta_{04}$ & B04 \\
\hline$\dot{\alpha}(\mathrm{N} 1)$ & N1C & $\beta_{03}$ & В03 \\
\hline$\alpha(\mathrm{N} 2) \exp$ & EN2C & $\beta_{02}$ & B02 \\
\hline$\alpha(\mathrm{N} 2)$ & $\mathrm{N2C}$ & $\beta_{00}$ & $\mathrm{~B} 00$ \\
\hline$\alpha(N 23) \exp$ & EN23C & $\beta_{12}$ & B12 \\
\hline$\alpha(\mathrm{N} 3)$ & N3C & $\beta_{1}$ & $\mathrm{~B} 1$ \\
\hline$\alpha(\mathrm{N} 3) \exp$ & EN3C & $\beta_{20}$ & B20 \\
\hline$\alpha(N 4) \exp$ & EN4C & $\beta_{24}$ & B24 \\
\hline$\alpha(N 4)$ & $\mathrm{N} 4 \mathrm{C}$ & $\beta_{22}$ & B22 \\
\hline$\alpha(\mathrm{N} 5)$ & $\mathrm{N} 5 \mathrm{C}$ & $\beta_{2} R^{\prime}$ & $\mathrm{B} 2 * \mathrm{R}$ \\
\hline$\alpha(\mathrm{N} 6)$ & $\mathrm{N} 6 \mathrm{C}$ & $\beta_{2}$ & $\mathrm{~B} 2$ \\
\hline$\alpha(01)$ & $01 \mathrm{C}$ & $\beta_{3}$ & B3 \\
\hline$\alpha(0.2)$ & $\mathrm{O} 2 \mathrm{C}$ & $\beta_{3} R$ & $\mathrm{~B} 3 * \mathrm{R}$ \\
\hline$\alpha(03)$ & $\mathrm{O} 3 \mathrm{C}$ & $\beta_{30}$ & $\mathrm{~B} 30$ \\
\hline$\alpha(04)$ & $\mathrm{O} 4 \mathrm{C}$ & $\boldsymbol{\beta}_{4}$ & $\mathrm{~B} 4$ \\
\hline$\alpha(\mathrm{P} 1)$ & P1C & $\beta_{42}$ & B42 \\
\hline$\alpha(\exp )$ & $\mathrm{ECC}$ & $\beta_{4} R$ & $\mathrm{~B} 4 * \mathrm{R}$ \\
\hline$\alpha$-decay & A-DECAY & $\beta_{5}$ & B5 \\
\hline$\alpha$-syst & A-SYST & $\beta_{5} R$ & $\mathrm{~B} 5 * \mathrm{R}$ \\
\hline$\alpha_{0}$ & ALPHAO & $\beta_{6}$ & B6 \\
\hline$\alpha_{1}$ & ALPHA1 & $\beta_{6} \mathbf{R}$ & $\mathrm{B} 6 * \mathrm{R}$ \\
\hline$a_{2}$ & ALPHA2 & $\beta_{7}$ & B7 \\
\hline
\end{tabular}


ENSDF Dictionary - ordered by output

\begin{tabular}{|c|c|c|c|}
\hline Translation & ENSDF & Translation & ENSDF \\
\hline $\boldsymbol{\beta}_{\mathrm{L}}$ & $\mathrm{BL}$ & $\gamma \gamma \tau$ & GGT \\
\hline$\beta_{L} R^{1 / 3}$ & $\mathrm{BL}^{*} \mathrm{R}^{*} \mathrm{~A}^{* *}(1 / 3)$ & $\gamma \gamma \gamma$ & GGG \\
\hline$\beta_{L}^{2}$ & $\mathrm{BL}^{* * 2}$ & $x$ & $\mathrm{CHI}$ \\
\hline$\beta_{L} \mathrm{R}$ & $\mathrm{BL} * \mathbf{R}$ & $\chi^{2}$ & $\mathrm{CHI}^{* * 2} 2$ \\
\hline$\beta \alpha$ & $\mathrm{BA}$ & $\in M(\exp )$ & ECM \\
\hline$\beta \beta$ & $\mathrm{BB}$ & $\in N(\exp )$ & $\mathrm{ECN}$ \\
\hline$\beta \gamma$ & $\mathrm{BG}$ & $\kappa$ & KAPPA \\
\hline$\beta \gamma \mathbf{n}$ & BGN & $\lambda$ & LAMBDA \\
\hline$\beta \gamma \gamma$ & BGG & $\mu$ & MOMM1 \\
\hline$\delta$ & $\mathrm{MR}$ & $\mu$ & $\mathrm{MU}$ \\
\hline$\delta^{2}$ & $\mathrm{MR}^{* * 2}$ & $\mu \mathrm{b}$ & UB \\
\hline$\varepsilon$ & EPSILON & $\mu \mathrm{b} / \mathrm{sr}$ & UB/SR \\
\hline$\varepsilon$ & $\mathrm{EC}$ & $\mu \mathrm{b} \times \mathrm{MeV}$ & $\mathrm{UB} * \mathrm{MEV}$ \\
\hline$\varepsilon 2 \mathrm{p}$ & $\mathrm{EC} 2 \mathrm{P}$ & $\mu g$ & UG \\
\hline$\varepsilon B$ & EPSILONB & $\mu \mathrm{g} / \mathrm{cm}$ & UG/CM \\
\hline$\varepsilon B(\mathrm{E} 2) \uparrow$ & EBE2UP & $\mu s$ & US \\
\hline$\varepsilon \mathrm{B}(\mathrm{E} 3) \uparrow$ & EBE3UP & $\mu^{-}$ & MU- \\
\hline$\varepsilon K$ & $\mathrm{CK}$ & $v$ & NU \\
\hline$\varepsilon \mathrm{K}(\exp )$ & ECK & $\pi$ & $\mathbf{P I}$ \\
\hline$\varepsilon L$ & $\mathrm{CL}$ & $\pi^{-}$ & PI- \\
\hline$\varepsilon L(\exp )$ & ECL & $\pi \beta$ & PIB \\
\hline$\varepsilon L I(\exp )$ & ECL1 & $\pi \beta \gamma$ & PIBG \\
\hline$\varepsilon L 2(\exp )$ & ECL2 & $\pi \gamma$ & PIG \\
\hline$\varepsilon \operatorname{LL} 3(\exp )$ & ECL3 & $\theta$ & THETA \\
\hline$\varepsilon \mathbf{M}$ & $\mathrm{CM}$ & $\theta^{2}$ & THETA**2 \\
\hline$\varepsilon N$ & $\mathrm{CN}$ & $\theta_{1}$ & THETA1 \\
\hline$\varepsilon p$ & ECP & $\theta_{2}$ & THETA2 \\
\hline$\varepsilon \alpha$ & $\mathrm{ECA}$ & $\theta_{\mathrm{p} 1}^{2}$ & THETAP $1 * * 2$ \\
\hline$\gamma$ & GAMMA & $\theta_{\mathrm{p} 2}{ }^{2}$ & THETAP $2 * * 2$ \\
\hline$\gamma$ & $\mathrm{G}_{-}$ & $\theta \alpha$ & THETAA \\
\hline$\gamma / \alpha$ & G/A & $\theta \alpha^{2}$ & THETAA $* * 2$ \\
\hline$\gamma \mathrm{X}$ & GX & $\theta \gamma$ & THETAG \\
\hline$\gamma c e$ & GCE & $P$ & RHO \\
\hline$\gamma e^{--}$ & GE- & $\rho^{2}$ & $\mathrm{RHO} * * 2$ \\
\hline$\gamma \mathrm{n}$ & GN & $\sigma$ & SIGMA \\
\hline$\gamma p$ & GP & $\sigma(n \gamma)$ & SIGNG \\
\hline$\gamma p^{\prime}$ & GP' & $\sigma(n \alpha)$ & SIGNA \\
\hline$\gamma p(t)$ & $\mathrm{GP}(\mathrm{T})$ & $\sigma_{0}$ & SIGMA(0) \\
\hline$\gamma^{ \pm}$ & $\mathrm{G}+-$ & $\sigma_{n}$ & SIGMAN \\
\hline$\gamma_{0}$ & G0 & $\sigma_{\gamma}$ & SIGMAG \\
\hline$\gamma \beta$ & GB & $\sigma \times \Delta E$ & SIGMA*DE \\
\hline$\gamma \beta^{-}$ & GB- & $\sigma v$ & SIGMANU \\
\hline$\gamma \gamma$ & GG & $\tau$ & $* \mathrm{TAU}$ \\
\hline$\gamma \gamma \mathrm{n}$ & GGN & $\tau$ & TAU \\
\hline
\end{tabular}


ENSDF Dictionary - ordered by output

Translation

$\omega$

$\omega^{2} \tau$

$\omega \tau$
ENSDF

OMEGA

OMEGA**2*TAU OMEGA*T 
Appendix $\mathbf{H}$

ENSDF Policies 


\section{GENERAL POLICIES - Presentation of Data}

The Nuclear Data Sheets are prepared from the Evaluated Nuclear Strueture Data File (ENSDF), a computer file maintained by the National Nuclear Data Center on behalf of the International Network for Nuclear Structure and Decay Data Evaluations. Sce page iii for a list of the members of this network and their evaluation responsibilities. The presentation of material in the Nuclear Data Sheets reflects the organization of ENSDF, which is a collection of "data sets". For each nuclear species, these data sets present the following types of information:

- The adopted properties of the nucleus.

- The evaluated results of a single type of experiment, such as a radioactive dceay, a single nuclesr reaction, or the combined results of a number of similar types of experiments, such as $(H I, x n \gamma)$ reactions. The data given in ENSDF are primarily derived from experimental information.

The gener al policies and conventions followed in the preparation of these data sets and in the presentation of material in the Nuclear Data Sheets (NDS) are discussed below.

\section{General}

The following policies apply to the adoption or presentation of data. Deviations from these policies will be noted by the evaluator.

1. The excitation energies of levels connected by $\gamma$ transitions are from a least-squares fit to the adopted $\gamma$ energies.

2. Dominant decay branches (i.e., for the decay of ground states and isomeric states) are rounded off to 100 when the competing branches total less than approximately $0.001 \%$. When only one branch has been observed and no estimate can be made for expected competing branches, the observed branch is given as $\leq 100$ and the competing branch(es) as "Fbranching=?".

3. Total internal-conversion coefficients $(\alpha)$ for each transition are theoretical values corresponding to the listed radiation character (i.e., multipolarity) and mixing ratio (8). For a transition of mixed character (two or more multipolarities) and unknown mixing ratio, $\alpha$ is the average of the possible extremes and the uncertainty overlaps the full range of values.

In all calculations by the evaluator involving internalconversion coefficients, a $3 \%$ uncertainty is assumed for the theoretical coefficients.

4. The cross reference flags (XREF), defined in the Adopted Jevels table are given for each adopted level. When a level in an individual reaction or decay data set may correspond to more than one adopted level, the flag for that data set is given in lower case. In case of ambiguity, the energy from a particular data set is given as a comment.

\section{Adopted Levels, Gammas data set}

The Adopted Levels and $\gamma$ radiations tables in the NDS are generated from an Adopted Levels, Gammas data set in ENSDF. This data set represents the best values for the level and $y$ properties as determined by the evaluator on the basis of all the available information.

The following information is included in an Adopted Levels, Gammas data set.

For the nuclide:

1. $Q\left(\beta^{-}\right): \beta^{-}$decay energy [always presented as $\left.Q\left(\beta^{-}\right)=M(A, Z)-M(A, Z+1)\right\}$ and $\alpha$ decay energy $\{Q(\alpha)]$ for the ground state.

2. $S(n)$ and $S(p)$ : Neutron and proton separation energies.

3. XREF: Cross-reference symbol assignments for the various experimental data sets.

For each level:

1. E(lev): Excitation exergy (relative to the ground state).

2. $J^{x}: S p i n$ and parity with arguments supporting the assignment.

3. $\mathrm{T}_{1 / 2}$ or $\mathrm{r}$ : Half-life or total width in center of mass.

4. Decay branching for the ground state and isomers (an isomer is defined as a nuclear level with $\mathrm{T}_{1 / 2} 20.1$ s or one for which a separate decay data set is given in ENSDF).

5. Q,H: Static electric and magnetic moments.

6. XREF Flags to indicate in which reaction and/or decay data sets the level is seen.

7. Configuration assignments (e.g., Nilsson orbitals in deformed nuclei, shell-model assignments in spherical nuclei).

8. Band assignments and possibly band parameters (e.g., rotational bands in deformed regions).

9. Isomer and isotope shifts (usually only a literature reference is given).

10. Charge distribution of ground states (usually only a literature reference is given).

11. Deformation parameters.

12. B(E2) $\uparrow, B(M 1) \uparrow, \ldots$ : Electric or magnetic excitation probabilitics when the level half-life or the ground-state branching is not known.

For $\gamma$-ray and E0 transitions:

1. Placement in level scheme.

2. E $\gamma$ : Measured $\gamma$-ray or E0 transition energy.

3. I : Relative photon intensity from each level.

4. Mult,o: Electric or magnetic multipole character, the mixing ratio, and nuclear penetration parameter.

5. CC: Total internal-conversion coefficient (when significant).

6. $B(E L)(W . u), B(M 1)(W . u)$,..: Reduced trangition probabilities in Weisskopf units. 


\section{GENERAL POLICIES - Presentation of Data (cont.)}

\section{Reaction and decay data sets}

These data sets include information about different types of experiments and may include data sets for $\beta$ decay, $\alpha$ decay, isomeric transition (IT) decay, Coulomb excitation, charged-particle reactions [such as $(d, p)$ and $(t, p)$, heavy-ion reactions [such as

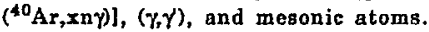

The following policies apply to the presentation of data in reaction and decay data sets. Any deviation from these policies will be noted by the evaluator.

1. The $J^{x}$ values in the decay data sets and reaction data sets with gammas are taken from the associated Adopted Levels, Gammas data set. For other reaction data sets the $J^{n}$ values are from the reaction data. The $J^{\pi}$ value to the capture state in thermal -neutron capture is assigned assuming s-wave capture.

2. The character of a $\gamma$ ray and its mixing ratio are from the associated Adopted $y$ radiation table.

3. The term "absolute intenaity" has the same meaning as the term "emission probability", and the term "relative intengity" is equivalent to "relative emission probability" or "relative emiasion rate." The former are given as. intensities per 100 decays.

4. Beta and electron-capture intensities are per 100 decays of the parent and are usually deduced from $\gamma$ intensity imbalance for the levels fed. The separation of $I\left(\varepsilon+\beta^{+}\right)$into $I(\varepsilon)$ and $I\left(\beta^{+}\right)$is based on theoretical $\varepsilon / \beta^{+}$ratios. The log $f t$ values for nonunique transitions are calculated as for allowed transitions.

5. Particle transition intensities (other than $\beta$ 's) are per 100 particle decays. The total particle branching is given both in the drawings and in the tables.

6. Tabular $\gamma$-ray intengities are relative valuen. The normalization factor to convert them to absolute intensities Iphotons per 100 decays of the parent for decay data sets, or photong per 100 neutron capturea for $(n, \gamma)$ data aets, etc.J is given in a footnote.

7. Radiations from the decay of neutron or proton resonances are not presented. The energies and other level properties for bound levels deduced from regonance experiments are included. Primary as well as secondary $\gamma^{\prime}$ following thermal-neutron capture are geneially included.

B. BEX, BMA for the excitation of levels are generally given.

9. Up to three references that make major contributions to the information in a specific data set are given in the data set heading. These major references also appear in the drawings.

\section{Organization of material}

Within each A chain, information is presented by nuclides which are arranged in order of increasing $Z$. There is an index for each evaluation which is followed by an isobaric diagram. A table of properties for the ground state and isomeric levels for all nuclides of the $A$ chain is given following or with the isobaric diagram.

For each nuclide, ${ }^{A}$, the arrangement of material and conventions for inclusion in tables are described below.

1. Adopted levels in $\mathbf{A}_{Z}$ - All adopted level properties are shown for each level, together with explanatory comments.

2. Adopted $\gamma$ radiations in ${ }^{A} Z$.

3. Band structure is shown where known.

4. Levels and radiations in $A_{Z}$ from radioactive decays Decays are ordered by increasing $A, Z$, and excitation energy of the parent.

u. Table of levels deduced from the decay.

b. Tables of radiations observed in the decay.

c. Decay Scheme

5. Levels and $\gamma$ rays in $A Z$ from nuclear reactions Reactions are ordered by increasing $A, Z$ of the target, thon by increasing $A, Z$ of the incident nucleus. $A$ heading is given for each reaction.

a. Table of levels deduced from the resction.

b. Table of $\gamma$ rays observed in the reaction, if any.

c. Level Scheme, if $\gamma$ rays were observed and placed. 
A reference "Theory $1967 \mathrm{Xy} 01$ " indicates theoretical predictione computed by the authors of $1967 \mathrm{Xy} 01$. A reference "Theory" alone indicates a determination by the evaluator of theoretical predictions described below.

\section{Internal Conversion Coefficients}

Theoretical conversion coefficients are obtained by spline interpolation (1968Ha53) from tables of Hager and Seltzer (1968Ha53) for the K-, L $1 \ldots 3^{-}, M_{1} \ldots 5^{-8 h o l l s}$ and of Dragoun, Plajner, and Schmitzler (1971Dr11) for the $(N+O+\ldots)$ -shells. For the $\mathrm{N}_{1 \ldots 5^{-s u b s h e l l s}}$, values are obtained by graphical interpolation from tables of Dragoun, Pauli, and Schrautzler (1969Dr09). For $\mathrm{K}-, \mathrm{L}_{1}{ }_{3}$-shells, conversion coefficients for transitions outside the $\mathrm{E}_{\gamma}, \Lambda$, or 2 ranges of Hager and Seltzer are obtained as follows: for $\mathrm{E}_{\gamma} \$ 6000 \mathrm{keV}$ and for $Z=3,6,10$ and $14 \leq Z \leq 30$ interpolation from tables of Band, et al. (1976Ba63); for $E_{\gamma}>2600 \mathrm{keV}$, by graphical interpolation from tables of Trusov (1972Tr09). For Eo transitions, K/L and $L_{1} / L_{2}$ ratios are obtained by graphical interpolation from tables of Hager and Seltzer (1969Ha61).

\section{Angular Diatribution and Correlation Coefficients}

The coefficients required for analysis of directional correlation, polarization correlation, directional distribution, and polarization distribution data are obtained as described by Steffen (19715t47, 1971St48). In particular, we adopt the phase convention for the mixing ratio, $\delta$, defined by Krane and Steffen (1970Kr03). Particle parameters required for the analysis of correlation and distribution data involving conversion electrons are obtained by graphical interpolation from tables of Hager and Seltzer (1968Ha54) The expression for the deorientation coefficient required to account for intermediate unobserved mixed radiations is given by Anicin (1972An20).*

A tabulation of gamma-gamma directional-correlation coefficients is given by Taylor, et al. (1971Ta32). These authors use the Steffen phase convention.

\section{Penetration Parameters}

Penetration parameters required for the analysis of internal conversion data and angular correlation or distribution data involving electrons are obtained by graphical interpolation from tables of Hager and Seltzer (1969Ha61).

\section{Internal Pair Conversion Coefficients}

Theoretical internal pair conversion coefficients for $\Lambda=E 1, M 1$, E2 are obtained by graphical interpolation in $\mathrm{Z}$, $\mathrm{E}$ from tables of Lombard, et al. (1968Lo16).

\footnotetext{
- As pointed out by these enthors, most earlier reforences which diecues thin conficient define it incorrectly.
}

\section{B-Decay Rate Probabilities}

Log ft values, capture-to-positron ratios, and electron-capture ratios for allowed, first-forbidden unique, and second-forbidden unique transitions are obtained as described by Gove and Martin (1971Go40). This reference also contains a tabulation of $\log f t$ values and total capture-to-positron ratios for allowed and first-forbidden unique transitions.

\section{Atomic Processes}

$X$-ray fluorescence yields are obtained from Bambynek, et al. (1972Bbi6) for $Z \leq 92$ and from Ahmad (1979Ah01) for $Z>92$.

Electron binding energies for $Z<84$ are taken from Bearden and Burr (1967Be73) and from Porter and Freedman (1978P008) for $\mathrm{Z}>84$.

\section{$\alpha$-Decay Hindrance Faotors}

The $\alpha$-hindrance factors (the ratio of the measured partial half-life for $\alpha$-emisaion to the theoretical half-life) are obtained from the spin-independent equations of Preston (1947Pr17). The nuclear radius for each even-even nucleus is determined by defining, for the g.s. to g.s. Q-transition, the hindrance factor $(H F)=1$. For odd $-A$ and odd-odd auclei, the radius parameters are chosen to be the average of the radii for the adjacent cven-even nuclei (1998Als04). In caes where only ono adjacent even-even radius is known, the extrapolated/interpolated value for the unknown radius is used in the calculation. A survey of the dependence of $\alpha$-hindrance factors on asymptotic quantum numbers and the variation of $\alpha$-hindrance factors within rotational bands is given for $A>=229$ in $1972 \mathrm{El} 121$.

\section{Electromagnetic Transition Rates}

The Weisskopf single-particle estimates for the halflives of electric and magnetic multipole radiation of energy $\mathrm{E}_{\gamma}$ are (1952B197)

$T_{1 / 2 W}(E L)=0.190\left(\frac{L}{L+1}\right)\left(\frac{3+L}{3}\right)^{2} \frac{(2 L+1) ! 1]^{2}}{A^{2 L / 3}}\left(\frac{161.14}{E_{1}(M e V)}\right)^{2 L+1} \times 10^{-21}$

$T_{1 / 2 W}(M L)=3.255 A^{2 / 3} T_{1 / 2 W}(E L)$

for a nuclear radius of $1.2 \mathrm{~A}^{1 / 2} \times 10^{-13} \mathrm{~cm}$.

\section{Unweighted and Weighted Averages}

If $x_{1} \pm \Delta x_{1}, x_{2} \pm \Delta x_{2}, \ldots x_{n} \pm \Delta x_{n}$ are $n$ independent measurements of a given quantity, $\Delta x_{i}$ being the ancertainty in $x_{i}$, then the weighted average of these measurements is $\bar{x} \pm \Delta \bar{x}$, where

$$
\vec{x}=W \sum x_{i} /\left(\Delta x_{i}\right)^{2},
$$

and $\bar{\Delta}$ is the larger of

$(\mathrm{W})^{1 / 2}$

$$
\text { and }\left[W \Sigma\left(\Delta x_{i}\right)^{-2}\left(\bar{x}-x_{i}\right)^{2} /(n-1)\right]^{1 / 2} \text {. }
$$

The unweighted average of these same measurements is given by $\bar{x} \pm \Delta \bar{x}$, where

$$
\begin{aligned}
\bar{x} & =\Sigma x_{i} / n, \\
\Delta \bar{x} & =\left[\Sigma\left(\bar{x}-x_{i}\right)^{2 / n(n-1)]^{1 / 2} .}\right.
\end{aligned}
$$




\section{SUMMARY OF BASES FOR SPIN AND PARITY ASSIGNMENTS}

\section{PROPOSITIONS ON WHICH STRONG ARGUMENTS} ARE BASED

\section{Ground States}

1. The ground state of an even-even nucleus has $\mathbf{J}^{\pi}=0^{+}$.

2. Spin determinations by such techniques as atomic-beam resonance, paramagnetic resonance, electron-spin resonance, and optical spectroscopy give correct values.

\section{Gamma Tranaftions}

3. The agreement of the measured value of a single conversion coefficient with the theoretical value for a multipolarity which is well separated from the value for any other multipolarity determines the transition multipolarity.

4. In all other cases if there is no olher evidence for multipolarity, agreement of two or more measured conversion coefficients or ratios with theoretical values is necessary in order to establish the multipolurities of a transition and its mixing ratio.

5. Since an E0 transition can proceed only by conversion or pair production, pure $\mathrm{E} O$ is ruled out if photons are observed.

6. Recommended upper limitg for $\gamma$-ray strengths $\left(\Gamma_{\gamma} / \Gamma_{w}\right.$, $\Gamma_{w}$-Weisskopf estimate) for various $A$ values are given below.

\begin{tabular}{|c|c|c|c|}
\hline \multirow[b]{2}{*}{ Character" } & \multicolumn{3}{|c|}{$\Gamma / r_{w}$ (Upper Limit) } \\
\hline & $A=6-44^{\mathrm{n} \delta}$ & $A=45-150^{\mathrm{b}, \mathrm{c}}$ & $A>150^{\mathrm{d}}$ \\
\hline E1 (IV) & $0.3^{*}$ & 0.01 & 0.01 \\
\hline E2 (IS)* & 100 & 300 & 1000 \\
\hline EO & 100 & 100 & 100 \\
\hline E4 & 100 & $100^{+}$ & \\
\hline$M$ (IV) & 10 & 3 & 2 \\
\hline$M E$ (IV) & 3 & 1 & 1 \\
\hline$M B$ (IV) & 10 & 10 & 10 \\
\hline M4 & & 30 & 10 \\
\hline
\end{tabular}

* 'TV' and 'IS' gtand for isovector and isoscalar

$+\Gamma_{\gamma} / \Gamma_{w}$ (Upper Limit) $=30$ for $A=90-150$

* $\Gamma_{\gamma}^{\gamma} / \Gamma_{w}$ (Upper Limit) $=0.1$ for $A=21-44$

$8 \Gamma_{\gamma} / \Gamma_{\text {r }}$ (Upper Limit) $=0.003$ for E1 (IS)

10 for E2 (IV), 0.03 for M1 (IS), 0.1 for M2 (IS)

- From 1979En05

b From 1979En04

- From 1981En06

d Deduced from ENSDF by M. J. Martin

- In super-deformed bands the E2 transitions can have $\Gamma_{\gamma} / \Gamma_{w}>1000$.

\section{Beta Transitionss}

7. If $\log f t<5.9$, the trangition is allowed: $\Delta J=0$ or $1, \Delta \pi=$ no (no change in parity). Superallowed $(\Delta \mathrm{T}=0) 0^{+} \rightarrow 0^{+}$ transitions have $\log f$ in the range 3.48 to 3.50 . Isospin forbidden ( $\Delta T=1)$ $0^{+} \rightarrow 0^{+}$transitions have $\log f t>6.4$. If $3.6<\log f t<6.4$, the transition is not $0^{+} \rightarrow 0^{+}$.

8. If $\log f^{1}{ }^{t} t<8.5\left(\log f^{\prime} t<7.4\right), \Delta \mathrm{J}=0,1$; $\Delta \pi=y e s$ or no.

9. If $\log f t<11.0, \Delta \mathrm{J}=0,1 ; \Delta \pi=$ yes or no or $\Delta J=2, \Delta \pi=$ yes.

10. If log $f t<12.8, \Delta \mathrm{J}=0,1,2 ; \Delta t=\mathrm{yes}$ or no.

11. If $\log f^{1} u_{t \geq 8.5}\left(\log f^{\prime} t \geq 7.4\right)$ and if the Fermi plot has the curvature corresponding to a shape factor $\left(p^{2}+q^{2}\right)$, then the transition is first-forbidden unique $(\Delta J=2, \Delta \pi=y e s)$.

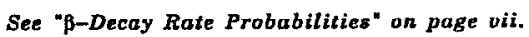

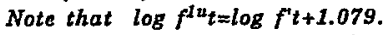

Note: For nuclei at, or very near to, closed shells values may be smaller. For example, in the mass region around $\mathrm{Z}=82$, the upper limit of 5.9 given in $\# 7$ above could be 5.1 . $\gamma$ Directional Correlation

$$
W(\theta)=\sum_{k=0 \text { ven }} A_{k} P_{k}(\cos \theta)
$$

12. If a gamma-gamma directional-correlation experiment yields $A_{2} \approx+0.36$ and $A_{4} \approx+1.1$, then the spin sequence is $0 \rightarrow 2 \rightarrow 0$.

13. Results of $\gamma \gamma(\theta)$ are strong evidence for excluding spin sequences for which the theoretical $A_{2}$ or $A_{4}$ falls well outside the experimental range.

By Directional Correlation

$$
W(\theta)=\sum_{k \rightarrow \theta \text { en }} A_{k}(\beta) A_{k}(\gamma) P_{k}(\cos \theta)
$$

14. If $\left|A_{2}(\beta)\right| \geq 0.1\left(A_{4}=0\right)$, the transition is not allowed. The converse is not true.

15. If $A_{4}(\beta) \neq 0$. the transition is neither allowed nor first forbidden.

16. If $A_{4}(\beta)=0$, the transition is allowed or first forbidden.

By Polarization Correlation

$$
P(\theta)=\frac{\sum_{k-\text { odd }} A_{k}(\beta) A_{k}(\gamma) P_{k}(\cos \theta)}{W(\theta)}
$$

17. In allowed transitions,

$$
\begin{array}{ll}
\beta^{-} & A_{1}(\beta)<0 \text { if } J_{i}=J_{f} \\
\beta^{+} & A_{1}(\beta)>0 \text { if } J_{i}=J_{f} \\
\beta^{-} & A_{1}(\beta) \geq 0 \text { if } J_{i}=J_{f^{+}} \\
& A_{1}(\beta)<0 \text { if } J_{i}=J_{f}-1 \\
& A_{1}(\beta) \leq 0 \text { if } J_{i}=J_{f^{+1}} \\
\beta^{+} & A_{1}(\beta)>0 \text { if } J_{i}=J_{f^{-1}}
\end{array}
$$

18. If $A_{3}(\beta) \neq 0$, the $\beta$-trancition is not allowed. The converse is not always true.

\section{y Angular Distribution}

19. In the angular distribution of gamma rays from deexcitalion of states populated in high-spin reactions (for a typical value of $\sigma / J=0.3$, where $\sigma$ is the magnetic substate population parmeter):

a. If $A_{2}=0.3$ and $A_{4}=-0.1$, the transition is generally $\Delta J=2$ (stretched quadrupole). (The same $A_{2}$ and $A_{4}$ values are possible for $\Delta J=0, D+Q$ transitions also, but such transitions are less common. $A_{4}=0$ for $\Delta J=0$, dipole transition).

b. If $A_{2}=-0.2$ and $A_{4}=0$, the transition is generally $\Delta \mathrm{J}=1$ (stretched dipole).

c. If $A_{4}>0\left(A_{2}=+0.5\right.$ to -0.8$)$, the transition is $\Delta J=1, D+Q$.

\section{y DCO Ratio}

In the angular correlation (DCO) of gamma rays from deaxcitation of states populated in high-spin reactions (for a typical value of $\sigma / J=0.3$, where $\sigma$ is the mannetic substatio population parmeter):

20. For $\Delta J=2$, stretched quadrupole as a gating transition:

a. $R(D C O)=1.0$, the transition is generally $\Delta J=2$ (stretched quadrupole). (The asme value is posaible for $\Delta J=0$, dipole but auch trunsitions are less common).

b. If $\mathrm{R}(\mathrm{DCO})=0.5$, the transition is generally $\Delta J=1$ (gtretched dipole). c. If $R(D C O)$ differs gignificantly from $=0.5$ or $\approx 1.0$, the trausition is $\Delta J=1$ (or 0$), D+Q$. 


\section{PROPOSITIONS ON WHICH STRONG ARGUMENTS ARE BASED continued \\ $\gamma$ DCo Ratio continued}

21. For $\Delta \mathrm{J}=1$, stretched dipole as a gating transition: a. If $R(D C O)=2.0$, the transition is generally $\Delta J=2$ (stretehed quadrupole). (The same value is possible for $\Delta \mathrm{J}=0$, dipole transitions, but such transitions are less common).

b. If $R(D C O) \approx 1.0$, the transition is generally $\Delta \mathrm{J}=1$ (stretched dipole). c. If $R(D C O)$ differs significantly from $\approx 2.0$ or $* 1.0$, the transition is $\Delta J=1$ (or 0$), D+Q$.

Reactions

22. Low-energy Coulomb excitation is predominantly E2 excitation.

23. Coulomb excitation determines $J^{\pi}$ if the excitation probability agrees with the calculated values of Alder (60Al23).

24. The spin of the compound nuclear state resulting from thermal-neutron capture is equal to the spin of the target nucleus plus or minus $1 / 2$.

25. Primary $\gamma$ 's from neutron capture are E1, M1, E2, or M:1+E2.

26. If the angular distribution in a single-nucleon transfer reaction can be fitted with anique $L$ value, the spin of the final state $J_{f}$ is related to the spin of the inital state $J_{i}$ by

$$
\vec{J}_{\mathrm{f}}=\vec{J}_{\mathrm{i}}+\overrightarrow{\mathrm{L}}+\overrightarrow{\mathrm{H}_{\mathrm{H}}}
$$

with parity change if $L$ is odd.

27. If the vector analyzing power for a single-nucleon transfer reaction shows a clear preference between $\mathrm{J}=\mathrm{L}+1 / 2$ and $\mathrm{J}=\mathrm{L}-1 / 2$ and if the $L$ value is known, then the $J$ value is determined.

28. Generally for the states populated in high-spin reactions, spins increase with increasing excitation energy. This is a result of the fiact that these reactions tend to populate yrast or near yrast itates.

29. If the angular distribution can be fitted with a unique Lvalue the $J^{\pi}$ of the final state is related to the $J^{\pi}$ of the initial state by $\vec{J}_{t}=\vec{J}_{i}+\vec{L}, \pi_{i} \pi_{i}=(-1)^{L}$, for the following cases

a. A strong group observed in $(p, t),(t, p)$, and $\left({ }^{3} \mathrm{He}, \mathrm{p}\right)$ reactions (strang groups are assumed to result from two identical nucleons transferred in a relative s state)

b. A strong group observed in the o-particle transfer reaction $\left({ }^{6} \mathrm{Li}, \mathrm{d}\right)$.

c. $\left(e, e^{\prime}\right)$ and $\left(\alpha, \alpha^{\prime}\right)$ inelastic scattering.

30. In reactions with $\mathrm{J}^{\mathrm{x}}=0^{+}$target, projectle, and ejectile, if the yield of a group at $0^{\circ}$ or $180^{\circ}$ is

a. non-zero, the parity of the final state is $(-1)^{\mathrm{J}_{f}}$

b. zero at several uncorrelated energies, the parity of the final state is $(-1)^{J^{+}} f^{+1}$

31. In reactiona with a polarized $\mathrm{J}^{\pi}=1$ projectile in the $m=0$ substate, with $J^{\pi}=0^{+}$ejectile and target, if the yield of a group at $0^{\circ}$ or $180^{\circ}$ is

a. non-zero, the parity of the final state is $(-1)^{J_{g}+1}$

b. zero at several uncorrelated energies, the parity of the final state is $(-1)^{\mathrm{J}}$

\section{Regions of Strong Nuclear Deformation}

The systematic occurrence of rotational-band structure in the strongly deformed nuclides can be a considerable help in making $J \pi$ assignments, since one can also use the level energy as one of the considerations. This frequently makes it possible to assign a $J \pi$ value to a level with confidence from data which, absent such structure, might yield an ambiguous assignment.

32. Level-energy considerations. If the couplings among the states are not too strong, the energies of the lower members of a band can be expressed by the relatively simple relation (see, e.g., 1971Bu16 and references therein):

$$
\begin{aligned}
E(J, K) & =A X+B X^{2}+C^{3}+\ldots \\
& +(-1)^{J+K} \prod_{i=1-K}^{K}(J+i)\left\{A_{2 X^{2}}+B_{2 K} X+\ldots\right\}
\end{aligned}
$$

where $\mathrm{X}=\mathrm{J}(\mathrm{J}+1)-\mathrm{K}^{2}$

The inertial parameter, A exhibita a systematic behavior in the various regions of strongly deformed nuclei, which can be helpful in assigning levels to rotational bands. In gome instances (e.g., strong Coriolis coupling) where the $A$ vaiues depart significantly from systematic trends, this observation can itself be useful, since it can help establish the presence of such effects and, hence, provide evidence for the relevant nucleonic configurations.

For the case of $K=1 / 2$ bands, the decoupling parameter, $a$, which is characteristic for each such band, is given by the ratio $A_{1} / A$ in (1). Eatablizhing a value for the decoupling parameter of a proposed band can be useful in assigning a nucleonic configuration to it - and vice-versa.

33. Allowed-unhindered beta transitions. In this region, beta transitions having logft values <5.0 arc elassificd as "allowed unhindered" (au). Such transitions take place between one-quasiparticle orbitals having the same asymptotic quantum numbers. In the "rare-earth" region ( $90 \leq N \leq 112,60<2$ $<-76$ ), four such orbital pairs are known: [532], near the beginning of this region; [523], near the middle of this region; [514], above the middle of this region; and, at the high end, [505]. Observation of an au transition is definitive evidence for the presence of the partioular pair of orbitzle.

34. Coulomb excitation. If a sequence of levels having "rotationallike" energy spaciogs is found to be excited with enhanced probabilities, this is evidence that this sequenco (at least below the firet "backbend") forms the ground-state rotational band for the nuclide involved. If the E2 transition probabilities involved are large (tens of Weisskopf units or larger) and comparable to each other, then this is definitive evidence for both a band structure and the sequence of $3 \pi$ values, assuming one of the spins is known.

35. Alpha decay. Observation of a "favored" $\alpha$ transition (HF <4) indicates that the two states involved have the same nucleonic configuration. If a sequence of levels having "rotational-like" energy spacings is associated with the level fed by this favored transition and these levels have HF's that vary according to the established trend within rotational bands (1972E121), then this sequence ean be considered to form a rotational band whose nucleonic configuration is the same as that of the alpha-decaying state. If the $J \pi$ value of this latter state and it configuration are known, then the corresponding quantitien can be considered to be known for the band in the daughter nuclide or vice versa.

36. Single-nucleon-transfer reactions (light-ion-induced). For a single-nucleon transfer reaction induced by light ions ( ${ }^{\mathrm{H}} \mathrm{He}$ and lighter), the characteristic pattern of cross sections among rotational-band members ("fingerprint") can be used to assign a set of levels as specific $J \pi$ members of a band based on a particular Nilsson configuration, if the fingerprint agrees well with that predicted by thy Nilsson-model wavefunctions and is distinct from those expected for other configurations in the mass region. (This method is even stronger if angular distributions giving unique I values, or vector analyzing powers, support the assignments for one or more of the levels.) 


\section{SUMMARY OF BASES FOR SPIN AND PARITY ASSIGNMENTS - continued}

\section{PROPOSITIONS ON WHICH STRONG ARGUMENTS ARE BASED continued}

\section{High-spin states}

In the decay of high-spin states, commonly produced in heavyion induced compound nuclear reactions or in highly excited nuclides created as products of nuclear fission or in Coulomb excitation, the multipolarities of the deexciting $\gamma$ transitions and the relative spins and parities of the levels are generally determined from angular distributions, angular correlations (DCO ratios), linear polarizations and internal-conversion coefficients. In addition, relative energy-level spacings and the increase of $\gamma$ intensity with decreasing excitation energy are important clues.

37. For a well-deformed nucleus when a regular sequence of $\Delta J=2$ (stretched quadrupole) transitions is observed at high spins as a cascade, the sequence may be assigned to a common band with E2 multipolarity for all the transitions in the cascade. A similar but somewhat weaker argument holds for less deformed nuclei where a common sequence of levels is connected by a regular sequence of $\Delta \mathbf{J}=2$ (stretched quadrupole) transitions in a cascade.

38. For near-spherical nuclei, when a regular sequence of $\Delta \mathrm{J}=1$ (stretched dipole) transitions is observed at high spins as a cascade, then the sequence may be agsigned to a common band with (MI) multipolarity for all the transitions in the cascade. (Cascades of $\Delta J=1, E 1$ transitions occur in rare cases of nuclides which show alternating-parity bands or reflection asymmetry.)

39. In the absence of angular distribution/correlation data, a regular sequence of transitions in a cascade may be assigned to a common structure or a band if (a) the low-lying levels of this structure have well established spin and parity assignments and (b) there is good evidence that, at higher energies and spins, the band has not changed in its internal structure due to band crossings or other perturbations.

\section{Alpha Decay}

40. The hindrance factor for an $\alpha$ transition from the ground state of an even-even nucleus to the ground gtate of the daughter nucleus is 1.0 by definition. For odd-A and odd-odd nuclei, hindrance factors $\leq 4$ identify favored $\alpha$ transitions, and these connect states having the same spin, parity and configuration.

41. For $\alpha$-decay between two states, one of which has $\mathrm{J}=0$, the parity change is given by $\Delta \pi=(-1)^{\Delta \mathrm{J}}$.

\section{PROPOSITIONS ON WHICH WEAK ARGUMENTS ARE BASED}

1. In cases where gammas of one multipolarity "cluster" in one time region in the half-life va. energy plot, as is true for M4's, other $\gamma^{\prime} s$ whose half-lives fall in this cluster may be assigned the corresponding multipolarity.

2. In cases where a cluster of two multipolarities,e.g. M1 and 22 occupies one time region, a new gamma of which the half-life falla in this region may be assigned one of the two multipolarities or a mixture of the two.

3. Whenever $A .7 \geq 2$, an appreciable part of the gamma transition proceeds by the lowest possible multipole order.

This statement is based on the cereity of counter-oxnmples and the obcervation that for E2 Y'a are as slow as M3's, fow MS2's as alow ax ES's, atc.
4. The spin and parity of a parent state may be inferred from the measured properties of its assumed isobaric analog resonance, and vice verso.

5. Low-lying states of odd-A nuclei have shell-model spins and parities, except in the regions where deformations appear. This argument is much stronger when supported by expected cross-section strengths $\left(C^{2} S\right)$ in single-nucleon transfer reactions.

It in recognized that some ghell-model predictions ar stronger than others. For example, the shell model would mildly deny that the ground-state $\mathrm{J}^{*}$ of the $39 t h$ proton be $3 / 2-$, but emphatically deny ita being $3 / 2^{*}$. Howaves, wo have not included this diatinetion here and congider all shell-model argaments to be weals.

6a. For low-lying states of odd-odd spherical nuclei, the Nordheim rules (1950No10):

$$
\begin{aligned}
& J=j_{p}+j_{n}, \text { if } j_{p}=1 p+-1 / 2 \text { and } j_{n}=I_{n}+-1 / 2 ; \\
& J=\mid j_{p}-j_{n} l, \text { if } j_{p}=l_{p}+-1 / 2 \text { and } j_{n}=l_{n}+1 / 2 .
\end{aligned}
$$

may be helpful in obtaining the ground-state spins and parities, if there is supporting evidence.

6b. For excited states of strongly deformed odd-odd nuclei, the Gallagher-Moszkowski rules (1958Ga27) may be helpful in deducing the relative positions of the two two-quasiparticle states formed by the two different couplings of the quasiparticle constituents, if there is supporting evidence. Here, the state corresponding to the parallel alignment $(\Sigma=1)$ of the projections $(=1 / 2)$ of the intrinsic spins of the two odd particles is expected to lie lower than that produced by the antiparallel $(\Sigma=0)$ alignment. This can be particularly useful in establishing the ground state $\mathrm{J} \pi$ values and nucleonic configurations for odd-odd nuclei.

(In the strongly deformed even-even nuclei, the opposite is expected to obtain, i.e., the $\Sigma=0$ coupling should lie lower than that with $\Sigma=1$. In these nuclei, however, the experimental situation is less clear since the two-quasiparticle excitations occur at or above the pairing gap, where the level densities are high and couplings to vibrational excitations can affect the two two-quasiparticle states differently.)

7. Statements similar to 5 and 6 based on other models.

8. Statements based on interpolation or extrapolation of regional trends, such as shown in 1971Bu16, 1972E121, 1977Ch27, 1990Ja11 and $1998 \mathrm{Ja07}$ for the rare-earth and heavy-mass regions.

9. All statements connected with the nonobservation of expected transitions.

10. Rules extracted in the survey by 1972El21 for unfavored $\alpha$ transitions can be uged to deduce the configuration of the parent or the daughter level, if the configuration of the other ig known.

11. For magnetic moments, the extreme rarity of pure single-particle states and observation of large deviations from free-nucleon $g$-factors in nutelei means that comparison between the experiment and the 'Schmidt Limit' estimates (based on such pure states) is not a sound basis for spin or parity assignment. The magnetic moments or g-factors, however, can give supporting evidence for assignments where predictions for possible alternatives, using $\mathrm{g}$-factors based on local systematics of measured moments, differ widely.

For excited states, the 'collective' aspects of the state frequently make substantial contribution to the magnetic moment. The correct $g$-factor for this contribution is a matter of detailed theory and any assignment based on assumed $g$ (collective)=Z/A must be viewed with caution. 


\section{CONVENTIONS USED IN NUCLEAR DATA SHEETS}

$\begin{array}{ll}\text { Units } & \\ \text { Finergies } & \\ \text { Cross Sections } & \text { keV } \\ \text { Magnetic dipole moments } & \text { barns } \\ & \text { nuclear } \\ \text { Eilectric quadrupole moments } & \text { magnetons }\left(\mu_{N}\right) \\ \text { B(EL) } & \text { barns } \\ \text { B(ML) } & e^{2} b^{L} \\ & : \mu_{N}^{2} b^{L-1}\end{array}$

Uncertainties ("Errors") The uncertainty in any number is given one space after the number itself:

$$
\begin{array}{ll}
4.6233 & \text { means } 4.623 \pm 0.003 \\
4.6 \mathrm{~h} 12 & \text { means } 4.6 \pm 1.2 \mathrm{~h} \\
5.4 \times 10^{3} 2 & \text { means } 5400 \pm 200 \\
4.2+8-10 & \text { means } 4.2_{-1.0}^{+0.8} \\
-4.2+8-10 & \text { means }-(4.2+10-8)=-4.2_{-1.0}^{+0.8}
\end{array}
$$

? Question Mark given after a quantity often indicates doubt as to the existence or the value of the quantity. For example, a "?" given after the $T_{1 / 2}$ value indicates that the assignment of that half-life to the associated level is not certain.

( ) Parentheses have the following interpretation for different quantities in the tabular data:

\begin{tabular}{ll} 
Quantity & \multicolumn{1}{c}{ Meaning of parentheses } \\
\cline { 2 - 2 } $\mathrm{J}^{\pi}$ & $\begin{array}{l}\mathrm{J}^{\pi} \text { based upon weak arguments. } \\
\text { See SUMMARY OF BASES FOR }\end{array}$ \\
SPIN AND PARITY ASSIGNMENTS. \\
$\begin{array}{l}\text { L transfer } \\
\text { or Mult. }\end{array}$ \\
Other & $\begin{array}{l}\text { established experimentally. } \\
\text { Value deduced (i.e., is not directly } \\
\text { measured) or taken from other sources. }\end{array}$
\end{tabular}

Examples:

$J^{\pi}=(1 / 2,3 / 2)^{-}$

Weak arguments limit the spin to $1 / 2$ or $3 / 2$. Strong arguments indicate negative parity.

$\mathrm{J}^{\pi}=4^{(+)}$

Strong arguments show the apin is 4; weak arguments suggest positive parity.

$L=(3)$

L value tentatively established as 3 .

Mult.=(MI)

Radiation character tentatively established as MI. Mult. $=M 1(+E 2)$

Radiation character includes $\mathrm{E} 2$ with a mixing ratio, $|\delta|$, that may be $>0$.

\section{[ ] Brackets}

7/2-[514] Nilsson asymptotic quantum numbers ${ }_{p} \mathrm{~K}^{\pi}\left[\mathrm{N} \mathrm{n}_{\mathbf{z}} \Lambda\right]$ Assumed quantity, e.g., [M1+E2] 
1947Pr17 M. A. Preston - Phys. Rev. 71, 865 (1947); The Theory of Alpha-Radioactivity

1950No10 L. W. Nordheim, Phys. Rev. 78, 294 (1950) Beta-Decay and the Nuclear Shell Model

1952B197 J. M. Blatt, V. F. Weisskopf - Theoretical Nuclear Physics, John Wiley and Sons, Inc., NewYork, p. 627 (1952)

1958Ga27 C. J. Gallagher and S.A. Moszkowski, Phys. Rev. 111, 1282 (1958); Coupling of Angular Momenta in Odd-Odd Nuclei

1958Ro60 M. E. Rose - Internal Conversion Coefficients, North-Holland Publishing Co., Amsterdam (1958)

1960Al 23 K. Alder, A. Winther, Kgl. Danske Videnskab, Selskab, Mat.-Fys. Medd. 32, No. 8 (1960); On the Theory of Multiple Coulomb Excitation with Heavy lons

$1967 B e 73$ J. A. Bearden, A.F. Burr - Rev. Mod. Phys. 39, 125 (1967); Reevaluation of X-Ray Atomic Energy Levels

1968 a53 R. S. Hager, E. C. Seltzer - Nucl. Data A4, 1 (1968); Internal Conversion Tables. Part I: $\mathrm{K}-, \mathrm{L}-$, $M-$ Shell Conversion Coefficients for $Z=30$ to $Z=103$

$1968 \mathrm{Ha} 54$ R. S. Hager, E. C. Seltzer - Nucl. Data A4, 397 (1968): Internal Conversion Tables. Part II: Directional and Polarization Particle Parameters for $\mathrm{Z}=30$ to $\mathrm{Z}=103$

1968 L 16 R. J. Lombard, C. F. Perdrisat, J. H. Brunner Nucl. Phys. Al10, 41 (1968); Internal Pair Formation and Multipolarity of Nuclear Transitions

1969Dro9 O. Dragoun, H. C. Pauli, F Schmutzler - Nucl. Data Tables A6, 235 (1969); Tables of Internal Conversion Coefficients for $\mathbb{N}$-Subshell Electrons

1969Ha61 R. S. Hager, E. C. Seltzer - Nucl. Data Tables A6, 1 (1969); Internal Conversion Tables. Part III: Coefficients for the Analysis of Penetration Effects in Internal Converaion and EO Internal Conversion

1970 Kro3 K. S. Krane, R. M. Steffen - Phys. Rev. C2, 724 (1970); Determination of the E2/M1 Multipole Mixing Ratios of the Gamma Transitions in $110 \mathrm{Cd}$

1971 Bu16 M.E. Bunker and C. W. Reich, Revs. Mod. Phys. 43, 348 (1971) A Survey of Nourotational States of Odd-A Nuclei $(150<A<190)$

$19710 r 11$ O. Dragoun, Z. Plajner, F. Schmutzler, Nucl. Data Tables A9, 119 (1971); Contribution of Outer Atomic Shells to Total Internal Conversion Coefficients

$1971 G 040$ N. B. Gove, M. J. Martin - Nucl. Data Tables A10, 205 (1971); Log- $f$ Tables for Beta Decay

1971 St 47 R. M. Steffen - Report LA-4565-MS, Los Alamos Scientific Laboratory (1971); Angular Distributions and Correlations of Radiation Emitted from Oriented Nuclei

1971St48 .R. M. Steffen - Proc. Int. Conf. Angular Correlationa in Nuclear Disintegration, Delft, Netherlands (1970), H. van Krugten, B. van Nooijen, Eds. Wolters-Noordhoff Publ., Groningen, p. 1 (1971); Angular Distributions and Correlations of Nuclear Radiations in Nuclear Spectroscopy

1971Ta32 H. W. Taylor, B. Singh, F. S. Prato, R. MePherson Nucl. Data Tables A9, No. 1, 1 (1971); A Tabulation of Gamma-Gamma Directional-Correlation Coefficients

1972An20 I. V. Anicin, R. B. Vukanovic, A. H. Kukoc - Nucl. Instrum. Methods 103, 395 (1972); The New Fenture of 1-3 Directional Correlations with Mixed Unobserved Transitions
$1972 B b 16$ W. Bambynek, B. Crasemann, R. W. Fink, H.-U. Freund, H. Mark, C. D. Swift, R. E. Price, P. Venugopala Rao - Rev. Mod. Phys. 44, 716 (1972); X-Ray Fluorescence Yields, Auger, and Coster-Kronig Transition Probabilities

$1972 E 121$ Y. A. Ellis, M. R. Schmorak - Nucl. Data Sheets B8, 345 (1972); Survey of Nuclear Structure Systematics for A 2229

1972 Tr09 V. F. Trusov - Nucl. Data Tables 10, 477 (1972); Internal Conversion Coefficients for High-Energy Transitions

1973Ra10 S. Raman, N. B. Gove - Phys. Rev. C7, 1995 (1973) Rules for Spin and Parity Assignments Based on $\log f t$ values

1976Ba63 I. M. Band, M. B. Trzhaskovskaya, M. A. Listengarten At. Nucl, Data Tables 18, 433 (1976); Internal Conversion Coefficients for Atomic Numbers $\mathrm{Z} \leq 30$

1977 Ch27 R. R. Chasman, I. Ahmad, A. M. Friedman and

J. R. Erskine, Revs. Modern Phys. 49, 833 (1977) Survey of Single-Particle States in Mass Region As228

1978 Po08 F. T. Porter and M. S. Freedman - J. Phys. Chem. Ref. Data 7, 1267 (1978)

Recommended Atomic Electron Binding Energies, 1s to $6 \mathrm{p}_{3 / 2}$, for Heavy Elements, $Z=84$ to 103

1979Ah01 I. Ahmad - Z. Phys. A290, 1 (1979)

Precision Measurement of K-Shell Fluorescence Yields in Actinide Elements

1979 En04 P. M. Fndt, At.Data Nucl.Data Tables 23, 547 (1979) Strengths of Gamma-Ray Transitions in $A=45-90$ Nuclei

1979 En05 P. M. Endt, At.Data Nucl.Data Tables 23, 3 (1979) Strengths of Gamma-Ray Transitions in $A=6-44$ Nuclei (III)

$1981 E n 06$ P. M. Endt, At.Data Nucl.Data Tabies 26, 47 (1981) Strenghts of Gamma-Ray Transitions in A=91-150 Nuclei

1990Ja11 A. K. Jain, R. K. Sheline, P. C. Sood and K. Jain, Revs. Modern Phys. 62, 393 (1990) Intrinsic States of Deformed Odd-A Nuclei in Mass Regions (151 $\leq A \leq 193)$ and $A 2221$

1998Ak04 Y. A. Akovali - Nuck. Data Sheets 84, 1 (1998) Review of Alpha-Decay Data from Double-Even Nuciei

1998Ja07 A. K. Jain, R. K. Sheline, D. M. Headly, P.C. Sood, D.G. Burke, 1. Hrivnacova, J. Kvasil, D. Nosek,

R. W. Hoff, Revs. Modern Phys. 70, 843 (1998) Nuclear Structure in Odd-Odd Nuclei, 144 $\leq A \leq 194$ 


\section{Nuclear Data Sheets Symbols and Abbreviations}

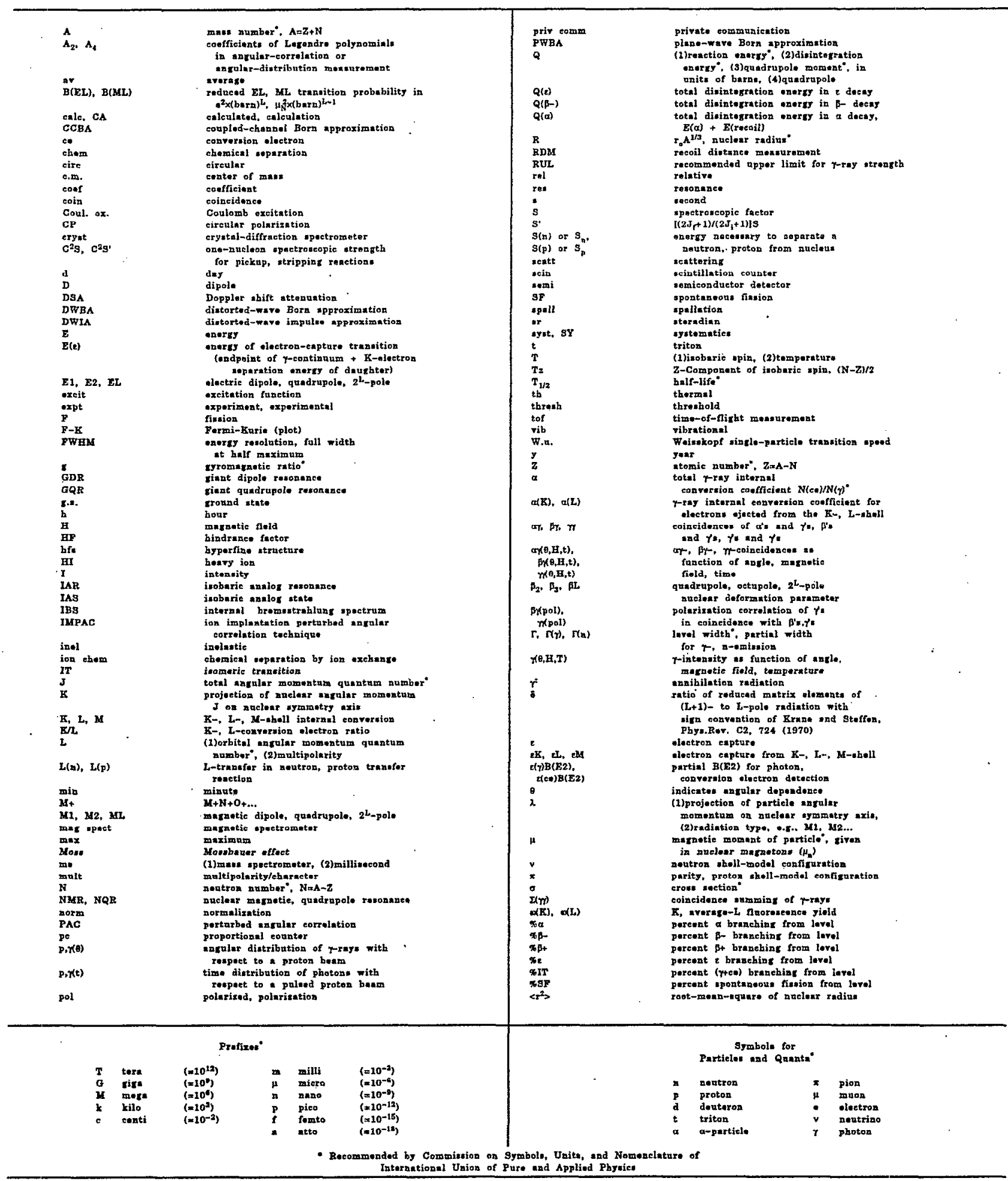

